University of Louisville

ThinkIR: The University of Louisville's Institutional Repository

Electronic Theses and Dissertations

$5-2010$

\title{
The second year itch: an examination of pre-entry factors that contribute to second-year college persistence.
}

Nora Allen Scobie 1967-

University of Louisville

Follow this and additional works at: https://ir.library.louisville.edu/etd

\section{Recommended Citation}

Scobie, Nora Allen 1967-, "The second year itch: an examination of pre-entry factors that contribute to second-year college persistence." (2010). Electronic Theses and Dissertations. Paper 1287. https://doi.org/10.18297/etd/1287

This Doctoral Dissertation is brought to you for free and open access by ThinkIR: The University of Louisville's Institutional Repository. It has been accepted for inclusion in Electronic Theses and Dissertations by an authorized administrator of ThinkIR: The University of Louisville's Institutional Repository. This title appears here courtesy of the author, who has retained all other copyrights. For more information, please contact thinkir@louisville.edu. 
THE SECOND YEAR ITCH: AN EXAMINATION OF PRE-ENTRY FACTORS THAT CONTRIBUTE TO SECOND-YEAR COLLEGE PERSISTENCE

\author{
By \\ Nora Allen Scobie \\ B.A., University of Louisville, 1990 \\ M.Ed., University of Louisville, 1993

\begin{abstract}
A Dissertation
Submitted to the Faculty of the

Graduate School of the University of Louisville

In Partial Fulfillment of the Requirements

For the Degree of
\end{abstract} \\ Doctor of Philosophy \\ College of Education and Human Development \\ University of Louisville \\ Louisville, KY
}

May 2010 
THE SECOND YEAR ITCH: AN EXAMINATION OF PRE-ENTRY FACTORS THAT CONTRIBUTE TO SECOND-YEAR COLLEGE PERSISTENCE

By

Nora Allen Scobie

B.A., University of Louisville, 1990

M.Ed., University of Louisville, 1993

A Dissertation Approved on

March 30, 2010

By the following Dissertation Committee:

Dissertation Director: Dr. Młchael Cuyjet

Dr. Dale Billingsley

Dr. Amy Hirschy

Dr. Brïdgette Pregliasco

Dr. Kathleen Rudasill 


\section{DEDICATION}

This dissertation is dedicated to the people that have had to put up with me at my worst: my mom (Ma), Copley, Linda Smith and Jane Bell, my furry babies (Gus, GrrTee, and Sierra), and most of all, my husband (aka my old man) Scobie. Thank you for

encouraging me and ignoring the fact that $I$ have been a stressed out beast for the last few years. What a long, strange trip it's been (hey, I got my Grateful Dead reference in). 


\section{ACKNOWLEDGEMENTS}

I would like to thank all of the folks that have helped me through this process. Thank you to my Undergraduate Affairs cohorts, Caitlin Dance and Michael Grillo, who have provided statistical advice and support. Bob Goldstein and his crew at Institutional Research, Matt, Becky, and Dr. Gilchrist, have been phenomenal! Thank you to Janet Spence and Chelsea Wightman for their support and sitting through my defense. I would like to acknowledge my extremely patient family and friends, especially my husband Scobie. I would like to express my gratitude to my committee: Dr. Billingsley, Dr. Pregliasco, Dr. Rudasill, Dr. Hirschy, and most of all Dr. Cuyjet. Dr. Cuyjet put up with me for almost 20 years and I cannot thank him enough for the tremendous influence that he has had on me. And finally, I want to express a huge thank you to Jason Browning, my little buddy and technical advisor. 


\section{ABSTRACT \\ THE SECOND YEAR ITCH \\ Nora Allen Scobie}

May 8, 2010

The persistence of second-year college students is gaining attention nationally. Vast resources have been dedicated to the retention of first-year students only to lose them at some point during the second year. Much of the research about the second-year experience is qualitative and focused on institutional inputs. This study examined preentry variables that predict second year attrition. The pre-matriculation factors and background characteristics as outlined by Tinto (1993) served as the focus of this study.

The participants of this study were first-time, full-time freshmen that attended the University of Louisville 2004 summer orientation, participated in the College Student Inventory Form-B survey, enrolled, and matriculated to the 2004 fall semester at the University of Louisville. The College Student Inventory Form-B data was used to analyze pre-entry levels of motivation, commitment, and selected background variables. A logistic regression model was used to predict the student outcomes of persistence and non-persistence for enrollment in the fourth and fifth semesters, which constituted the second year for traditional, first-time, full-time freshmen. Findings from this study suggest that second-year students have experiences and needs distinct from those of firstyear students. 
TABLE OF CONTENTS

PAGE

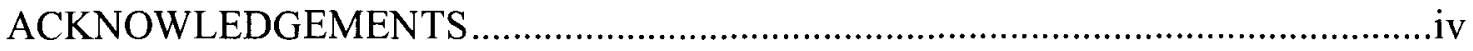

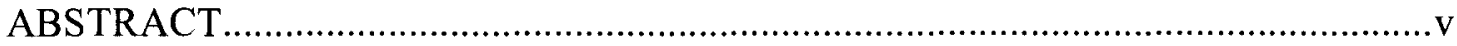

LIST OF TABLES

\section{CHAPTER}

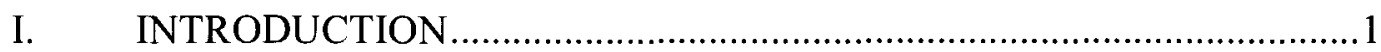

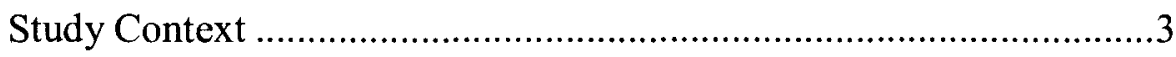

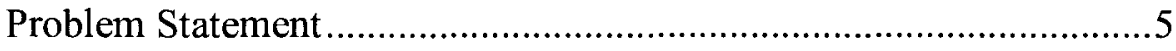

Rationale .............................................................................. 7

Theoretical Context..................................................................... 10

Significance of the Study ............................................................ 11

Research Questions................................................................ 13

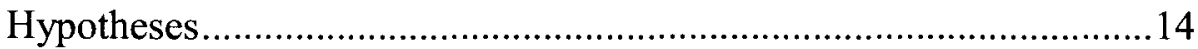

Limitations .......................................................................... 16

Definition of Terms ...................................................................... 19

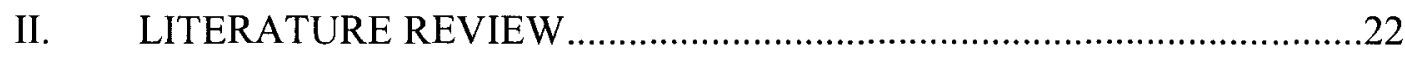

Tinto's Model of Student Departure ................................................23

Additional Theories and Models................................................28

Demographic Characteristics..................................................35

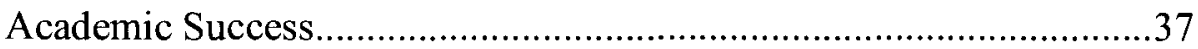

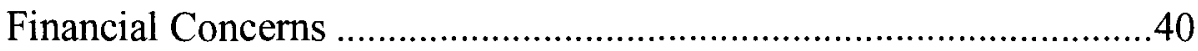


Motivation and Commitment.........................................................43

First Year Students..................................................................46

Second Year Students ...........................................................44

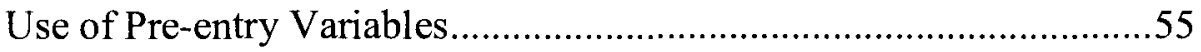

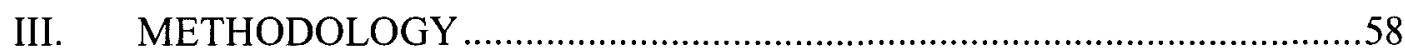

Population and Sample ............................................................58

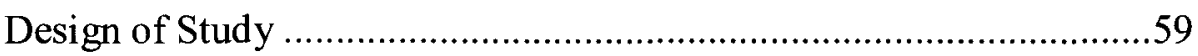

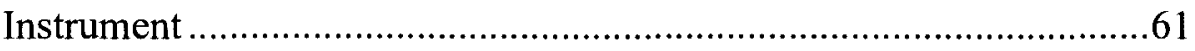

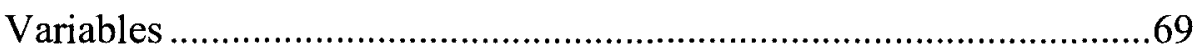

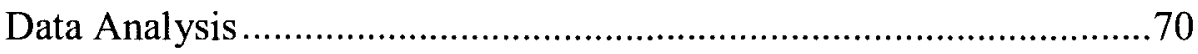

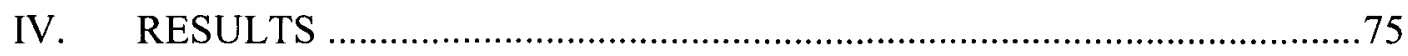

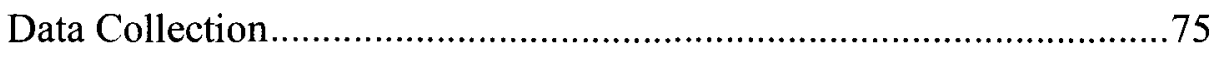

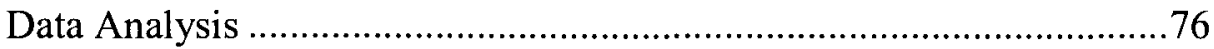

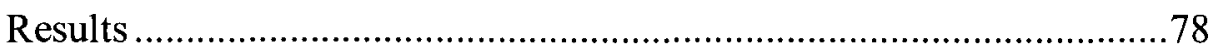

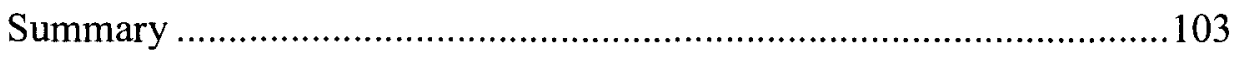

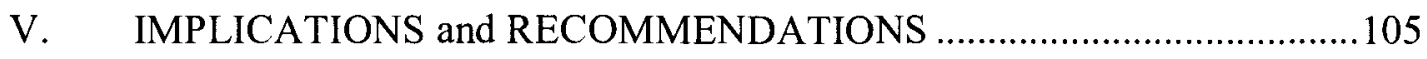

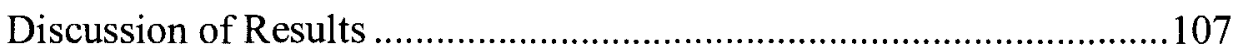

Recommendations for Practice.....................................................116

Recommendations for Research ............................................123

Conclusion............................................................................. 127

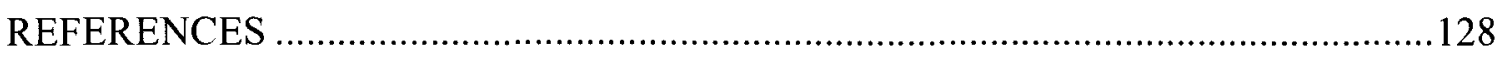

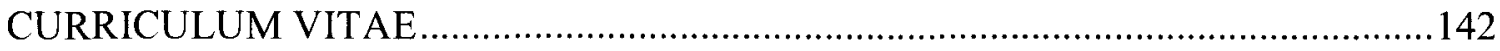




\section{LIST OF TABLES}

TABLE

PAGE

1. College Student Inventory Form-B Subscales ...................................................63

2. Cronbach Alpha Coefficients from CSI-B Independent Scales............................68

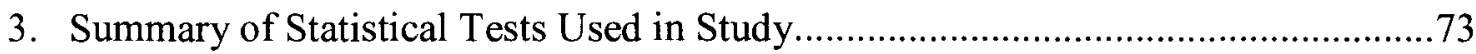

4. Coding Scheme for Categorical Variables............................................................ 74

5. Frequency Distribution of Age, Gender, \& Ethnicity ...........................................79

6. Frequency Distribution of Median Family Income ...........................................81

7. Frequency Distribution of First Generation College Students...............................82

8. Frequency Distribution of Intended Work Hours ........................................... 82

9. Frequency Distribution of Students Undecided/Decided About College Major .......83

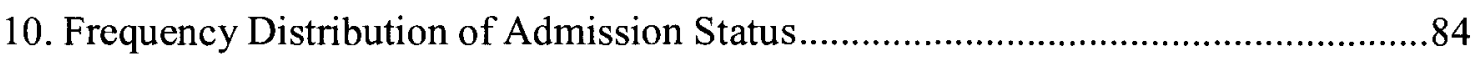

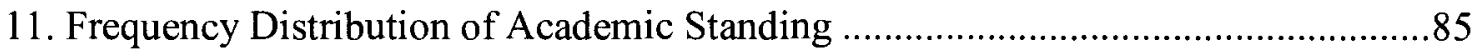

12. Descriptive Statistics for Cumulative University GPA .................................86

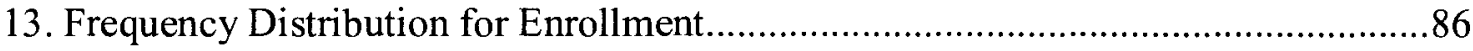

14. Descriptive Statistics for High GPA \& ACT Scores ..........................................87

15. Frequency Distribution for Financial Aid.................................................... 88

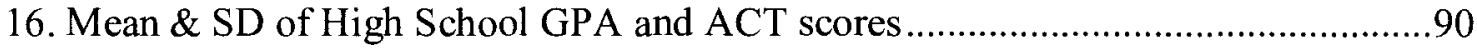

17. Mean \& SD of ACT Math \& Reading Sub-scores ........................................ 91

18. Mean \& SD of Cumulative University GPA \& Academic Standing .......................92

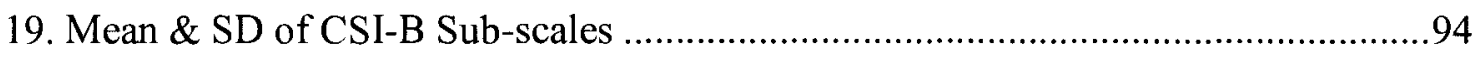


20. Logistic Regression Results for Research Question Six...................................97

21. Logistic Regression Results for Research Question Seven ...................................101

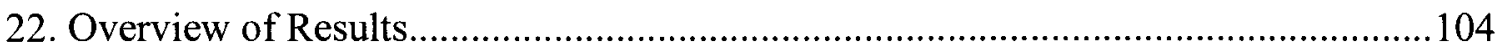




\section{CHAPTER I}

\section{INTRODUCTION}

\section{Overview}

This study explored the factors that predict college persistence beyond the second year. The issue of second year attrition is gaining national prominence. Pattengale and Schreiner (2000) cautioned that as first-year retention rates at institutes of higher education improved, second-year students seem to be floundering and are leaving colleges and universities in significant numbers. Although the specific percentages vary, it is evident that second-year attrition is a matter of grave concern. For those who drop out, $85 \%$ do so within the first two years of enrollment, with $50 \%$ departing during the first year and 35\% leaving by the end of the second year (Wilder, 1993).

Lipka (2006) stated that research by the U.S. Department of Education has shown that attrition rates are greatest during the first two years of college and that second-year attrition rates are comparable to first-year rates. A study by the Educational Policy Institute (2000) offered a more conservative picture of student attrition with $14 \%$ of all entering students leaving higher education during the first year of enrollment and an additional 13\% leaving during or immediately following the second year. Wilder (1993) further suggested that the efforts of four-year public institutions tend to concentrate mainly on reducing first-year attrition rates. However, research confirms that second-year students have some of the highest expectations with regard to curricular and co-curricular experiences but are in the most need of help (Pattengale \& Schreiner, 2000). 
At the University of Louisville, first year retention rates for first-time, full-time, baccalaureate degree-seeking students were $76.5 \%$ in $2004,78.1 \%$ in 2005 , and $78 \%$ in 2006 (Office of Institutional Research, 2007a), which slightly exceeded the national average of $75.8 \%$ (NCHEMS, 2007). In comparison, the retention rates for the 2004 cohort of entering students dropped to $64.9 \%$ after the second year but the drop after the third year was marginal to $60.2 \%$ (Office of Institutional Research, 2007a). Retention rates were slightly higher for the 2005 cohort of students with $65.4 \%$ retention after the second year and $61.3 \%$ after the third year; however the drop after the second year still far exceeded that after the third year (Office of Institutional Research \& Planning, 2007a). What is happening with second-year students? Are efforts to retain first-year students merely delaying the inevitable? As greater scrutiny is paid to graduation rates by state legislatures and accrediting agencies, it is imperative to identify the factors that contribute to second-year attrition.

In 1975, Vincent Tinto outlined a model of student attrition. His model included pre-matriculation variables and background characteristics as well as formal and informal experiences that influence the student's level of integration. On the individual level, intention and commitment are at the root of the pre-entry attributes that affect students' decisions to persist (Tinto, 1993). Tinto surmised that, "Departure mirrors the students an institution recruits. In particular, it reflects the character of student commitments and the quality of effort students are willing to make on behalf of the goal of college completion" (p. 205). At a 2005 National Conference on Recruitment, Tinto stated that we now have a better understanding of the complexities of how diverse student backgrounds interact with institutional forces to shape patterns of persistence. The pre-entry factors outlined in Tinto's model of student departure will serve as the theoretical basis and context for this 
study. The remaining sections of this chapter provide a description of the context for this study; statement of the research problem; rationale for the study; significance of the study; research questions and hypotheses; limitations; and definition of terms.

\section{Study Context}

This study examined pre-entry variables that predict student persistence at the end of the second academic year. This study explored how pre-entry attributes of entering freshmen (levels of motivation and commitment as evidenced by College Student Inventory Form- B sub-scores), demographics (age, gender, ethnicity, median family income), student background (parental level of education, intended number of work hours, decided about college major), ability indicators (high school GPA, ACT composite score, ACT math and reading sub-scores, and admission status), financial aid (aid to be repaid, aid that did not require repayment, or no known financial assistance) relate to persistence behaviors of second-year students at a four-year, metropolitan, public institution. The institutional experience variables of university GPA and academic standing at the end of the third and fourth semesters (the second college year) will be included as a control measure.

Student persistence to graduation has become a hot topic among colleges and universities nation-wide, especially as public financial support shrinks (Reason, 2003). This issue is particularly poignant in the state of Kentucky. In 2001, Kentucky ranked $47^{\text {th }}$ in the nation for adults holding a bachelor's degree with only $20 \%$ of adults 25 years of age and older having obtained a bachelor's degree or higher compared to an average of $27 \%$ nationally (US Census Bureau, 2007). Economic pressures weigh heavily on the minds of most Americans. The current 10\% unemployment rate in the Louisville Metro area is a major problem for the city and for the state since a sizable portion of the state 
budget originates from Jefferson County. In order to attract new businesses to spur economic growth in the state, the number of adults with at least a bachelor's degree must be dramatically increased. Two education reform acts were enacted in an effort to improve degree completion rates in Kentucky: the Kentucky Education Reform Act (KERA) of 1990 and the Kentucky Postsecondary Education Improvement Act (KPEIA) of 1997. The focus of the former act are public elementary and secondary schools, the target of the latter act is the state's public postsecondary education institutions.

The University of Louisville's 2007 six-year graduation rate of $45.7 \%$ (Office of Institutional Research, 2007b) lags behind the five-year national average of $48.6 \%$ for four-year, Ph.D. public institutions (ACT, Inc., 2008). In support of the state initiatives, the University of Louisville had been charged with achieving status as a premier research institution. Low graduation rates hinder this goal. If the factors that lead to student attrition can be identified, then the institution may be able to improve rates of degree completion.

In 1992, ACT reported that first year attrition represented from $53.3 \%$ to $67.7 \%$ of all students who leave institutions of higher education (Tinto, 1993). In 2006, that number had dropped to approximately $25 \%$ nationally (NCHEMS, 2007). The reasons for this drop in attrition range from greater selectivity in admitting new students to an abundance of first-year programs and services aimed at assisting students to overcome obstacles that could endanger academic success.

Awareness of sophomore-related issues is on the rise, however, institutions of higher education focus on first-year initiatives as a primary way to improve upon lagging graduation rates. Retention efforts and allocation of scarce resources are often frontloaded into the first-year experience. The first year is critical to retention and should be a 
priority but we cannot afford to ignore students in their second year. Pattengale and Schreiner (2000) contend that sophomores may be in a state of internal conflict and have some of the greatest needs of any group on campus. It is only in recent years that institutions of higher education have recognized the need to address the problems and challenges that face second-year students (Gahagan \& Hunter, 2006). Even though there is a relative scarcity of research studying the second-year experience, the concept of a "sophomore slump" is hardly new. Freedman (1956) described sophomores as disorganized and characterized by a sense of inertia. Financial concerns, academic performance, and questions about future goals are all issues that impact second-year students (Gahagan \& Hunter, 2006).

Tinto (1993) raised questions about how attrition rates vary among different groups: sex, race, ability, and social class. He identified four forms of individual experience which affect student departure: adjustment, difficulty, incongruence, and isolation. Each represents an interactive outcome derived from the student's experience within the institution. Additionally, he identified external forces that impact departure, those involving finances and outside obligations. Individual intentions or goals regarding participation in higher education and commitment to a specific institution are also considered to be important predictors of degree completion.

\section{Problem Statement}

The problem that was examined in this study was high attrition levels at the end of the second year and the contributing factors for student departure. This study focused on the effects of motivation and commitment, academic ability, demographic and background data, and finances on persistence after two years. Unfortunately, there is a limited amount of research in the area of sophomore persistence. Scheiner (2010) 
outlined the types of research about second-year students currently available: (a) qualitative research on developmental and experiential changes within individual students at specific campuses (Schaller, 2005), (b) sophomore programs and services surveys (Tobolowsky \& Cox, 2007), and (c) institution specific surveys (Graunke \& Woosley, 2005). Few quantitative studies attempt to isolate predictive variables that impact student persistence beyond the second year: Examples include Jullierat's (2000) study which compared satisfaction of second-year students that persisted versus those that did not persist at faith-based private institutions; and Schreiner's (2007) follow-up study that examined retention factors at 31 of the same faith-based schools using the Sophomore Experiences Survey.

Existing student persistence research explores cognitive development, internal support services and programs, and traditional predictors of student performance (high school GPA, ACT/SAT scores, gender, and race). Academic performance has traditionally been a predominant variable for predicting success and persistence. Astin (1993) maintained that "GPA, despite its limitations, appears to reflect the student's actual learning and growth during the undergraduate years" (p. 242). This study included college GPA and academic standing as a control measure.

Support and services tend to focus predominantly on first-year students. Boivin, Fountain, and Baylis (2000) ascertain that without adequate support, successful first-year students will fail in the second year as developmental challenges continue and/or intensify. Second-year persistence research can be examined to improve overall graduation rates and to reveal where first-year programs may fall short.

The problem of low rates of bachelor's degree attainment is of critical importance to the state of Kentucky and to the University of Louisville. The state languishes at the 
bottom of the national average for an educated populace and the University of Louisville lags behind peer institutions in graduation rates. However, recent increases in first-year persistence and graduation rates at the University of Louisville suggest that measures to stem freshman attrition are paying off. To facilitate further improvement, it is imperative to identify the factors that contribute to sophomore attrition. The economic impact of low graduation rates could have negative consequences for the economy of the state. If institutions can stem the tide of second year attrition rates, increased revenue realized from enhanced persistence and graduation rates could bolster the state's economic future.

The problem this study investigated was whether or not a combination of characteristics (such as demographic data, student background, academic ability, levels of motivation/commitment, and finances) predict the chances a college student will persist beyond the second year.

\section{Rationale}

The study was conducted at the University of Louisville (UofL) located in Louisville, KY, Kentucky's largest metropolitan area. The University of Louisville is a public, four-year, research institution with an enrollment of approximately 22,000 students (University of Louisville, 2008). Kentucky's higher education institutions are under tremendous pressure to increase graduation rates. Kentucky's legislature has advanced reform acts and strategic initiatives designed ultimately to improve the state's economic profile. In order to meet the goal of improving Kentucky's economic future, the Double the Numbers initiative was enacted in 2007 in support of the Higher Education Reform Act of 1997, otherwise known as House Bill 1. The goal is to increase the number of adults in Kentucky with at least a bachelor's degree from the current 400,000 to 800,000 by the year 2020 (KY Council for Postsecondary Education, 2008). 
The KY Council for Postsecondary Education mandated that the University of Louisville become a preeminent metropolitan research institution by the year 2020 in support of the state's goals.

This study identified factors that contributed to second-year persistence. A review of research literature explored student development theory, the cognitive development of sophomores, first-year experience research, the effect of financial influences on retention, current sophomore retention efforts, and an overview of Tinto's model of student departure.

For the purposes of this study, the term second-year student was used instead of sophomore, which is a less definitive classification. Most institutions set arbitrary credit hour requirements to class standings. For example, at the University of Louisville, the designation of sophomore is given to those students who have accrued between 30 and 59 earned hours. This standard can be misleading, due to advanced placement, dual credit, and CLEP credit; students may matriculate with enough credits to achieve the sophomore designation, but are in actuality first-year students. Therefore, this study did not use the criterion of earned college credit to designate second-year standing. Instead, second-year students are those students who have reached their second academic year (enrollment in the third and fourth semesters respectively). This study did not merely represent a chronological period of enrollment but examined important issues that may occur during the second year of enrollment. Second-year students have needs and experiences distinct from first-year students. Research and programs targeted on second-year students is warranted.

This study examined a statistical analysis of the 2004 cohort of incoming freshmen at the University of Louisville (UofL). The University of Louisville is a public, 
mid-sized, metropolitan institution that is largely comprised of commuter students with the exception of first year students who predominantly reside on campus. From the year 2000 to 2006, the College Student Inventory Form-B was administered to all students who participated in summer orientation. The participants of this study were first-time, full-time freshmen that attended the 2004 summer orientation, enrolled, and matriculated to the 2004 fall semester.

The criterion variable for this study was student persistence through and after the second college year as measured by enrollment in the fourth and fifth semesters. Ability was measured by high school GPA, ACT composite, math, and reading scores, cumulative university GPA, and academic standing. Demographic data, background, financial aid data, and the 17 sub-scales of the College Student Inventory Form-B (CSIB) were independent variables. The CSI-B data were used to assess motivation, academic and institutional commitment, and sense of financial security. The CSI-B data set was obtained from the Office of Retention Management and Research at UofL. Student records and financial aid data were retrieved from the Office of Institutional Research and Planning.

A logistic regression model was used to predict the student outcomes of persistence or non-persistence as evidenced by enrollment in the fourth and fifth semesters. Odds ratios were used to determine the relative contribution of demographic characteristics, background variables, ability, motivation and commitment factors, and financial aid data. Cumulative college grade point average and academic standing were entered into the regression model first as a control method.

The overall research question is: What combination of individual circumstances and predictor variables accounts for student persistence beyond the second year? 


\section{Theoretical Context}

Tinto's (1993) model of student departure has been examined extensively in the realm of student persistence. A large body of work has focused on first year retention rates and persistence to graduation. For the purposes of this study, components of Tinto's model were applied to the retention rates of second year students, specifically focusing on the role of predictor variables. One can look to patterns of entry to observe differences in the composition of college populations and eventual levels of departure. The use of Tinto's model specifically to predict second-year persistence makes this study unique.

Tinto (1993) identified four common attributes among students who depart an institution before degree completion: adjustment, difficulty, incongruence, and isolation. Even though these issues emerge following entry, Tinto maintained that these attributes mirror the skills and disposition of students prior to entry. Intention and commitment stood out as the primary pre-entry attributes that predispose student departure on an individual level. Tinto stated that commitment, drive, and effort are central to patterns of departure. Students with strong levels of commitment and motivation to meet educational and occupational goals are more likely to persist despite academic and social challenges (Tinto, 1993).

A better understanding of how the complexities of student background variables interact with institutional environments provide colleges and universities with a clearer picture of the factors that shape student persistence. Institutions can use information about student characteristics to develop comprehensive, proactive strategies designed to address the problems of unique student populations.

The tenets of Tinto's model are represented in the sub-scales of the College Student Inventory Form - B (CSI-B). The CSI-B is an integral part of the Noel-Levitz, 
Inc., Retention Management System. As explained in the Advisor's Guide to the CSI-B, in order to understand student motivational patterns, it is necessary to have an overview of an individual's background (Noel-Levitz, 2001).

Financial security is measured in two of the sub-scales of the CSI-B. Students often list financial concerns as a reason for departure, although much of the impact of finances on persistence occurs prior to or at the point of entry into college (Tinto, 1993). Tinto (1993) argued that finances may be a rationalization after the fact and may mask the underlying reasons for departure. If a student places a strong value on education and the inherent rewards of degree completion, then he or she will endure financial hardship in order to complete a degree (Tinto, 1993). In an effort to explore the predictive power finances have on second year persistence rates, this study used student financial aid data as an independent variable.

\section{Significance of the Study}

Research that focuses specifically on issues that impact second-year or sophomore retention is relatively sparse. Few studies attempt to identify predictive variables that may be useful in understanding the reasons for second-year attrition. Much of the research in this area relates to traditional measures of student performance (i.e. cognitive development, programs and services designed for sophomores, and anecdotal student experiences). The results of this research study contribute to the base of knowledge associated with sophomore persistence. With so many resources invested into first-year initiatives, sophomores are left to disengage, depart, drift passively along, or to navigate the sea of policies, programs and procedures on their own (Pattengale \& Schreiner, 2000). This study identified factors that impacted sophomore persistence at the University of Louisville. 
A great deal of attention and resources have been given to freshmen and the criticality of the first-year experience. Institutions of higher education invest significant amounts of time and capital to help ensure that first-year students have the support necessary to become engaged, successful, members of the university community. The collection of pre-existing information about students aids in ascertaining a student's academic preparedness, degree of motivation, and adaptability to fit into institutional culture. Information about pivotal student characteristics will allow administrators to focus attention and resources where they are needed most. This study addressed the lack of research in second-year persistence and contributed to the body of available research.

The results of this study should be of interest to post-secondary policy-makers, administrators, and researchers which provides insight into the plight of second-year students and address the interventions needed to aid in college student success. Research related to the sophomore year is in its infancy at a time that educators are trying to determine best practice for this student population (Gahagan \& Hunter, 2006). This study adds to the knowledge base relative to the sophomore year and should aid educators in developing services and programs that address sophomore needs.

This study should be of interest to the Kentucky Council for Post-Secondary Education (CPE). In light of the low ranking of the Commonwealth for adults who hold bachelors degrees and the Council's charge to increase graduation rates by the year 2020, the results from this research highlight factors that contribute to persistence.

Finally, this study has direct significance to the faculty, staff, and administration at the University of Louisville. The University of Louisville falls short of the national average for graduation rates. Gains in freshmen retention and the large number of students that leave before the third year leads to the obvious conclusion that greater 
retention of second-year students may ultimately put graduation rates in line with the national average. The predictors identified in this study could help the University be more proactive in its efforts to identify those at risk and put in place programs and services to stem second-year attrition. Additionally, the results of this study will allow academic support and student affairs staff to determine which variables that contribute to persistence are pre-entry conditions and what percentage result from the institution environment and could be subject to institutional change.

\section{Research Questions}

The research questions used for this study are listed below:

1. Is there a statistically significant difference between college students who persist beyond the second college year and students who leave after the second year with respect to high school grade point averages (GPAs)?

2. Is there a statistically significant difference between college students who persist beyond the second college year and students who leave after the second year with respect to ACT composite scores?

3. Is there a statistically significant difference between college students who persist beyond the second college year and students who leave after the second year with respect to ACT math and reading sub-scores?

4. Is there a statistically significant difference between college students who persist beyond the second college year and students who leave after the second year with respect to their cumulative college grade point averages and academic standing?

5. What are the statistically significant differences between college students who persist beyond the second college year and students who leave after the 
second year for each of five selected sub-scales (desire to transfer, attitude toward educators, study skills, verbal confidence, and sense of financial security) as measured by the College Student Inventory Form - B (CSI-B)?

6. What are the predictive relationships among (a) cumulative college GPA and academic standing (b) student background variables (age, gender, median family income, race/ethnicity, decided/undecided major, number of intended work hours, parental education level); (c) academic ability (high school GPA, ACT composite score, ACT reading and math sub-scores); (d) CSI-B scale scores (17 sub-scales); (e) financial aid (aid that must be repaid, aid that does not require repayment, combination of repaid and no repayment, no aid) on the dependent variable students who enroll in the fourth college semester?

7. What are the predictive relationships among (a) cumulative college GPA and academic standing (b) student background variables (age, gender, median family income, race/ethnicity, decided/undecided major, number of intended work hours, parental education level); (c) academic ability (high school GPA, ACT composite score, ACT reading and math sub-scores); (d) CSI-B scale scores (17 sub-scales); (e) financial aid (aid that must be repaid, aid that does not require repayment, combination repaid and no repayment, no aid) on the dependent variable students who enroll in the fifth college semester?

\section{Hypotheses}

The hypotheses that were used for this study are:

H1) There are significant statistical differences between college students who persist beyond the second college year and students who leave after the second year with respect to high school grade point averages (GPAs). 
Students who experience higher high school GPAs are more likely to persist beyond the second college year.

H2) There are significant statistical differences between college students who persist beyond the second college year and students who leave after the second year with respect to ACT composite scores. Students with higher ACT composite scores are more likely to persist beyond the second college year.

H3) There are significant statistical differences between college students who persist beyond the second college year and students who leave after the second year respect to ACT math and reading sub-scores. Students with higher ACT math and reading sub-scores are more likely to persist beyond the second college year.

H4) There are significant statistical differences between college students who persist beyond the second college year and students who leave after the second year with respect to their cumulative college grade point averages and academic standing. Students with higher college GPAs and in good academic standing are more likely to persist beyond the second college year.

H5) There are significant statistical differences between college students who persist beyond the second college year and students who leave after the second year for each of the five selected sub-scales (desire to transfer, attitude toward educators, study skills, verbal confidence, and sense of financial security) as measured by the CSI-B. 
H6) There is a significant predictive relationship among (a) cumulative college GPA and academic standing (b) student background variables (age, gender, median family income, race/ethnicity, decided/undecided about major, number of intended work hours, parental education level); (c) academic ability (high school GPA, ACT composite score, ACT reading and math sub-scores); (d) CSI-B scale scores (17 sub-scales); (e) financial aid (aid that must be repaid, aid that does not require repayment, combination repaid and no repayment, no aid) on the dependent variable students that enroll in the fourth college semester.

H7) There is a significant predictive relationship among (a) cumulative college GPA and academic standing (b) student background variables (age, gender, median family income, race/ethnicity, decided/undecided major, number of intended work hours, parental education level); (c) academic ability (high school GPA, ACT composite score, ACT reading and math sub-scores); (d) CSI-B scale scores (17 sub-scales); (e) financial aid (aid that must be repaid, aid that does not require repayment, combination repaid and no repayment, no aid) on the dependent variable students that enroll in the fifth college semester.

\section{Limitations}

The CSI-B was administered during summer orientation prior to the start of freshmen year classes, therefore, the responses were anticipatory in nature. How expectations correlated with actual behaviors was not measured for this study.

This study only estimated aggregate rates of persistence since only the fall 2004 first-time, full-time students who attended summer orientation were examined. This study 
did not consider alternate forms of entry (spring and summer admission, transfer students, part-time students, or students admitted for the fall that did not attend freshman orientation). So this was not a complete and fully representative picture of all second year students at the University of Louisville.

A major limitation of this study was that only those institution interaction factors that could be obtained from student records data, specifically academic indicators (cumulative college grade point averages and academic standings at the end of the third and fourth semesters) were examined. However, the preponderance of institution interaction outcomes were not explored such as student sub-population membership, first-year experience initiatives, faculty engagement, and the effects of academic advising. There are two reasons for this omission: first, there was not a concise and timely method for determining which experiences within the institution negatively or positively impacted student persistence. There were simply too many variables to examine with a single instrument at a single point in time. An endeavor of that magnitude would be beyond the scope of this study. Second, institutional experiences affect individuals differently. Two individuals may experience the same phenomenon and react in completely different ways. This study included predictive factors that could act as a guide to other institutions. But interactive experiences would only be institution-specific. It should be noted that self-study is vital and should be conducted on a routine basis and in a longitudinal context.

This study relied on an existing data set. Therefore, additional demographic and background questions were not explored. Additionally, this study was limited by the confines of the College Student Inventory-Form B (CSI-B) and data available through the student records system. 
Only the 2004 freshman cohort who participated in summer orientation was represented in this study. Repetitive testing of multiple cohorts may have revealed differences among cohorts. Additionally, current events that will undoubtedly impact future cohorts were not reflected in this study.

This study did not differentiate between academic units or majors nor did it examine the intra-university transfer process. This is unfortunate because each academic unit sets different minimum requirements for grade point average to remain in good academic standing. It was impossible to determine whether or not students were in academic peril for one academic unit but in good standing with another, thus whether departure was voluntary or truly involuntary was unclear. Cleaner record keeping and tracking is necessary to make such determinations as accurate as possible.

The use of the CSI-B was not a perfect fit with Tinto's (1993) model of departure. Traditionally the composite scores focus on dropout proneness which differs in essence from Tinto's model. The use of the sub-scales of the CSI-B was a somewhat radical attempt to tease out the factors of motivation and commitment from the existing data. Still, this may not have been an ideal fit. Even though this is a limitation, it was an innovative attempt to take the research of the second year experience in a new direction.

Finally, the data was generated from an existing data set that was collected by a single university. Information from other institutions were not investigated or compared with results from colleges and universities that used a similar instrument. Therefore, the findings may not be pertinent to other types of institutions. Institutions that differ by type (i.e. two-year, four-year, public, private, small, large, residential, commuter) would undoubtedly have different results if this study is replicated. Even among like institutions, it is questionable whether or not this study can be generalized to other institutions. 


\section{Definition of Terms}

The following definitions will be used throughout this study:

Academic standing - Designates whether the student has achieved the minimum grade point average for his/her major in order to meet the minimum standard for acceptable academic progress. Those who fall below the minimum grade point average will be at risk of suspension and designated as either in warning status or on probation. Attrition - Departure or a break from post-secondary enrollment prior to degree attainment.

Commuter - A student who lives in off-campus housing not affiliated with the university. First-generation college student - Students whose parent(s) never attended college after departure or graduation from high school.

First-time student - A student who enters a college or university for his/her first traditional higher education experience. However, students who completed college level dual credit work in high school prior to enrollment as full-time college students qualify as first-time students (CPE, 2008).

First-year student - A student who enrolls into higher education as a first-time, full-time student.

Freshman - Used interchangeably in the literature with first-year student. Colleges and universities attach completion of a designated number of credit hours to the class standing of freshmen. For the purposes of this study, a freshman is a student that enrolls into higher education as first-time, full-time student; this designation is valid until the end of the first year. 
Graduation rates - The proportion of Kentucky resident students who enter as first-time, full-time, degree-seeking students who earn a bachelor's degree over a six year period of continuous enrollment. Non-resident students are not included in the state's standard GRS report (CPE, 2008).

Matriculation - Successfully moving from one level of education to another, such as completing a high school diploma or GED and continuing on to a college or university, or continuing enrollment from one year to the next in a postsecondary institution (CPE, 2008).

Motivation - The student's desire to attend college and complete a bachelor's degree. Persistence - Used interchangeably with the term retention, defined as students' state of continuous enrollment.

Persisters - For the purposes of this study, those students who remain enrolled after the end of the second academic year.

Retention - The proportion of first-time postsecondary students who enter an institution in the fall semester and return the following fall semester, excluding summer (CPE, 2008).

Second-year student - Students that began as first-time, full-time freshmen that persist to the second year of continuous enrollment.

Sophomores - Used interchangeably in the literature with second-year student. Colleges and universities attach completion of a designated number of credit hours to the class standing of sophomore. For the purposes of this study, sophomores are those students who have persisted to their second year of enrollment that initially enrolled as first-time, full-time freshmen. 
Specified group membership - A defined sub-group of students within the general population at a college or university. 


\section{CHAPTER II}

\section{LITERATURE REVIEW}

\section{Overview}

Despite decades of research into the causes of student attrition, the national average for graduation rates have remained at approximately $50 \%$ over the past 100 years according to the Educational Policy Institute (2004). Tinto (1993) affirmed that, "More students leave their college or university prior to degree completion than stay" (p. 1). The costs of attrition are tangible to the individual student, the institution, and society at large. The pressure is on to discover the reasons for attrition and to devise innovative solutions. But this is not an easy task. The reasons for student attrition are complex and include both academic and non-academic factors. Student characteristics such as background, prior experiences, motivation, and commitment impact institutional inputs aimed at retention. It is important for institutions to understand not only who their students are but how these individuals will react to a particular institutional culture. McGrath and Braunstein (1997) urged colleges and universities to conduct their own research to explore the issues within their own campus cultures.

The developmental needs of first-year students have been studied extensively over the past three decades. Considerable resources have been dedicated to first-year initiatives in order to stem student attrition. However, as first-year retention rates improve, graduation rates remain virtually the same. During the last 10 years, researchers 
and institutions have turned their attention to the second-year student experience in an effort to improve upon stagnant persistence to graduation rates. As of 2000, very little research focused on the second-year experience. Since the publication of Schreiner and Pattengale's 2000 monograph, Visible solutions for invisible students: Helping sophomores succeed, research into the second-year experience has significantly increased (Pattengale \& Schreiner, 2007). However, much of the research is qualitative and there are still gaps in the literature depending on institution type.

This study examined pre-entry variables that predict college student persistence beyond the second year at the University of Louisville. The pre-entry factors outlined in Tinto's model of student departure served as the theoretical basis and context for this study.

\section{Tinto's Model of Student Departure}

Vincent Tinto has been researching student retention and persistence for over 30 years. In his classic 1975 article, Tinto introduced what remains the dominant sociological model of how students enter and progress through higher education. Following a multi-year, longitudinal study, he later revised his student integration model in Leaving college: Rethinking the causes and cures of student retention $(1987,1993)$. Student populations and the college experience have changed dramatically over the years. The dialog on student persistence continues today. Even Tinto (1993) admits that "Student departure has been a much studied phenomenon. Yet there is still much we do not know" (p. 35).

There is a wealth of information about successful retention programs. Discerning which attributes of successful programs are institution specific and which can be 
generalized is problematic. It is difficult to isolate how and why one set of actions work for certain students or institutional types yet fail with others. Much of the information about successful retention programs tends to be descriptive and over-simplified rather than explanatory in nature.

Tinto (1993) proposed that attrition appears to be more situational in essence. In order to understand why students depart from higher education, we must first look to the manner in which students enter our institutions. The attributes of individuals and institutions must be viewed in concert. The isolation of broad characteristics will not divulge an accurate portrait of persistence patterns.

Based on the works of Durkheim $(1897,1951)$, van Gennep $(1908,1960)$, and Spady (1971), Tinto $(1975,1993)$ developed a person-environment model of college student attrition. His model recognized that student pre-entry characteristics influence the student's experiences within the college environment. Tinto $(1975,1993)$ suggested that pre-entry variables impact levels of commitment and motivation which affect integration into the institution's culture. Tinto (1993) addressed the complexity of student departure:

Individual departure from institutions of higher education arises from several major causes and roots. These have been described here as intention, commitment, adjustment, difficulty, congruence, isolation, obligations, and finances. The first two pertain to dispositions, with which individuals enter institutions of higher education, the next four to experiences they have after entry, and the latter to external forces which impinge upon their experiences within the institution (p. 81). 
Tinto (1993) considered integration into the institution's environment to be critical to retention. The motivation to complete college combined with commitment to the institution will determine the student's decision to persist or drop out. The tendency of institutions to front load retention strategies in the first semester of enrollment may be attributed to Tinto's (1993) assertion that the decision to depart is typically made within the first six weeks of enrollment. However, these efforts only begin to unlock the persistence puzzle. Changes in student populations and public policy could negatively impact retention efforts; the need for more remedial course offerings, change in the availability of financial aid, part-time enrollment, and students who must work in addition to taking classes were of particular concern (Tinto, 1993).

Concentrated persistence to graduate efforts will need to be multifaceted, adaptable, and in many cases, institution specific. Tinto (1993) cautions that:

These data, whether on institutional or on system departure, are aggregate data which describe the behavior of groups of individuals and institutions. They do not describe the behavior of each and every group member. Similarly, though differences in rates of system departure among groups of students may be indicative of broad differences in the character of their experiences in higher education, only knowledge of the experiences of individuals within specific institutional settings will tell us of the unique character of individual departure from institutions of higher education (pp. $27-28$ ).

There is not an easy explanation for student attrition, nor is there a magic formula to ensure persistence. Institutions must consider a complex set of variables that contribute to persistence. Tinto (1993) cited common behaviors and themes reported in retention research, "These pertain to the dispositions of individuals who enter higher education, to the characteristics of their interactional experiences within the institution following entry, and to the external forces which sometimes influence their behavior within the institution" (p. 37). 
Following a longitudinal study of student departure, Tinto $(1987,1993)$ outlined six attributes that stand out as primary roots of student attrition. The first two, intention and commitment, are marked as predispositions on the individual level, which are of particular interest to this study. Adjustment, difficulty, incongruence, and isolation are all forms of individual experiences with the institutional. Tinto (1993) also cites two external factors that shape persistence, obligations and finances. All of these attributes are closely tied together. Institutional attributes mirror the attitudes, skills, and dispositions of individuals prior to entry and the external forces which impact student participation (Tinto, 1993). The institutional environment is impacted by the student populations it matriculates. Therefore, institutional inputs should address the attributes and needs of its particular student population.

Most students enter higher education with established expectations, only to find that the reality of the campus environment is not quite what they expected. Choice of institution is related to student expectations about the character of the institution. The more accurate and realistic the expectations, the better the fit (Tinto, 1993).

First-year students that enjoyed high GPAs in high school, might experience a dip in college grades as they become accustomed to a new system. Additionally, first-year students typically lack concrete career goals. This process of identity exploration is a natural part of the acculturation process. Tinto (1993) postulated that:

Apparently the two processes, namely, college grade performance and career decision making, are not related to each other in any simple fashion. Rather, it is argued by some, persistence and departure should be seen as one component of the larger process of career and identity formation. Then those careers and identities are crystallized, that is, when individuals are more certain as to their futures, they are more likely to finish college (p. 41). 
Intention, or motivation, and commitment will be of particular interest for the proposed study. Tinto (1993) cites two forms of commitment: goal and institutional. Goal and institutional commitment are often interrelated. An individual may be committed to goal attainment (for example degree completion in four years) but not within the original institution of enrollment. In this case, the student may transfer to another institution in order to achieve his/her goals. Terenzini, Lorang, and Pascarella (1981) caution that, "Individuals who are committed to graduating from a specific institution are more likely to graduate from that institution than are persons whose commitments have no specific institutional referent" (in Tinto, 1993, p. 43). If initial goal and/or institutional commitment are weak, the impact of external communities and obligations could mean the difference between persistence and departure. Tinto (1993) maintains that if commitment to external peer, family, and work obligations are greater than commitment to the institution, then persistence could be negatively impacted.

If institutions can determine initial levels of commitment and the strength of external obligations, institutional inputs can focus on increasing institutional commitment and reinforcing the desire for degree completion during the first-year and further define and solidify education and career goals the second-year. Tinto (1993) confirms that, "The higher the level of one's educational or occupational goals, the greater the likelihood of college completion" (p.38). Strong goal commitment will lead individuals to persist in difficult circumstances while those with weak to modest commitment may be able to overcome obstacles (Tinto, 1993).

Tinto has been cited countless times, numerous studies have used his model as a foundation, and others have revisited and revised his model. Braxton, Hirschy, and 
McClendon (2004) revised Tinto's model of student departure and identified 16 propositions for commuter student attrition. Of particular interest to this study are the financial factors of accumulation of debt and worth of continued enrollment and motivation to make progress toward degree completion.

Tinto's (1993) model is but one of many attempts to explain student behavior. Human beings seek to understand the behaviors of others and of themselves. An examination of additional theories provided a canvas for painting a more detailed picture of student development.

Additional Retention/Attrition/Development Theories and Models Student development theory falls into many different categories: psychosocial, identity, cognitive, and transition to name a few. All contribute to the understanding of the factors that contribute to student persistence. Of course, theory is a guide into the student experience. Institution-specific information provides a more accurate insight into the student experience (Schaller, 2007). The past experiences and characteristics of entering students can positively or negatively impact their ability to cope with the pressures of a new environment. No single theory is all-encompassing, therefore it is necessary to examine several possible explanations for how the college environment affects diverse populations of students. Persistence has been studied extensively over the years but the results can be contradictory. Tinto (1987) observed that, "It is not uncommon, for instance, to find one set of studies claiming ability to be directly related to leaving, another arguing the reverse, and yet another asserting that no relationship exists between the two" (p. 208). 
Two early psychosocial theorists paved the way for many later models of student development: Durkheim $(1897,1951)$ and van Gennep $(1908,1960)$. Beginning with the pioneering work of Emile Durkheim, considered to be the father of modern sociology. Durkheim (1897) introduced his sociological theory of suicide in Le Suicide (translated to English in 1951). He proposed that suicide is a social structure rather than a biological anomaly centered in the individual. Durkheim $(1897,1951)$ argued that suicide must be viewed through an examination of sets of social circumstances associated with the individual.

Durkheim's theory did not address student attrition, but viewed suicide as a social construct rather than a defect rooted in the individual. Spady and Tinto later applied components of Durkheim's theory to student attrition. Durkheim's examination of how individuals interact with a particular environment is similar to factors that contribute to student departure.

Durkheim $(1897,1951)$ outlined three categories of suicide: egotistic, altruistic, and anomic. Egotistic suicide refers to the individual's failure to integrate into social communities (family, friends, religious, political, or national affiliation). Students that fail to make connections to or within the institution may feel isolated and lack the desire to continue. The student that does not establish relationships with other students, faculty and staff may in essence experience something akin to commitment suicide. This is not to say that failure to make connections is solely the fault of the individual, the institution, or society, has a responsibility to foster such relationships.

At the other end of the scale, an altruistic individual is extremely integrated in a social sect and strictly adheres to rules, customs, and norms. Altruistic suicide occurs 
when the individual "sacrifices" himself/herself for the sake of the social group. Anomic suicide is marked by a sudden life change in which the individual is unable to reconcile the new set of circumstances within the confines of his/her established social structure (Durkheim, 1897, 1951). First-year students that do not adequately find a balance between pre-college and college life may not be able to navigate the expectations of the institution. Similarly, second-year students accustomed to the intense attention they received during the first year, may not be able to adjust to the "freedoms" they are thrust into during the second. Many institutions effectively cut second-year students off from the structure and support they received as first-year students. Second-year students may not be able to adjust to such a sudden and drastic change.

Durkheim's $(1897,1951)$ influence is evident in Tinto's (1993) model of student departure in which he outlines four interactional roots that lead to institutional departure: adjustment, difficulty, incongruence, and isolation. These roots of departure mirror Durkheim's $(1897,1951)$ egotistic and anomic categories of suicide. Tinto (1993) defines incongruence as a lack of institutional fit and isolation as an absence of sufficient interactions necessary for integration. Inability to integrate stems from these two factors.

Lack of institutional commitment and low motivation to persist to graduation are two of the underlying causes for attrition. Higher education has a culture complete with expectations, rules, norms, and values. In addition, there are institutional variances to the greater culture which mirrors that of regional differences (i.e. rural, big city, mid-west, west-coast, southern culture) one finds throughout the United States. The factors that influence drop out behavior are similar to factors that Durkheim $(1897,1951)$ outlined in his suicide theory: "normative congruence" and "friendship support". Durkheim (1897, 
1951) argued that the prevalence of suicide increases when an individual lacks close social relationships and rejects dominant societal norms and values. Likewise, students that do not establish connections with others on campus, fail to adhere to institutional expectations, and maintain incompatible goals and values may be more likely to drop out.

Inability to break old ties and forms new ones is a recurrent theme in student retention literature. In his 1908 work, Les rites de passage (translated to English in 1960 by Vizedom and Caffe) van Gennep proposed a theory of socialization that viewed human existence as a series of successive stages that involve changes in the interactions between the individual and the rest of the group members. Each stage is characterized by rites and ceremonies. There are three distinct stages: separation, transition, and incorporation. In the separation stage, the individual begins to decrease interaction with his/her original social/cultural group. During the transition stage, the individual begins interacting with members of the new group and participates in the rituals and ceremonies designed to acculturate new members to the society. The final stage, incorporation, the individual establishes membership in the new group and adheres to the values and norms of that society (van Gennep, 1908, 1960).

College students' integration into higher education mirrors van Gennep's (1908, 1960) rites of passage. Individuals must move from membership in one society to membership in another. New students, first-year and transfer, must establish new relationships. However, separation from family, long-time friends, and other social networks could prove to be counterproductive, especially in certain ethnic groups. In contrast, attempts to balance what may be conflicting membership in both the old and new groups could have a negative impact on persistence. Assisting students in finding 
that balance is the key. Second-year students could fall anywhere between the late stages of separation to the early stages of incorporation. The combination of individual characteristics, external demands, and the institutional environment contribute to the duration and subsequent success of the process. If students fail to come to terms with this process in a timely fashion, instances of departure will likely increase.

van Gennep $(1908,1960)$ cautioned against the examination of rites and ceremonies in isolation of the broader social context in which they operate. Practitioners in higher education are often tempted to review isolated programs or policies at other institutions and apply them to their own institutions without examining them within the proper context. Policies, programs, and procedures must be viewed in a broad spectrum that includes student characteristics and how the student population interacts with the campus environment. Practitioners should spend time examining the characteristics of their student populations and objectively review institutional culture in order to plan appropriate acculturation initiatives.

Spady $(1970,1971)$ adapted Durkheim's theory of suicide to higher education and formulated a model to explain college student attrition. His model examines the interactions between student background characteristics, pre-entry variables, and institutional commitment. Spady (1971) recognized that student attrition is the result of "A complex social process that includes family and previous educational background, academic potential, normative congruence, friendship support, intellectual development, social integration, satisfaction, and institutional commitment" (p. 38). Spady (1971) contends that attrition results from a complex decision making process which is influenced by a variety of variables including: "family and previous educational 
background, academic potential, normative congruence, friendship support, intellectual development, grade performance, social integration, satisfaction, and institutional commitment" (p.38).

Each student that enters higher education must traverse a number of challenges during the acculturation process. Spady (1971) views this process as problematic due to an incongruence between the institutional culture and pre-entry factors and states that, "Each student enters college with a definite pattern of dispositions, interests, expectations, goals, and values shaped by his family backgrounds and high school experiences" (p. 38). According to Spady (1971) family background and pre-entry experiences shape student interests, goals, attitudes, values, and expectations. Coping skills are established through past experiences. Spady $(1970,1971)$ viewed the attrition process as an interrelationship between the individual student and the campus culture.

Spady's (1970) model reflects a sociological explanation of student attrition which asserts that "The dropout process is best explained by an interdisciplinary approach involving an interaction between the individual student and his particular college environment in which his attitudes are exposed to influences, expectations and demands from a variety of sources" (p. 77). Bean (1985), however, takes a slightly different approach to solving the student attrition dilemma. Bean's (1985) work centers on student socialization. His research focused specifically on reasons for attrition as opposed to strategies to improve persistence. He contends that student peers are the most critical component to the socialization process.

Bean (1985) outlined three forms of socialization that impact student retention: academic socialization, institutional fit, and institutional commitment. Academic 
socialization pertains to whether or not a student can meet the expectations of the faculty and academic rigor of the institution. Institutional fit relates to how well the values, norms, and goals of the student match those of the institution. Institutional commitment reflects both initial level of commitment and the integration process.

Astin $(1972,1993)$ and Pascarella (1980) turned their attention to the institutional interactions that impact persistence. Astin $(1972,1993)$ spent over 20 years examining factors that support persistence in college. He surmised that the major factors that improve retention are living on campus, involvement with faculty, and interaction with peers. He also found that institution size has a major influence; as institutional size increased, retention and student satisfaction decreased.

Astin's (1977) model of Input-Environment-Outcome supports a holistic view of student persistence. Student success includes student characteristics prior to entry into higher education and what happens to them after enrollment. Environment is comprised of institutional characteristics and student curricular and co-curricular experiences. Student persistence does not exist in a vacuum. There is no single factor that predict or explain who will persist and who will not. Persistence is a complicated phenomenon that requires institutions to examine several aspects of student success. This study represents a first step to unraveling persistence patterns. The first part of the process involves identification of the characteristics of entering students which leads to the formulation of expectations of how students might react to particular inputs. Institutions also must be able to characterize their own unique environments and be able to collect accurate data. Studies of how student populations respond to the overall environment and particular inputs are also necessary to produce a better understanding of the persistence puzzle. 
Interaction with faculty was of particular importance in Astin's findings. Students form perceptions of how approachable the faculty is based on what they perceive faculty attitudes to be. Astin (1993) suggests that faculty attitude toward students directly impacts effectiveness of student outcomes, more so than many other campus environmental factors. If students perceive that the faculty is student oriented, they are more satisfied with their college experience (Astin, 1993). The importance of faculty interactions was found to be a significant predictor in this study.

Pascarella (1980) outlined five sets of variables that build upon one another and in turn impact student development. The first set encompassed the structural and organizational features of the institution. The second consisted of student background and pre-college traits. The first and second sets worked in concert to form the third set, institutional environment. The previous three sets clustered to influence the fourth set of variables that involved student interactions with campus agents of socialization (faculty and students). The final set, quality of effort, are shaped by the previous four sets.

Theory provides insight into the human experience and the theoretical framework necessary to form our own assumptions. Taken in tandem with institutional and student characteristics, institutions can fashion their own solutions to the attrition crisis.

Demographic Characteristics

An exploration of demographic variables is common in most studies. The variables that were examined in this study included age, gender, ethnicity, median family income, and parental level of education (first-generation college status). Only one of these characteristics was found to be a significant predictor of persistence in this study, median family income. It is important for institutions to have an accurate assessment of 
the demographics of their students. Student sub-populations present their own set of opportunities and challenges. Demographic variables interact with background characteristics and institutional inputs to create a unique set of circumstances. Each institution has a particular pattern of needs that must be met. Student characteristics combined with institutional culture may explain the contradictions in the literature.

Traditionally, an examination of demographic variables suggest that lower income, male, non-traditional aged, first generation, and racial/ethnic minority (with the exception of Asian) students have been found to be at a higher risk of attrition than other groups (Cabrera, Stampen, \& Hansen, 1990, Pascarella \& Terenzini, 2005). However, various studies have found conflicting results. Davis et al (2004) suggested that black students at predominantly white institutions had lower graduation rates than their white peers. But Crawford (2007) found that race/ethnicity did not have a significant impact on first year persistence or graduation rates.

Allen, Robbins, Casilles, and Oh (2008) stated that students from a lower socioeconomic class were more likely to depart prior to the third academic year. Students with lower incomes were more likely to engage in behaviors that hinder academic success such as living off campus, attending public universities, working, and attending class part-time (Paulsen \& St. John, 2002). But Aldeman (1999) found that students from the lowest median family income levels earned bachelor's degrees at a rate equal to students from the highest income brackets.

Berkner, He, and Cataldi (2002) uncovered several factors that put first generation students at a higher risk of attrition. These factors included: delayed entry into higher education, having children, financial independence, and having a high school equivalency 
rather than a traditional high school diploma. Ishitani (2006) found that if the parents of first generation students did not express specific educational expectations, there was a negative impact on student persistence.

The study of student persistence is multifaceted. It is difficult at best, perhaps impossible to separate the contribution of a single variable for such a complex topic. For example, a study by Leppel (2001) revealed an interaction between major and gender. Women were more likely to succeed in education, health, humanities, or liberal arts majors, whereas men were more successful as business majors.

\section{Academic Success}

Academic preparedness is perhaps one of the most utilized predictors for student persistence. Astin (1972) conducted an extensive study of student attrition in higher education that included over 51,000 college students and over 200 institutions. Even though he could not generalize who would drop out across institutions, he was able to determine the role that certain factors play in influencing student persistence; high school GPA and standardized test scores were positive indicators of persistence. For this reason, many institutions have increased minimum admission standards in hopes of matriculating a "higher caliber" of student that will be more likely to succeed.

High school and standardized test performance may not provide a comprehensive vision of persistence patterns. Even though high school grade point average has been found to be a significant predictor of college persistence, the relationship lacks power. High school GPA accounted for only 12\% of the variance in Irvine's 1966 study (Tinto, 1993). 
Academic dismissal represents a small percentage of total departure from higher education (Tinto, 1993). Tinto (1987) found that nearly $85 \%$ of the departures in his study were voluntary and that most students maintained acceptable levels of academic performance. According to Tinto (1993), lack of ability may not be the variable that triggers departure:

Their subsequent departure, whether in the form of academic dismissal or voluntary withdrawal, is less a reflection of the lack of ability or even intention than it is of an inability or unwillingness to apply their talents to the attainment of desired goals (pp. 41-42).

High school GPA may not be a pure indicator of academic preparedness. Morrison and Brown (2006) reported that 70\% of public high school students graduate, however; only $32 \%$ of the high school graduates are prepared to enter a four-year university. Skills and behaviors such as study skills, active participation in class, and engagement in academic dialog are key factors to academic success. DiPerna and Elliot (2002) contend that motivation directly influences the development of such skills.

Long and Riley (2007) found academic preparedness is a major obstacle to college enrollment and persistence. High school seniors are increasingly unprepared for the rigors of higher education: only $32 \%$ of students that graduate from high school are ready to study at college-level (Greene \& Foster, 2003). Findings consistent with those of Morrison and Brown (2006) found that only $32 \%$ of students who graduate from public high schools are prepared to attend a four-year institution.

Family income has a major impact on college preparedness. Students from families with an annual income of $\$ 30,000$ or less had an average math score of 474 on the SAT, whereas students from more affluent families (those with an income of at least $\$ 100,000)$ had a mean score of 564 (College Board, 2006). 
The most common institutional intervention for underprepared students is remedial education, and the number of students in need of remediation is growing (Long \& Riley, 2007). A study by Bettinger and Long (2006) suggested that developmental courses have a positive effect on retention. On the contrary, Attewell, Lavin, Domina, and Levey (2006) found that students in remedial course at four-year institutions were less likely to graduate than students that were not required to take remedial coursework. Students at both the low and high ends of the economic spectrum were required to take at least some remedial classes. Twice as many students from the lowest economic quartile (52\%) required medial work as opposed to $24 \%$ of students from the highest quartile.

A growing number of universities are funneling remediation to community colleges and delaying enrollment to a four-year institution until the remedial courses are completed. Additionally, many institutions are raising admissions standards in order to increase retention rates. Even if this tactic is successful for the institution's persistence rates, it can be detrimental for the students who fail to meet initial standards of enrollment. Long and Riley (2007) caution that this could have dire consequences for students who wish to complete a bachelor's degree, "Students who begin higher education in two-year institutions are less likely to earn bachelor's degrees than those who begin at four-year institutions, this trend is likely to reduce access and persistence toward a bachelor's degree" (p. 41).

Academic performance can have positive or negative effects on self-efficacy. First semester grades play a critical role in persistence (McGrath \& Braunstein, 1997). Astin (1993) stated that, "GPA, despite its limitations, appears to reflect the student's actual learning and growth during the undergraduate years" (p. 242), thus making it 
appropriate for measuring academic success. Many students equate competence with academic performance. If students fail to achieve at the level of academic success they expect, they may experience feelings of incompetence and low self-esteem. These feelings could lead to insecurity and apathy (Lemons \& Richmond, 1987). Students may judge one another based on academic achievement thus influencing social integration (McGrath \& Braunstein, 1997).

\section{Financial Concerns}

Due to the economic downturn, financial concerns have become more prevalent than in past decades. But finances have been an issue for some time. According to Tinto $(1975,1993)$, external forces that affect persistence include finances and obligations outside the college environment such as family and work. Employment limits time for academic pursuits which impacts persistence (Tinto, 1993). He acknowledges the role of economics in student persistence. The value of a college degree is weighed against the cost of both time and resources. Students are more likely to withdraw if they perceive other options, such as employment or marriage, to be more beneficial and desirable. Manski and Wise (1983) and Voorhees (1984) agree that student persistence mirrors any other economic decision that weighs the costs and benefits of investing scarce resources.

Students often cite financial difficulties as the main reason for departure. Tinto (1993) views this argument as an ex post facto form of rationalization that masks the real reasons for departure. Students who view college experiences as rewarding and/or intertwined with future goals will persist despite financial burden and accept short-term debt in order to achieve degree completion (Tinto, 1993). He contends that the impact of finances upon persistence primarily occurs before or at the point of entry into higher 
education and then diminishes as a factor in and of itself. Short term financial constraints may prevent students from making tuition payments or purchasing books. However, Tinto (1993) maintains that financial shortfalls are more pertinent early in the college career when the goal of completion is remote. Financial considerations may induce individuals to enter higher education in ways that increase likelihood of departure prior to degree completion (Tinto, 1993). A student may base choice of institution on the cost of tuition rather than other factors more closely related to career and life goals resulting in poor institutional fit.

Tinto (1993) argued that adequate financial aid eliminates the financial reasons for attrition for low-income students and that grants and Federal Work Study are preferable to loans. However, he cautions that finances are but one factor in a broader number of events that shape persistence. Financial aid decreases the cost for eligible students but has little effect on the benefits side of the equation (Tinto, 1993).

But in the last 10 years much has changed. Unemployment is up, consumer debt is at an all-time high, and tuition has sky rocketed. Pattengale (2000) noted that students' financial needs may change during the course of their college careers. Loss of scholarship, increases in tuition, and loss of income are just a few of the issues that might arise. A study by McGrath and Braunstein (1997) revealed freshmen who were not troubled by financial difficulties were more likely to persist. The students who persisted came from higher socioeconomic backgrounds or were participants in financial aid programs. Students that experience financial concerns may have to expend more time and energy on non-academic endeavors. Additionally, students' perceptions of other students may be influenced by financial variables (McGrath \& Braunstein, 1997). Students that 
experience feelings of guilt or frustration due to financial dependence on parents are at risk of dropping out (Lemons \& Richmond, 1987).

One of the most common complaints that Anderson and Schreiner (2000) documented from second-year focus groups was the difficulty in justifying the cost of tuition when they had no clear direction in life. Even though financial aid is known to impact persistence, few institutions have special funding packages for sophomores (Tobolowsky \& Bradley, 2007). Some progressive institutions recognize the need to give special financial assistance to second-year students, other than the external resources available to all students. Benedict College offers grants to second-year students that earn a 3.5 cumulative GPA at the end of the first year. The College of New Jersey has a scholarship program for second-year students who make a commitment to building community on campus. Beloit College offers grants that enable second-year students to study abroad, engage in research, or start a business (Tobolowsky \& Bradley, 2007). But these efforts may not be enough. Institutions need to be aware of the impact of financial factors and determine how to make an impact on this issue.

The rising cost of tuition is becoming a major barrier to attending college for lowincome and minority students. Long and Riley (2007) argue that, "In recent years, U.S. financial aid policy has shifted its emphasis from expanding college access for lowincome students toward defraying costs for middle- and upper-income families, "Loans, merit-based aid, and education tax breaks are increasingly replacing need-based aid" (p. 39). The decline in the role of grants could ultimately make higher education unobtainable for underrepresented students (Long \& Riley, 2007). 
There has been a major shift over the past 40 years in the type of financial aid available to students. In $1970,70 \%$ of financial aid awards were in the form of grants, but by 2003 loans make up $60 \%$ of student aid (Kim, 2007). This trend to an increased dependence on loans was precipitated in the early 1990s by two major amendments to the Higher Education Act: increased limit on loan amounts and expanded eligibility to off-set the increased cost of tuition (Kim, 2007).

Kim (2007) asserts that, "Low-income or minority students, who on average face less certain job prospects and higher risks of degree non-completion, are likely to have higher loan aversion than their higher-income or white counterparts" (p. 69). The disparity between loans and grants is startling. The Education Resources Institute (1995) reported that there was a 3\% increase in attrition associated with an additional $\$ 1000$ of loan debt, however there was a $14 \%$ decrease in attrition when grants were increased by $\$ 1000$. Unless something is done to increase the availability and amount of grant awards to low-income and minority students, higher education may become out of reach for these students.

\section{Motivation and Commitment}

A college education is now considered the norm by mainstream society and is equated with future employment opportunities. Many families will make great financial sacrifices in order to assure their children have a "decent education". Students, their families, and society in general view higher education in terms of vocational benefits. The question is whether or not an external, occupational motivation for obtaining a college degree breeds passive learners. Are students that are committed, active learners that are internally motivated more likely to persist? Spady (1971) theorized that student 
attitude toward learning was a more significant predictor of persistence than intellectual ability.

Motivation shapes attitudes and behaviors that ultimately impact academic competence. Lack of motivation influences important academic behaviors such as studyskills, class attendance and class participation (DiPerna \& Elliott, 2002). According to Anderson and Schreiner (2000) "motivational slump" is one of the most important issues that academic advisor must contend with when advising sophomores. Baker, McNeil, and Siryk (1985) blame the "matriculant myth" for this decline in motivation. First-year students enter higher education with high expectations and an unrealistic perception of what college life will entail. By the second-year, the myth has become reality and if the two do not match, then the student will be disillusioned, disappointed, and unmotivated. One of the many issues that incoming college students must adjust to is a lack of structure. Students are expected to make their own decisions, to accept the consequences for their actions, and to be active participants in their education (Eggen \& Kauchak, 2004).

Freedman (1956) considered second-year persistence to be "A function of her intrinsic ability, interest, and motivation" (p. 21). "Some sophomores will make connections to the campus on their own, with seemingly little effort. Others will struggle; of these, some students will follow their peers while others will falter and give up" (Gardner, 2000, p. 74). Students have a variety of reasons for choosing to attend a particular institution: interests in a particular major, prestige of the institution, high profile faculty, or proximity to home are just a few. Not everyone has his/her pick of schools. Many times the decision is one of convenience or the result of limited options. 
Levels of institutional commitment can affect students' ability and willingness to make connections on campus. It is important for student goals to be consistent with that of the institution in order to support commitment levels and persistence to graduation (Morrison \& Brown, 2006). Waterman and Waterman (1972) stress the effect that personality, motivation, and disposition have on a student's willingness to meet the demands of academia.

Tinto (1993) asserts that individual levels of commitment, motivation, and effort are key factors to student persistence. In order to persist to graduation, students must be willing to commit time, energy and resources to meet the academic demands of the institution. The motivation to complete a degree has a variety of roots. Some students are motivated by a desire to improve their economic situation, others strive for recognition, while others view a degree as a way to ensure upward mobility (Macey, 1993). Tinto (1993) describes how student characteristics impact commitment levels:

Individuals enter institutions of higher education with a range of differing family and community backgrounds (e.g., as measured by social status, parental education, and size of community), a variety of personal attributes (e.g., sex, race, and physical handicaps), skills (e.g., intellectual and social), financial resources, dispositions (e.g., motivations; intellectual, social, and political preferences), and varying types of precollege educational experiences and achievements (e.g., high school grade-point average). Each attribute is posited as having a direct impact upon departure from college... More importantly, each affects departure indirectly through its effect upon the continuing formulation of individual intentions or goals specify both the level and type of educational activities ( $p$. 115).

Cabrera, Nora, and Castaneda (1993) developed an integrated retention model that identified two powerful factors that affect retention: GPA and intent to persist. However, both factors were significantly influenced by other variables. GPA was impacted by academic integration and financial attitudes. Intent to persist was directly affected by 
academic integration, support of family and friends, and social integration. Goal commitment was influenced by academic integrity and the support of family and friends. These interactions between variables demonstrate the complex and competing influences that determine persistence on many campuses (Cabrera, Nora, \& Castaneda, 1993). External commitments also have an indirect impact on attrition. Students' social and academic integration may suffer if external commitments are too great or are in conflict with those of the institution (Tinto, 1993).

\section{First-Year Students}

Many college students enter college without long-term educational or occupational goals. Even those who enter with goals will alter them during the course of their academic career. Most college students will experience uncertainty about educational and career goals. Tinto (1993) cautions that uncertainty among new students will likely increase in the initial months of enrollment. Uncertainty, however, is a natural process and should not be treated as a deficiency by institutions of higher education (Tinto, 1993).

First year students enter higher education with their own values, attitudes, and expectations. Their expectations may be based on information from family members, friends, teachers, guidance counselors, or even popular culture. Some students begin their first year highly motivated and prepared to succeed while others may feel insecure and unsure. Pre-enrollment variables are a major determinant of freshmen success. It is vital to examine the influence of background, demographics, cultural characteristics, personality, and experiences prior to college enrollment in order to understand the variables that affect freshman success (Upcraft, Gardner, \& Associates., 1989). 
During the freshman year, students start to develop competency in the following areas: (1) academic and intellectual pursuits, (2) interpersonal relationships, (3) identity, (4) decisions about career and lifestyle, (5) personal health and wellness, (6) integrated philosophy of life (Upcraft, 1984).

It is easy to understand why colleges and universities invest so much attention and devote sizable resources to first year initiatives. The largest proportion of institutional attrition occurs prior to the second year. Therefore, the first college year is vital to the process of persistence. Tinto (1993) contends that, "The character of one's experience in that year does much to shape subsequence persistence" (p.14). Student success is largely determined by the freshman year experience (Noel Levitz \& Saluri, 1985).

First-year students encounter a number of developmental tasks that must be addressed: (1) develop intellectual and academic competence, (2) establish and maintain interpersonal relationships, (3) explore of identity, (4) make career decisions, (5) maintain health and wellness, (6) preserve faith and spiritual self, (7) develop multicultural awareness, and (8) enact civic responsibility (Upcraft, Gardner, \& Barefoot, 2005). The ability to confront and move through all of these tasks would be improbable during the first year, perhaps not even by degree completion. Many, if not most, of these tasks will undoubtedly carry over to the second year.

In order to enhance student success, institutions must: (1) develop clear and broad definition of success, (2) commitment to a set of beliefs that maximize opportunities, (3) have knowledge and understanding of the variables that affect success (Upcraft, Gardner, \& Associates., 1989). It is important to remember that freshman success entails more 
than persistence to graduation; progress to the fulfillment of educational and personal goals is just as important (Upcraft, Gardner, \& Associates., 1989).

Despite our best efforts, first-year programs may not go far enough to acculturate new students nor prepare them for the challenges of the second year. The next section explores the trials and tribulations of second-year students.

\section{Second-Year Students}

Tinto's model has provided the framework for many studies. Because previous research has highlighted the large numbers of students leaving during the first year of college, much of the research regarding student success and attrition has focused on firstyear students (Graunke, Woosley, \& Helms 2005). Tinto (1993) suggested, however, that the important issues for first-year students may not be important issues for students at other stages in a college career. Tinto (1987) stated that "Forces that shape departure during the first year of college, especially during the first six weeks of the first semester, are qualitatively different from those that mold departure in the latter years of college" ( $p$. 439).

Mohr, Eiche, and Sediacek (1998) studied seniors who left before graduating. They found that seniors who had departed did not differ significantly from returning seniors in terms of dissatisfaction with university policies or levels of campus involvement. Thus, the different components of Tinto's model adopt different levels of importance as students' progress through their college career (Graunke, Woosley, \& Helms 2005).

Tinto (1993) suggested that, "Long-term retention efforts beyond the first year should focus on three major sources of student departure: academic difficulties, the 
inability of individuals to resolve their education and occupational goals, and their failure to become or remain incorporated in the intellectual and social life of the institution" (p. 176). Problems with institutional fit may linger until the second year, "Students leaving in the second year more often cited issues or problems pertaining to the school itself and its ability to deliver in terms of the students' initial expectations" (Boivin, Fountain, \& Bayard, 2000, p. 1). Graunke, Woosley, and Helms (2005) contended that sophomores' view of institutional commitment may be superficial. Freshmen are provided with connections and contact to the institution through first-year programs. Juniors and seniors have connections through participation in their academic major and greater leadership roles in student activities. Sophomores, who have fewer opportunities in these areas, may view the university from a more global perspective than others.

As previously stated, institutions have invested a great deal of their resources to the retention of first year students. That expenditure appears to have succeeded, as firstyear retention rates have increased over the past several years. Yet these efforts may have only delayed the inevitable until the end of the second year (Pattengale \& Schreiner, 2000). Sophomores are left to struggle through the remainder of their general education requirements and begin to navigate courses in a major they may not be suited for.

Many colleges and universities front-load services and resources the first-year, yet fail to continue support and programs for second-year students. Flanagan's (1990) study of colleges in the Associated Colleges of the Midwest and in the Great Lakes Colleges Association found that attrition levels from the second-year to the third-year were higher than first-year rates. Pattengale and Schreiner (2000) have observed that, "For some sophomores, the negative behavior patterns or academic struggles that began in their first 
year and were tolerated by the institution because they were first year students are now beginning to catch up with them" (p. vi).

Boivin, Fountain, and Baylis (2000) caution that, "Unless consideration is given to the sophomore year experience, successive cohorts of first-year students will continue to weather the storms of first-year transition, only to bail out of higher education when they face the serious developmental challenges which continue and even intensify in the sophomore year" (p. 2). Schaller (2007) supports the argument, "New students experience a decline in competence during the first college year, which may indicate that sophomore students begin the second year still attempting to manage some competence issues" ( p. 2).

The idea of a "sophomore slump" is not new. More than 50 years ago, Freedman (1956) dismissed the implication that second-year students are characterized by inertia and disorganization. The sophomore slump, as defined by Feldman and Newcomb (1969), is a time when students experience dissatisfaction with both college and self. This phenomenon has been studied, described and defined, but very few of the studies have systematically measured its existence (Schaller, 2007).

Freedman (1956) believed that the "slump" period was more likely to occur with second semester freshmen. This observation appears to support the idea that the focus on first-year retention may have delayed a developmental crisis until the second-year. Tobolowsky and Serven (2007) define the "sophomore slump" as period in which students struggle to establish their own identities, realize interests, and set goals. Secondyear students are in a state of flux and may experience confusion and uncertainty. This state of crisis leads to dissatisfaction with self and college (Feldman \& Newcomb, 1969). 
At a time when they may need the most help, second-year students find that they have lost their status as being "special" within the institution (Schaller, 2007). It is little wonder that these students may feel betrayed, insecure and disenfranchised.

In recent years, researchers have turned their attention to identifying the causes of the so-called "sophomore slump". Lemons and Richmond (1987) link the "slump" to Chickering's vectors of developing competence and establishing identity. They view the second-year as a time of "developmental confusion”. Lemons and Richmond used Chickering's vectors to explain sophomore identity crisis. They surmised that the phenomenon of the sophomore slump could be traced to issues encompassed in the following four vectors: achieving competence, developing autonomy, establishing identity, and developing purpose.

Increasingly, the second year is being viewed as a time of moratorium, in which students seek to solidify their career decisions and personal goals (Graunke, Woosley, \& Helms, 2005). Sophomores face many daunting challenges. They feel pressured to make decisions about choosing a major, whether or not to study abroad, plan for internships, and take weed-out classes all while struggling with identity issues (Lipka, 2006). Pattengale and Schriener (2000) stated that the sophomore year may be a time in which students disengage from academic life.

Gardner (2000) found that sophomores were more likely than other classes to state that "Confirming their major selection or deciding on an appropriate career was their biggest personal problem" (p.72). Commitment to an academic major and satisfaction with faculty interactions were both found to be significant predictors of grade point average (Graunke, Woosley, \& Helm, 2005). But not all second-year students have 
decided upon a major and those that have not may be at risk of being disengaged from their coursework. Therefore, sophomores may have few meaningful interactions with faculty (Graunke, Woosley, \& Helms, 2005). Second-year students may not know what they are interested in nor feel that they are good at anything (Boivin, Fountain, \& Baylis, 2000). " Confused about where they want to go and unsure how their academic work relates to their future, sophomores become anxious, frustrated, and overly cautious in dealing with their academic and post-graduation plans" (Gardner, 2000, p. 74).

Sophomore students are often in the transition from general education courses to courses in an academic major. Issues such as uncertainty about a major may create tensions that could have an adverse effect on their success (Anderson \& Schreiner, 2000). Similarly, Graunke, Woosely, and Helms (2005) stated that since sophomores are transitioning from general education to their academic majors, it would seem logical that attitudes and experiences regarding faculty would take on a more central role and possibly have greater impact.

Wilder (1999) conducted a study that compared second-year students that experienced at least a $20 \%$ decline in grade point average (GPA) their second year with those that either maintained or improved upon their first-year GPA. He found that those who declined lacked commitment to the institution in which they were enrolled and lacked commitment to educational goals.

Juillerat (2000) cites lack of involvement and motivation in college as key causes of the phenomenon known as the "sophomore slump". Her study explores the expectations and levels of satisfaction of second-year students in both public and private colleges. She found that second-year students at public institutions expect and demand 
high quality services and fluid systems that facilitate goal attainment. Students at private schools place a high value on an enjoyable campus environment, academic excellence, and opportunities for self-expression. It is evident there is not a silver bullet that will solve higher education's attrition woes. It is difficult to generalize what will improve second-year retention rates. Institutions must have a keen understanding of the characteristics and experiences that students bring with them to their campuses and how those variables will intersect with individual campus environments.

Thus far, sociological models of development have been prevalent in the discussion of student retention. Yet psychological models are also relevant when examining the cognitive development of second year students. Perry's (1968) theory of intellectual and ethical development outlines nine positions (developmental phases). Position 1, dualism: centers on absolute answers, right or wrong. Position 2, multiplicity prelegitimate: views differing or alternate answers and ways of thinking as suspect. Position 3, multiplicity legitimate but subordinate: recognizes that there is not always an answer. Position 4, multiplicity coordinate/relativism subordinate: acknowledges that there are many alternate perspectives and that there is a difference between opinion and fact. Position 5, relativism: knowledge is relative and contextual. Questions must be answered by examining the evidence and providing support for a particular argument. Position 6, commitment foreseen: one can consider other perspectives. Decision-making may be delayed in order to weigh differing perspectives and options. Positions $7-9$, evolving commitments: seeks to establish identity; self awareness; incorporates varying views to one's own perspective. 
Most first-year students fall somewhere between positions two and three (Rogers, 1990). Schaller (2007) acknowledges that second-year students may fall at or between any number of positions. Furr and Gannaway (1982) contend that the range of positions second-year students operate at makes the demands of the college environment difficult to adjust to. Pre-entry variables further compound the problem of how students respond to institutional inputs and progress through cognitive development.

Schaller's (2005) study of traditional-aged sophomore students outlines a fourstage model of second-year development: (1) during random exploration, students make decisions based on convenience rather than critical thought; (2) focused exploration centers on students taking choices more seriously and becoming concerned about academic major, relationships, and personal identity; (3) at the tentative choice stage, students begin to feel comfortable enough to make tentative decisions about major, relationships, and self; and (4) once students reach the commitment stage, they feel secure and certain about the decisions they make. Schaller (2007) stresses that, "Supporting students in the move toward tentative choice and eventually commitment is not a simple task. It requires that students stay in the search, engage in self-reflection, and fully explore their options for a life direction" (p.11). Institutions should be proactive in planning interventions for the complex issues that evolve as students progress toward degree completion.

Second-year students experience their own period of transition. They are no longer new to higher education but they may not yet have found their way. Boivin, Fountain, and Baylis (2000) contend that second-year students are in a state of crisis, one of identity, purpose, direction, and commitment. Some students will undoubtedly have a 
more difficult time than others. Without the assistance to move through this transitional phase, second-year students are at risk of floundering and failing. But which students are more likely to experience difficulty during their second year? Is there a way for institutions to be proactive in their retention efforts rather than reactive? An examination of pre-entry characteristics may hold the key. Pre-entry levels of commitment, motivation, and openness to change may offer valuable insight.

\section{Use of Pre-entry Variables}

Newcomb (1966) argued that pre-entry variables are the most influential determinants of what happens to students following enrollment. The background characteristics and past experiences of students influence their levels of commitment to the institution and persistence to graduation (Tinto, 1993).

The reasons that students decide to enter higher education vary. Some are motivated by the desire to gain employment upon graduation while others look forward to the social aspect of college. The expectations and motivations that students enter with will impact their experiences and perceptions following enrollment. Likewise, reasons for departure are complex and varied. Some students never intended to stay until degree completion, while others enter with the intention to transfer to another institution (Tinto, 1993).

Conley (2003) affirmed that preliminary assessment can be used in an effort to negate potential barriers to retention. Pascarella and Terrinzini (1991) assert that:

It is typically the case that student background characteristics [sic] are not merely the best predictors of many of the outcomes associated with college; they are also a major determinant of whether or not one attends college and, if so, the type of college attended and the extent and quality of involvement in different academic and social experiences during college (p. 658). 
A combination of institutional, personal, and external factors should be considered when developing programs aimed at preventing attrition (Cabrera, Casteneda, Nora, \& Hossler 1992). The Cabrera (1992) study confirmed that factors predicting intent to persist on each campus should be identified and closely examined. Tinto's (1993) psychosocial model of student departure supports the notion that student pre-entry traits influence initial levels of goal and institutional commitment which in turn impact acculturation and integration in the institution's culture.

Institutions have the opportunity to reinforce and/or improve upon initial levels of institutional commitment through the integration process. Strong institutional commitment coupled with a clear desire to attain a college degree results in greater student persistence (Tinto, 1993). Tinto (1993) cautions that, "Though it is important to know the broad forces that shape persistence in the aggregate, our knowledge of attrition must eventually be informed by the particular person and the particular setting with which we are dealing" (p. 69). Colleges and universities would be wise to utilize preentry assessment in order to be pro-active in responding to student needs and concerns before they become problematic (Tinto, 1993). In the end, students themselves must take responsibility for their own learning, which is the purpose of effective education (Tinto, 1993).

Individual student background and characteristics will impact institutional inputs, so programs or initiatives that are successful at one institution may not produce the same results even at other like-institutions. The results of Astin's 1972 national study of student attrition in higher education yielded a wide range of persistence rates across 200 institutions which supports the need for institution specific research. Pre-entry variables 
are commonly used in conjunction with studies of first-year attrition. Few, if any, studies have applied these variables to second-year students.

\section{Summary}

This study attempted to determine if use of pre-entry variables can be used successfully to explore the unique problems that face second-year students. An examination of the routines, expectations, motivations, and commitments that students enter with may give institutions insight into how to prepare for the pitfalls they may encounter. Anticipating how well incoming students will adapt to the college environment and how receptive particular cohorts will be to intervention strategies may stem the departure of second-year students. The next chapter will outline the data set, statistical analyses, and the College Student Inventory- Form B instrument that was used to examine motivation, commitment, and student background variables. 


\section{CHAPTER III}

\section{METHODOLOGY}

\section{Overview}

This study examined factors that predict college persistence beyond the second year for students who initially enrolled at the University of Louisville in the fall of 2004. The study focused on the potential for pre-entry variables to predict persistence to the end of the second academic year at the University of Louisville. The theoretical context for this study was drawn from some of the constructs of Tinto's model of student departure. Chapter III describes the research procedures that were be used to address the research questions discussed in Chapter I.

\section{Population and Sample}

The population examined in this study was second-year students who entered the University of Louisville as first-time, full-time, degree-seeking college freshmen in the fall 2004 semester. For the purposes of this study, second-year students were defined as those students who began and remained continuously enrolled at the University of Louisville from the fall 2004 semester to the fall 2005 semester. This excluded external transfer students. However, it did include students who completed college level dual credit work in high school prior to enrollment at the University of Louisville. 
The original, raw data sample included approximately 2,387 incoming freshmen who voluntarily participated in the College Student Inventory survey during the 2004 summer orientation and subsequently enrolled for the fall 2004 semester. The final number for the sample was reduced somewhat due to attrition of first-year students. First-year retention rates for the fall 2004 cohort of first-time, full-time, degree-seeking students was $76.5 \%$. Therefore, the final sample included 1554 students. This sample size was still within the ratio of 15 subjects per predictor variable suggested by Stevens (2002) for social science research. The 15 to $1 \mathrm{n} / \mathrm{k}$ ratio was important in order to ensure an equation that cross-validated with little loss in predictive power (Stevens, 2002).

\section{Design of Study}

This research is a quantitative predictive study that used existing data sets from the University of Louisville's Office of Retention Management and Research and the Office of Institutional Research and Planning. The predictive study examined the relationship between predictor variables representing demographic/background factors, College Student Inventory - Form B (henceforth CSI-B) scale scores, financial aid factors, and the criterion variable student's completion of the second year of college (enrollment in the fourth and fifth semesters). This study differed from many reported second-year persistence studies by exploring the importance of independent variables as predictors of second-year persistence. Additionally, this study examined CSI-B sub-scale scores in relation to second-year persistence. Traditionally, the CSI-B has been used primarily with first-year students.

This study examined a single cohort of second-year students who initially enrolled as first-time, full-time freshmen in the fall of 2004. Demographic/background 
data included age, gender, race/ethnicity, and median family income, decided or undecided about college major, parent's level of education, and intended number of work hours. Academic ability was determined by high school GPA, ACT/SAT score (including math and reading sub-scores which determined remedial placement). Financial factors included financial aid awards: no aid/data, aid to be repaid, aid that did not require repayment and a combination package which included both aid to be repaid and aid that did not require repayment. The pre-entry attributes of motivation and commitment were measured by the results of the 17 CSI-B sub-scales. The criterion variable was persistence through and after the second year (termed persisters and non-persisters). Persistence was determined by identifying which students from the fall 2004 student cohort sample enrolled for the fall 2006 semester. This study also examined persistence at the end of the third (fall 2005) and fourth (spring 2006) college semesters in order to determine at what point during the second year non-persisters drop out.

Descriptive statistics were examined in order to determine characteristics of the second-year student population. The institutional experience variables of college GPA and academic standing were compared and contrasted with persisters and non-persisters. Additionally, persisters and non-persisters were compared within some of the CSI-B subscales.

The sample of second-year college students who were analyzed in this study completed the CSI-B survey instrument during Freshman Orientation in the fall of 2004. The CSI-B is comprised of 17 independent scales which measure various aspects of academic motivation as expressed by the four compound CSI-B predictor scales. This study did not utilize the four compound scales because they did not adequately fit the 
context of this study. Instead, the sub-scales of the CSI-B were examined. Student records data gathered by the Office of Retention Management and Research and the Office of Institutional Research and Planning were obtained to determine second-year persistence and other related variables (cumulative grade point averages and academic standing at the end of the third and fourth semesters).

Instrument

\section{Description}

The instrument used in this study is the College Student Inventory Form- B (CSIB). The CSI-B is a trademarked survey instrument. The original version of the College Student Inventory (titled the Stratil Counseling Inventory) was developed by Michael L. Stratil in 1971 and published in 1984 at Noel-Levitz Inc. (Low, 2003). The instrument was designed to assess how background information and motivational variables related to student persistence and academic success in college (The Mental Measurement Year Book, 2005).

The current version of the College Student Inventory, Form-A and Form-B, were published in 1988 and 2000 respectively. The newest version, Form-C, was introduced in late summer of 2006. All three instruments are available in a pencil-and-paper format and in an on-line format (Noel-Levitz, 2007). The cohort for this study completed the CSI-B in the traditional pencil-and-paper format at the 2004 Freshman Orientation.

The CSI is the foundation for the Noel-Levitz Retention Management System (Noel-Levitz, 2001, p. 10). The primary focus of the instrument is to provide background information and to obtain data about the motivation of first-year students entering higher education for the first time (Noel-Levitz, 2007). The CSI has been used extensively to 
guide the development of retention and intervention strategies for first-year students identified as drop out prone. When controlling for high school GPA, the CSI-B has been able to distinguish between persisters and non-persisters in approximately $70 \%$ of the cases (Stratil, Schreiner, \& Noel, 2001).

Survey Design

The CSI-B survey instrument includes 100 items contained in 17 independent scales. The survey takes approximately 30 minutes to complete. Responses to the instrument items are summarized within the 17 independent scales, which are organized under 3 main categories: Academic Motivation, General Coping Skills, and Receptivity to Support Services. A total of 15 items report background and demographic characteristics such as planned work hours, age, gender, ethnicity, father's and mother's education attainment levels, academic motivation, and sense of financial security (NoelLevitz, 2001). Other predictor variables were used in conjunction with the CSI-B obtained through the student records system from the University of Louisville's Office of Retention Management and Research and the University of Louisville Office of Institutional Research and Planning.

The 17 sub-scales, corresponding categories and number of items which make up each independent scale are shown in Table 1 (Miller, 2005). 


\section{Table 1}

College Student Inventory Form-B Sub-Scales By Category and Number of Items

\begin{tabular}{llc}
\hline \multicolumn{1}{c}{ Category } & \multicolumn{1}{c}{ Sub-Scales } & Number of Items \\
\hline Academic Motivation & 1. Attitude toward educators & 6 \\
& 2. Desire to finish college & 8 \\
3. Desire to transfer & 2 \\
& 4. Intellectual interests & 4 \\
& 5. Math \& science confidence & 6 \\
6. Study habits & 6 \\
7. Verbal confidence & 6 \\
General Coping & & \\
& 8. Career closure & 4 \\
9. Family emotional report & 4 \\
10. Opinion tolerance & 6 \\
11. Sense of financial security & 4 \\
Receptivity to Support & 12. Sociability & 4 \\
Services & 13. Academic assistance & 6 \\
& 14. Career counseling & 5 \\
15. Financial guidance & 4 \\
& 16. Personal counseling & 6 \\
\hline 17. Social enhancement & 4 \\
\hline
\end{tabular}

* There are 5 additional items that fall under the category of internal validity to establish that the respondent did not answer randomly.

Previous studies typically focus on dropout proneness and academic difficulty as the variables of interest in the prediction of academic performance. Academic stress and receptivity have been regarded as descriptive rather than predictive of academic performance. However, for the purposes of this study only the 17 sub-scales were examined as predictors of persistence beyond the second year.

\section{Independent Sub-Scales}

The 17 independent scales are weighted to construct four compound scales designed to summarize each respondent's academic motivation: 1) Dropout Proneness; 2) Predicted Academic Difficulty; 3) Educational Stress; 4) Receptivity to Institutional 
Help. The decision was made not to use the compound scales in this study because these scales did not adequately measure the specific tenants of Tinto's model that this research sought to examine. Therefore, the sub-scales were utilized in this study.

The 17 independent scales provide information about a student's level of academic motivation, commitment to academic success, and overall desire to complete a college degree. The scores for each scale are reported in a percentile rank which measure where students fall in the normative sample. The scores from each scale are categorized into four sections: academic motivation, general coping, receptivity to support services, and a supplementary scale that measures internal validity (Noel-Levitz, 2001, p. 16).

1. Academic Motivation

a) Study habits. The focus of this scale is on the amount of effort a student expends on academics. This scale measures whether or not a student is willing to make sacrifices in order to achieve academic success (Noel-Levitz, 2001).

b) Intellectual interests. This scale measures how much a student enjoys intellectual pursuits such as reading or the discussion of ideas (Noel-Levitz, 2001). The focus of this scale is the degree to which a student enjoys the learning process.

c) Verbal confidence. This scale measures how comfortable a student is with course that require an aptitude for reading, oral communication, and writing. It is a measure of student self-confidence in the prescribed areas, not an assessment of aptitude (Noel-Levitz, 2001).

d) Math and science confidence. This scale mirrors the verbal confidence scale. It measures student comfort levels with math and science courses. Again, this 
is not an aptitude assessment. It is an indication of a student's academic confidence of doing well in this subject area (Noel-Levitz, 2001).

e) Desire to finish college. This scale measures the student's commitment level and motivation to persist, regardless of aptitude and prior academic performance (Noel-Levitz, 2001).

f) Desire to transfer. This scale is an additional sub-scale that measures the student's intent to eventually transfer to another institution.

g) Attitude toward educators. This scale measures a student's pre-college experiences and subsequent attitudes toward faculty, staff, and administrators (Noel-Levitz, 2001).

2. General Coping

a) Sociability. Measures the level of importance that the student places on social activities (Noel-Levitz, 2001).

b) Family emotional support. This scale identifies the level of satisfaction the student has with the quality of his or her family relationships (Noel-Levitz, 2001).

c) Opinion tolerance. This scale focuses upon the degree to which the student can accept other people regardless of differences in political and social belief systems. This scale not only measures how tolerant the student is of people from diverse backgrounds, but also course content that may be unfamiliar or in opposition to the student's personal belief system (Noel-Levitz, 2001).

d) Career closure. This scale measures the degree of commitment a student has to a chosen career (Noel-Levitz, 2001). 
e) Sense of financial security. This scale measures how secure a student feels about his/her financial situation in relation to the expected cost of a college education (Noel-Levitz, 2001).

3. Receptivity to Support Services.

a) Academic assistance. This scale measures the student's desire to receive tutoring and other forms of academic support (Noel-Levitz, 2001).

b) Personal counseling. Gages how much the student feels he/she needs help with personal issues (Noel-Levitz, 2001).

c) Social enrichment. This scale measures the level of importance the student places on meeting other students and being included in group activities (NoelLevitz, 2001).

d) Career counseling. This scale measures the level to which the student feels he/she needs assistance with choosing a major and career (Noel-Levitz, 2001).

e) Financial guidance. This scale measures the student's desire to receive financial guidance and information about financial resources (Noel-Levitz, 2001).

4. Supplementary Scale.

a) Internal validity. The scale measures the care with which the student took in completing the survey (Noel-Levitz, 2001).

Previous studies involving freshmen and persistence to graduation have focused exclusively on the compound scales as predictors. As previously stated, only the subscales will be examined in this study. 


\section{Validity and Reliability}

The original version of the CSI (titled the "Stratil Counseling Inventory") was the result of over seven years of research by Michael Stratil in the area of student academic and social motivation. Stratil's main goal was to develop an instrument designed to maximize homogeneity of each scale while keeping the length of the instrument as short as possible. The instrument was field tested and revised based on statistical analyses and item content input from expert judges. Over the years, the CSI has been established as a standardized, nationally normed, reliable and valid instrument (Noel-Levitz, 2006).

Richard Miller (2005) examined the reliability of the 17 independent scales of the CSI-B and the predictive validity of two of the composite scales, Dropout Proneness and Predicted Academic Difficulty. Miller's study utilized non-experimental data and focused up the relationship between CSI-B scores, student persistence, and cumulative GPA (Miller, 2005).

In order to determine reliability, Miller conducted an analysis of the CSI-B by computing the Cronbach's alpha coefficient for each of the 17 independent scales using the Reliability Procedure in SPSS. The coefficient for two-year and four-year schools was calculated separately. The averaged alpha for all schools was 0.79 , which falls slightly below the minimum used for standardized tests, but does exceed the minimum used in psychometrics. However, the averaged alpha for four-year schools was 0.806 which suggests a well-grounded and statistically sound instrument (Miller, 2005).

Table 2 is taken directly from Miller's study $(2005$, p.4). It outlines the name of each independent scale, the number of instrument items for each scale, Cronbach's alpha 
for four-year schools, Cronbach's alpha for two-year schools, as well as the averaged coefficient alphas.

\section{Table 2}

Cronbach Alpha Coefficients for CSI-B Independent Scales

\section{CSI-B}

Independent Scales
Number of Items
Alpha for FourYear Colleges
Alpha for TwoYear Colleges
Alpha for All Colleges

0.851

0.837

0.836

0.828

0.821

0.808

0.826

0.822

0.815

0.807

0.846

0.787

0.814

Desire to

Transfer

Math and Science

Confidence

Study Habits

Sense of Financial

Security

Receptivity to

Personal

Counseling

Verbal Confidence

Attitude toward

Educators

Opinion Tolerance

Sociability

Receptivity to

Social Enrichment

Receptivity to

Financial

Guidance
0.828

0.823

0.828

0.820

0.819

0.800

0.795

0.775

0.660

0.618
0.812

0.810

0.808

0.807

0.798

0.796

0.763

0.747

0.711

0.623
0.780

0.736

0.719

0.743

0.630

\begin{tabular}{lccc} 
Average Alpha & 0.806 & 0.780 & 0.793 \\
\hline & & & \\
Observations & Four-Year & Two-Year & All Schools \\
\hline
\end{tabular}

* Taken from Miller (2005, p. 4) 
Thirteen of the 17 CSI-B independent scales had reliability coefficients that met or exceeded a coefficient of 0.80 for a least one of the two- or four-year segments (Miller, 2005). The Receptivity to Financial Guidance scale reflects the weakest reliability score. This scale is typically not used to predict student success or performance. Instead, this scale reflects interest in various types of financial aid. When this scale is dropped from the reliability coefficient, the re-calculated Cronbach alpha for all schools is 0.803 , which exceeds the criteria recommended by Babbie (1998) and Nunnally (1978) (as cited in Jassal, 2007).

In the fall of 2001, Noel-Levitz initiated a validity study. Miller (2005) used the non-experimental data from the Noel-Levitz study to test the validity of the Dropout Proneness and Predicted Academic Difficulty composite scales. Validity was assessed in two ways: (a) an examination of the relationship between the predictions and the criterion data set (Miller, 2005, p. 5) and (b) observation of the relative predictive strength of all variables available in the CSI-B (Miller, 2005, p. 6).

In summary, Miller (2005) found both the Dropout Proneness and Predicted Academic Difficulty composite scales demonstrate significant relationships with their criterion variables (dropout behavior and cumulative college GPA) and that both scales outperform High School GPA as a predictor of college student success (Miller, 2005, p. $10)$.

\section{Variables}

\section{Predictor Variables}

The predictor variables used in this study include: college indicator variables (cumulative GPA and academic standing); demographic variables (age, gender, ethnicity, 
median family income, and decided/undecided about college major); background variables contained in the CSI-B (number of intended work hours, students' parents' level of education); academic ability (admission status, high school GPA, ACT composite score, and need for remedial course as evidenced by the ACT math and reading scores); financial aid (payment required, no repayment required, combination, or no aid), and the CSI-B sub-scale scores. Variable information collected from the CSI-B included: number of intended work hours, parents' level of education, and the sub-scale scores. Information from the CSI-B consisted of self-reported data by the participants on the survey instrument. All other predictor information was collected from student records in order to ensure accuracy.

\section{Criterion Variables}

The criterion variable for this study was retention after the second year of college. The dependent variable was dichotomous and measured by "yes" or "no" and recorded, 1 and 0 . Retention was measured by enrollment in the fourth and fifth semesters to determine at what point students attrite.

\section{Data Analysis}

This study used existing data collected by the Office of Retention Management and Research and the Office of Institutional Research and Planning at the University of Louisville. In order to ensure the protection and anonymity of the research subjects all identifying data (student ID numbers) were removed following the matching of the various data sets. Integer numbers $(1,2,3, \ldots \mathrm{n})$ replaced ID numbers in the final data file. SPSS was used for the statistical procedures. Descriptive statistics were used to summarize demographic data and institutional experience variables. Predictor variables 
were examined through the use of logistic regression due to the dichotomous nature of the criterion variables. Table 3 contains a description of the research question, the statistical test used to analyze the data, and the independent and dependent variables used in the study.

MANOVA was conducted to address hypotheses one through five, with the independent variable student persistence status (persister, non-persister) and with the respective dependent variable(s): (H1) high school grade point average; (H2) ACT composite score; (H3) ACT reading sub-score and ACT math sub-score; (H4) cumulative college grade point average and academic standing; (H5) sub-scales of the CSI-B. MANOVA is used to detect whether or not statistically significant differences exist between means. It is a descriptive measure of group differences among key variables. For the purposes of this study, key variables are those which are typically examined in relation to persistence.

For hypotheses six and seven, binomial logistic regression was conducted to measure the predictive nature and magnitude of the relationship between the variables (background, academic ability, CSI-B scales, and financial aid) and student persistence. Hierarchical logistic regression was appropriate due to the use of a dichotomous dependent variable and a set of continuous and/or categorical predictor variables. The variables were entered in five blocks: (a) cumulative GPA and academic standing; (b) student background variables (age, gender, median family income, ethnicity, decided about major, number of intended work hours, admission status and parental education level); (c) academic ability (high school GPA, ACT composite score, ACT reading and math sub-scores); (d) CSI-B sub-scale scores; (e) financial aid (no aid, repayment 
required, no repayment required, combination). The criterion variable was student persistence (enrollment in the fourth semester) for $\mathrm{H} 6$ and persistence (enrollment in the fifth semester) for H7.Logistic regression was used in an attempt to predict retention based on key variables. 


\section{Table 3}

Summary of Statistical Tests Used in the Study

\begin{tabular}{llcc}
\hline Research & Statistical & Independent & Dependent \\
Questions & Tests & Variable(s) & Variable(s)
\end{tabular}

$1 \& 2$ MANOVA Persistence beyond $2^{\text {nd }}$ year

$$
(1=\text { Yes, } 0=\text { No })
$$

ACT composite score

\& High School GPA

3 MANOVA Persistence beyond $2^{\text {nd }}$ year

$$
\left(1=\text { Yes, } 0=N_{o}\right)
$$

ACT math \& reading sub-scores

4 MANOVA Persistence beyond $2^{\text {nd }}$ year

$$
(1=\text { Yes, } 0=\text { No })
$$

Cumulative college GPA and academic

5 MANOVA Persistence beyond $2^{\text {nd }}$ year

$$
(1=\text { Yes, } 0=\text { No })
$$

standing

CSI-B sub-scale

scores

6 Logistic 1. Cumulative college GPA \& academic standing

Regression 2. Student background: age, gender, race/ethnicity, median family income, decided/undecided college major, number of intended work hours, parental education level

3. Academic ability: high school GPA,

ACT composite score, ACT reading and math sub-scores

4. CSI-B: 17 sub-scale scores

5. Financial aid: aid to be repaid, aid the requires no repayment, no aid

1. Cumulative college GPA \& academic standing Regression

2. Student background: age, gender, race/ethnicity, median family income, decided/undecided college major, number of intended work hours, parental education level 3. Academic ability: high school GPA, ACT composite score, ACT reading and math sub-scores

4. CSI-B: 17 sub-scale scores

5. Financial aid: aid to be repaid, aid the requires no repayment, no aid

Persistence to enrollment in the $4^{\text {th }}$ college semester $(1=$ Yes, $0=$ No $)$
Persistence to enrollment in $5^{\text {th }}$ college semester $(1=$ Yes, $0=$ No) 
Table 4 outlines the coding scheme for the categorical variables.

Table 4

Coding Scheme for Categorical Variables

\begin{tabular}{|c|c|c|}
\hline Variable Name & Coding Sequence & Range \\
\hline Persistence & $\begin{array}{l}\text { Non-persistence }=0 \\
\text { Persistence }=1\end{array}$ & \\
\hline Admit Status & $\begin{array}{l}\text { Good Standing }=1 \\
\text { Conditional }=2 \\
\text { Exception } / \text { Other }=3\end{array}$ & \\
\hline Academic Standing & $\begin{array}{l}\text { Good Standing }=1 \\
\text { Warning }=2 \\
\text { Probation }=3 \\
\text { Suspension } / \text { Dismissal }=4\end{array}$ & \\
\hline Gender & $\begin{array}{l}\text { Male }=0 \\
\text { Female }=1\end{array}$ & \\
\hline Ethnicity & $\begin{array}{l}\text { White }=1 \\
\text { Black }=2 \\
\text { Other }=3\end{array}$ & \\
\hline Age & $\begin{array}{l}\text { Under } 18=1 \\
18-19=2 \\
20-22=3 \\
23 \text { and over }=4\end{array}$ & \\
\hline Median Family Income & $\begin{array}{l}\text { Low }=1 \\
\text { Middle }=2 \\
\text { Upper-middle/Upper }=3\end{array}$ & $\begin{array}{l}\text { Low }=\text { under } \$ 36,000 \\
\text { Middle }=\$ 36,001-91,000 \\
\text { Upper-middle/Upper }=\text { over } \\
\$ 91,000\end{array}$ \\
\hline $\begin{array}{l}\text { First Generation College } \\
\text { Student (parental level of } \\
\text { education) }\end{array}$ & $\begin{array}{l}\text { Not first generation }=0 \\
\text { First generation }=1\end{array}$ & \\
\hline $\begin{array}{l}\text { Intended Work Hours per } \\
\text { Week }\end{array}$ & $\begin{array}{l}0 \mathrm{hrs} / \mathrm{wk}=0 \\
1-10 \mathrm{hrs} / \mathrm{wk}=1 \\
11-20 \mathrm{hrs} / \mathrm{wk}=2 \\
21-30 \mathrm{hrs} / \mathrm{wk}=3 \\
31-40 \mathrm{hrs} / \mathrm{wk}=4\end{array}$ & \\
\hline Decided About Major & $\begin{array}{l}\text { Undecided }=0 \\
\text { Decided }=1\end{array}$ & \\
\hline Financial Aid Award & $\begin{array}{l}\text { No aid } / \text { data }=0 \\
\text { Aid to be repaid only }=1 \\
\text { Aid that does not require } \\
\text { repayment only }=2 \\
\text { Combination }=3\end{array}$ & \\
\hline
\end{tabular}




\section{CHAPTER IV}

\section{RESULTS}

\section{Overview}

This study examined pre-entry factors that predict college student persistence at the end of the second academic year. Tinto's (1993) model of student departure provides the theoretical context for this study. Variables of interest include levels of commitment and motivation, demographics, background data, and financial aid factors that relate to persistence behaviors of second-year students at the University of Louisville. The participants in this study were second-year students who entered the University of Louisville as first-time, full-time degree-seeking college freshmen in the fall 2004 semester. This chapter describes the data sample, collection methods, and results of the study.

\section{Data Collection}

The data for this study were obtained from existing data sets maintained by the University of Louisville's Office of Institutional Research and Planning. Student zip code data was collected from the Office of Institutional Research and Planning and was compared with U.S. Census data which provided an estimate of median family income. The College Student Inventory Form-B (CSI-B) data was collected by the University of Louisville's Office of Retention Management and Research. The following variables were obtained from the student records system (PeopleSoft): birth date, which was used 
to calculate age; gender; ethnicity; ACT scores; high school grade point average; admission status; enrollment status; college cumulative grade point average; financial aid award; decided about college major; and college academic standing. Parental level of education, used to determine first generation in college status, and intended number of work hours were obtained from the CSI-B data and were self-reported by the student.

The survey instrument used in this study was the College Student Inventory Form-B (CSI-B). The CSI-B was administered by the Office of Retention Management and Research to incoming freshmen during the University of Louisville's 2004 Freshmen Orientation prior to the beginning of the 2004 fall semester.

\section{Data Analysis}

Data analyses were conducted using the Statistical Package for Social Sciences 17.0 (SPSS), now known as Predictive Analytics SoftWare (PASW). Two statistical procedures were used for this study: multivariate analysis of variance (MANOVA) and logistic regression. The level of significance ( $p$-value) for all statistical tests was set at .05 .

Traditionally, studies using the CSI-B examine the composite scales (dropout proneness, predicted academic difficulty, sense of financial security, and receptivity to support services) to predict first-year success. The composite scales did not adequately address the theoretical context for this study. The issues that students face in the second year of enrollment differ from the perils of the first year, as discussed in Chapter II of this dissertation. However, the sub-scales represent variables that address concerns of motivation, commitment, and financial security that are prevalent in the second-year. 
There were seven research questions outlined in Chapter I. The first five questions treated persistence beyond the second year as the independent variable. Enrollment in the fifth college semester, the fall 2006 semester, was the criteria for persistence beyond the second year. The dependent variables used in the first five research questions were: ACT composite score; high school GPA; ACT math and reading sub-scores; cumulative college GPA; academic standing; and selected CSI-B sub-scale scores. Research questions one and two were grouped together and a MANOVA was conducted. MANOVA was also used to analyze questions three through five.

There was a large disparity between the group sizes of persisters (1272 students) and non-persisters (282 students) for the data sample. The drastically unequal group sizes resulted in statistical significance of the Box's Test which is the test of the MANOVA assumption that the covariance matrices of the dependent variables are equal across groups. This is equivalent of the homogeneity of variance assumption. In order to meet this assumption, a random sample of the cohort was drawn using the data select cases function of the PASW package. In order to eliminate the significance of the Box's Test and thus meet the covariance assumption, it was necessary to reduce the disparity between the groups. The assumption was met when a $10 \%$ random sample was drawn from the original cohort of 1554 students. The random sample used for the MANOVA consisted of 159 subjects. Although the groups were still unequal (133 persisters and 26 non-persisters), the assumption of equality of the covariance matrices was met.

Binary logistic regression was used to examine research questions six and seven due to the categorical, dichotomous nature of the dependent variables: enrollment in the fourth college semester and enrollment in the fifth college semester. The predictor 
variables were entered using the forced entry methods in blocks: (block 1) cumulative college GPA and academic standing; (block 2) age, gender, ethnicity, median family income, decided/undecided college major, number of intended work hours, and first generation in college status (parental education level); (block 3) CSI-B sub-scales; (block 4) financial aid award. Table 3 in Chapter III details the research questions, variables, and statistical procedures used in the study.

There were concerns about problems of multicollinearity due to the large number of variables used for the logistic regression analysis despite the large sample size. The CSI-B sub-scales fall into three broad categories: academic motivation, general coping ability, and receptivity to support services. A factor analysis was conducted to determine if the 17 sub-scales of the CSI-B could be reduced to a smaller number that corresponded to the broader categories outlined above. Six factors had Eigenvalues of greater than 1.0. The Scree Plot suggested a drop off at three factors. Examination of the Rotated Component Matrix revealed that 16 of the 17 sub-scales had values of above .4 on at least one factor. Math and science confidence was the only sub-scale that had low values across the matrix. Subsequent analyses of five, four, and three factors had similar results. The underlying components did not correspond to the categories listed above nor did underlying factors emerge that validated the need to eliminate any of the sub-scales. All 17 sub-scales were included and entered as one block for the logistic regression model.

\section{Results}

\section{Sample Characteristics}

The data for this study were collected from a sample of first-time, full-time, degree-seeking freshmen enrolled at the University of Louisville in fall 2004. The total 
entering (full-time) freshmen class contained 2387 students. A total of 2026 students who attended the 2004 Freshman Orientation completed the CSI-B. The final 2004 secondyear cohort sample of $N=1554$ reflected the failure of some of the incoming freshmen cohort to matriculate to the first semester and first year attrition rates.

\section{Table 5}

Frequency Distributions for Age, Gender, and Ethnicity

\begin{tabular}{lllll}
\hline \multicolumn{1}{c}{ Variable Name } & \multicolumn{1}{c}{ Level } & & Percent \\
\hline Age & Under 18 & 9 & .6 \\
& $18-19$ & 1526 & 98.2 \\
& $20-22$ & 16 & 1 \\
Gender & 23 \& over & 3 & .2 \\
& Male & 720 & 46.3 \\
Ethnicity & Female & 834 & 53.7 \\
& White & 1279 & 82.3 \\
& Black & 192 & 12.4 \\
& Other & 83 & 5.3
\end{tabular}

Descriptive statistics obtained from the university student records system (PeopleSoft) were calculated. Table 5 summarizes the results for age, gender, and ethnicity of the full $N=1554$ sample.

The majority of the sample was of traditional college age of 18 to 19 years (98.2\%). Students under the age of 18 made up less than $1 \%$ of the sample and students 
over the age of 19 made up a little over $1 \%$ of the sample. Females made up $53.7 \%$ of the sample which slightly out numbers males who made up $46.3 \%$ of the sample. The sample was predominantly white at $82.3 \%$. Black students made up $12.4 \%$ and other ethnicities/nationalities made up $5.3 \%$ of the sample.

Table 6 outlines results for median family income. No consensus exists on the categorization of middle and upper class. The poverty thresholds issued by the U.S. Census Bureau depend on the size of the family unit and age for single individuals. The poverty threshold ranges from $\$ 10,991-\$ 44,346$ for a family of four (U.S. Census Bureau, 2008). The Department of Health and Human Services included state residence in the formula. Hawaii and Alaskan residents have a higher threshold (Institute for Research on Poverty, 2009). A poll of American citizens revealed that there are vastly different interpretations of what constitutes middle class. Responses ranged from as low as $\$ 19,000$ to as high as $\$ 250,000$ (Congressional Research Service, 2007). The midpoint level of income in the 2005 U.S. Census was $\$ 46,326$ (U.S. Census Bureau, 2008). The U.S. Census Bureau reports income in quintiles. For the purposes of this study, the bottom two quintiles were combined to form the lower income classification (under $\$ 36,000)$, the third and fourth quintiles comprise the middle classification $(\$ 36,001$ $\$ 91,000$ ), and the final quintile depicts upper-middle to upper income levels (over $\$ 91,000)$. 


\section{Table 6}

Frequency Distribution for Median Family Income

\begin{tabular}{llll}
\hline Income Level & Range & $\boldsymbol{N}$ & Percentage \\
\hline Lower & Under $\$ 36,000$ & 206 & 13.3 \\
Middle & $\$ 36,001-\$ 91,000$ & 1304 & 83.8 \\
Upper-Middle to & Over $\$ 91,000$ & 29 & 1.9 \\
Upper & & 15 & 1.0 \\
Missing Cases & &
\end{tabular}

The majority of the sample fell into the middle income level at $83.8 \%$. The next highest percentage fell under the lower income classification at $13.3 \%$. Very few fell into the upper income level at $1.9 \%$. There were 15 missing cases which accounted for $1 \%$ of the sample.

Parental education level information was obtained from the College Student Inventory Form-B. Students self-reported levels of education for both the mother and father. First generation in college status was derived from the answers on the parent education items. Students were considered first generation if the parent(s) reported high school diploma as the highest level of education and/or had never attended college. Several students only reported education level for the mother. First generation status was based on the information given rather than throw out cases in which nothing was reported for one parent. Many students live in single family households and may not have information about the absent parent.

Table 7 summarizes first generation status. The majority of the sample was not first generation students and comprised $81.7 \%$ of the sample. $17.3 \%$ were first generation students and $1 \%$ of the sample was missing cases. 


\section{Table 7}

Frequency Distribution of First Generation College Students

\begin{tabular}{lll}
\hline Variable Level & $\boldsymbol{N}$ & Percentage \\
\hline Not First Generation & 1269 & 81.7 \\
First Generation & 270 & 17.3 \\
Missing & 15 & 1
\end{tabular}

Many students today spend at least some portion of the week at a work place.

Table 8 outlines the number of intended work hours per week students self-reported on the CSI-B.

Table 8

Frequency Distribution of Intended Work Hours per Week

\begin{tabular}{lll}
\hline Variable Level & $\boldsymbol{N}$ & Percentage \\
\hline $0 \mathrm{hrs} / \mathrm{wk}$ & 405 & 26.1 \\
$1-10 \mathrm{hrs} / \mathrm{wk}$ & 250 & 16.1 \\
$11-20 \mathrm{hrs} / \mathrm{wk}$ & 597 & 38.4 \\
$21-30 \mathrm{hrs} / \mathrm{wk}$ & 234 & 15 \\
$31-40$ & 47 & 3 \\
Missing & 21 & 1.4
\end{tabular}

The majority of the sample, $38.4 \%$, intended to work between 11 and 20 hours per week. The next most prominent group was comprised of those who did not intend to work at all at $26.1 \%$. The $1-10 \mathrm{hrs} / \mathrm{wk}$ at $16.1 \%$ and $21-30 \mathrm{hrs} / \mathrm{wk}$ at $15 \%$ were fairly even. Very few students intended to work $31-40 \mathrm{hrs} / \mathrm{wk}$ at only $3 \%$. There were 21 missing cases for this variable. 
Table 9 displays the frequency distribution of students in the sample that are undecided about the academic major. Students are either classified as decided or undecided about major. This study did not delineate between the various academic majors or enrollment units. The majority of students fell into the decided category at $72.5 \%$, leaving $27.5 \%$ in the undecided category.

\section{Table 9}

Frequency Distribution of Students Undecided College Major

\begin{tabular}{lll}
\hline Level & $\boldsymbol{N}$ & Percentage \\
\hline Undecided & 428 & 27.5 \\
Decided & 1126 & 72.5
\end{tabular}

Incoming students that meet minimum requirements for high school equivalency, pre-college curriculum, standardized tests scores, and high school grade point average are admitted in good academic standing. Students that are deficient one of the criteria areas may be admitted under conditional status. Students who do not initially qualify for admission may be given special consideration on a case by case basis and may be admitted as an exception. Table 10 outlines the frequency distribution for admission status. 


\section{Table 10}

Frequency Distribution for Admission Status

\begin{tabular}{lll}
\hline Level & $\boldsymbol{N}$ & Percentage \\
\hline Good Standing & 1232 & 79.2 \\
Conditional & 292 & 18.8 \\
Exception & 29 & 1.9 \\
Missing & 1 & .1
\end{tabular}

The majority of the students in this sample were admitted in good standing at $79.2 \%$, $18.8 \%$ were admitted conditionally, $1.9 \%$ was admitted by exception, and there was one missing case.

Students must maintain a minimum college grade point average (GPA) in order to remain in good academic standing. Each academic unit sets its own minimum GPA, whereas a 2.0 GPA may represent good standing for one unit but not for another. This study does not explore differences in minimum GPA requirements. Table 11 summarizes frequency distributions for university academic standings and Table 12 provides descriptive statistics for cumulative University of Louisville GPA. The standings and GPAs are for the semesters that represent the second year for the 2004 cohort. 


\section{Table 11}

Frequency Distribution for Academic Standing

\begin{tabular}{llll}
\hline Semester & Level & $N$ & Percentage \\
\hline 2005 fall & Good Standing & 1177 & 75.7 \\
& Warning & 91 & 5.9 \\
& Probation & 125 & 8.0 \\
& Suspension/Dismissal & 160 & 10.3 \\
& Missing & 1 & .1 \\
& Good Standing & 1168 & 75.2 \\
& Warning & 81 & 5.2 \\
& Probation & 127 & 8.2 \\
& Suspension/Dismissal & 178 & 11.4
\end{tabular}

The percentages for the two semesters are comparable with around $75 \%$ of the sample for each semester was in good standing. Academic warning is a one-time only standing, so it is understandable why this group had the smallest percentages at about $5 \%$. The probation group each semester represented $8 \%$ and the suspension group ranged from $10.3 \%$ to $11.4 \%$ of the sample. As a point of clarification, students that were suspended or on probation from one academic unit, may have been eligible for admission in good standing to another academic unit within the university.

The university GPAs for the sample ranged from .0000 to 4.000 with means of 2.867 for the 2005 fall semester and 2.851 for the 2006 spring semester. 


\section{Table 12}

Descriptive Statistics for Cumulative University GPA

\begin{tabular}{llllll}
\hline Semester & $\boldsymbol{N}$ & Minimum & Maximum & Mean & Std.Deviation \\
\hline 2005 fall & 1554 & .0000 & 4.000 & 2.867 & .7562 \\
2006 spring & 1554 & .0000 & 4.000 & 2.851 & .7609
\end{tabular}

Enrollment in the fourth and fifth college semesters (2006 spring and 2006 fall) is outlined in Table 13. Of the original 1554 students in the sample, $145(9.3 \%)$ students did not enroll for the fourth semester and an additional $137(8.8 \%)$ failed to enroll for the fifth college semester. This represented a total loss of $18.1 \%$ of the sample from the second college year to the third year.

\section{Table 13}

Frequency Distribution for Enrollment in the Second College Year

\begin{tabular}{|l|l|l|l|}
\hline & Enrollment Status & $\boldsymbol{N}$ & Percentage \\
\hline 2006 spring & Not enrolled & 145 & 9.3 \\
\hline & Enrolled & 1409 & 90.7 \\
\hline 2006 fall & Not enrolled & 137 & 8.8 \\
\hline & Enrolled & 1272 & 81.9 \\
\hline
\end{tabular}

High school grade point averages and ACT scores are summarized in

Table 13. ACT scores include the ACT composite scores which are used to determine 
admission status and the math and reading sub-scores which determine remedial placement. In 2004, scores of 18 or below on the ACT indicated the need for remedial work in Math or English.

\section{Table 14}

Descriptive Statistics for High School GPA and ACT Scores

\begin{tabular}{lllllll}
\hline Variable & $\boldsymbol{N}$ & Missing & Min. & Max. & Mean & SD \\
\hline HS GPA & 1510 & 44 & 2.20 & 5.05 & 3.53 & .447 \\
$\begin{array}{l}\text { ACT } \\
\text { composite }\end{array}$ & 1526 & 28 & 15 & 35 & 24.06 & 3.92 \\
$\begin{array}{l}\text { ACT } \\
\text { reading }\end{array}$ & 1406 & 148 & 12 & 36 & 25.26 & 5.06 \\
$\begin{array}{l}\text { ACT math } \\
\text { (1406 }\end{array}$ & 148 & 14 & 36 & 23.45 & 4.49
\end{tabular}

High school GPAs for the sample ranged from $2.20-5.05(M=3.53)$. Composite ACT scores for the sample ranged from $15-35(M=24.06)$. There were 148 missing cases of the ACT reading and math sub-scores which may have been the result of converted SAT scores. ACT reading sub-scores ranged from $12-36(M=25.26), 7.2 \%$ of the scores were 18 or below which indicated the need for remedial coursework. The ACT math sub-scores ranged from $14-36(M=23.45), 9.6 \%$ of the scores were 18 or below which indicated the university rerquirement for remedial coursework.

Table 14 indicates the frequency distribution of financial aid awards. The levels of financial aid represent $0=$ no data/aid, $1=$ repayment required, $2=$ no repayment required, and $4=$ combination repayment/no repayment. The data was collected from the Office of Institutional Research and Planning using the financial aid data in the student 
records system (PeopleSoft). A code of 0 was recorded for those students in the sample who did not receive an award from the University of Louisville Financial Aid Office. Unfortunately, there was no way to determine if the student secured funding, such as loans, from private sources.

\section{Table 15}

Frequency Distribution for Financial Aid

\begin{tabular}{|c|c|c|c|}
\hline Semester & Level & $N$ & Percentage \\
\hline \multirow[t]{4}{*}{$4^{\text {th }}$ sem:2006 spring } & No aid/data & 272 & 17.5 \\
\hline & $\begin{array}{l}\text { Repayment } \\
\text { required }\end{array}$ & 85 & 5.5 \\
\hline & $\begin{array}{l}\text { No repayment } \\
\text { required }\end{array}$ & 865 & 55.7 \\
\hline & $\begin{array}{l}\text { Combination } \\
\text { repayment/no } \\
\text { repayment }\end{array}$ & 332 & 21.3 \\
\hline \multirow[t]{4}{*}{$5^{\text {th }}$ sem:2006 fall } & No aid/data & 395 & 25.4 \\
\hline & $\begin{array}{l}\text { Repayment } \\
\text { required }\end{array}$ & 68 & 4.4 \\
\hline & $\begin{array}{l}\text { No repayment } \\
\text { required }\end{array}$ & 773 & 49.7 \\
\hline & $\begin{array}{l}\text { Combination } \\
\text { repayment/no } \\
\text { repayment }\end{array}$ & 318 & 20.5 \\
\hline
\end{tabular}

Aid award eligibility was reported for the fourth and fifth college semesters. For the fourth college semester, $55.7 \%$ of the sample received some form of aid that did not have to be repaid. That number fell to 49.7 in the fifth semester. $21.3 \%$ of the sample had a combination package for the fourth semester which was comparable to the $20.5 \%$ that had a similar package for the fifth semester. $17.5 \%$ of the sample did not have a financial 
aid award for the fourth semester but that number grew to $25.4 \%$ for the fifth semester. The smallest percentages for both semesters were the packages that included only funds that had to be repaid with $5.5 \%$ for the fourth semester and 4.4 for the fifth semester.

\section{Research Questions 1 and 2}

Is there a statistically significant difference between college students that persist beyond the second college year and students that a leave after the second year with respect to high school grade point averages (GPAs) and ACT composite scores?

One hundred fifty-nine subjects were randomly selected and fell into one of two groups: those who enrolled in the fifth college semester and those that did not. A multivariate analysis of variance (MANOVA) was conducted with persistence group the independent variable and high school GPA and ACT composite score the dependent variables. MANOVA was chosen to examine the differences between persistence groups because the method allowed two related research questions to be combined into one analysis. High school GPA and ACT composite scores are used to determine college admission and have been shown to be positively correlated (Bean \& Metzner, 1985).

Box's test for equality of covariance matrices revealed no differences in variability between groups, $F(3,26594)=2.466, p>.05$.

The MANOVA was statistically significant, Hotelling's trace $=.071, F(2,148)=$ $5.218, p<.05$. Tests on individual dependent variables indicated differences for high school GPA but not for the ACT composite score. On high school GPA, the mean for persistence $(M=3.587)$ exceeded that of non-persistence $(M=3.260), F(1,149)=$ $10.476, p<.01$. Partial eta square statistics were .066 indicating that the effect size or 
magnitude of the differences in high school GPA between persistence and nonpersistence can be classified as small to moderate.

Table 16 depicts the descriptive statistics for the analysis. Students that persisted to the third year, had somewhat higher high school GPAs and ACT composite scores than those that did not persist.

\section{Table 16}

Means and Standard Deviations of High School GPA and ACT Composite Scores for Research Questions 1 \& 2

\begin{tabular}{lllll}
\hline & HS GPA & \multicolumn{3}{l}{ ACT Comp. } \\
\hline Level of IV & $M$ & $S D$ & $M$ & $S D$ \\
Non-persistence & 3.26 & .457 & 23.62 & 3.38 \\
Persistence & 3.59 & .472 & 24.83 & 4.14
\end{tabular}

\section{Research Question 3}

Is there a significant difference between college students that persist beyond the second college year and that leave after the second year with respect to ACT math and reading sub-scores?

One hundred fifty-nine subjects were randomly selected and fell into one of two groups: those that enrolled in the fifth college semester and those that did not. A multivariate analysis of variance (MANOVA) was conducted with persistence group the independent variable and ACT math and reading sub-scores the dependent variables.

Box's test for equality of covariance matrices revealed no differences in variability between groups, $F(3,25199)=1.007, p>.05$. 
The MANOVA was not statistically significant, Hotelling's trace $=.030, F(2$, $134)=2.015, p=>.05$. Tests on individual dependent variables were not significant.

Table 17 depicts the descriptive statistics for the analysis. Students that persisted to the third year, had higher ACT reading and math sub-scores than those that did not persist.

\section{Table 17}

Means and Standard Deviations of ACT Math \& Reading Sub-Scores Scores for Research Question 3

\section{ACT Reading $\quad$ ACT Math}

\begin{tabular}{lllll}
\hline Level of IV & $M$ & $S D$ & $M$ & $S D$
\end{tabular}

$\begin{array}{lllll}\text { Non-persistence } & 24.12 & 5.247 & 22.76 & 3.655\end{array}$

$\begin{array}{lllll}\text { Persistence } & 26.35 & 5.088 & 24.17 & 4.827\end{array}$

Research Question 4

Is there a statistically significant difference between college students who persist beyond the second college year and those that leave after the second year with respect to their cumulative college grade point averages and academic standing?

One hundred fifty-nine subjects were randomly selected and fell into one of two groups: those that enrolled in the fifth college semester and those that did not. A multivariate analysis of variance (MANOVA) was conducted with persistence group the independent variable and college cumulative GPA and academic standing the dependent variables. 
Box's test for equality of covariance matrices revealed no differences in variability between groups, $F(3,26012)=3.078, p>.01$.

The MANOVA was statistically significant, Hotelling's trace $=.826, F(2,156)=$ $64.396, p<.01$. Tests on individual dependent variables indicated differences for both cumulative GPA and academic standing. On cumulative GPA, the mean for persistence $(M=3.048)$ exceeded that of non-persistence $(M=1.555), F(1,157)=124.663, p=.000$ $<.01$. On academic standing, the mean for non-persistence $(M=3)$ exceeded that of persistence $(M=1.346), F(1,157)=69.674, p<.01$. Partial eta square statistics were .452 for cumulative GPA and .307 for academic standing indicating that the effect size or magnitude of the differences in cumulative GPA and academic standing between persistence and non-persistence can be classified as large.

Table 18 depicts the descriptive statistics for the analysis. Students that persisted to the third year had much higher cumulative GPAs than those that did not persist. Students that persisted were more likely to be in good academic standing than students who did not persist.

\section{Table 18}

Means and Standard Deviations of Cumulative GPA \& Academic Standing for Research Question 4

\begin{tabular}{lllll}
\hline & Cumulative GPA & \multicolumn{2}{l}{ Acad. Standing } \\
\hline Level of IV & $M$ & $S D$ & $M$ & $S D$ \\
Non-persistence & 1.56 & .78 & 3.00 & 1.20 \\
Persistence & 3.05 & .59 & 1.35 & .86
\end{tabular}




\section{Research Question 5}

The use of a random sample for the MANOVA resulted in a concern about low levels of power when using a large number of dependant variables (the 17 sub-scales of the CSI-B). Therefore, the original research question five that examined the differences among the 17 sub-scales of the CSI-B was modified to include only five of the subscales. The MANOVA was run that only used the five sub-scales of the CSI-B that were found to be significant for the logistic regression. The results using the five sub-scales as opposed to the 17 sub-scales were virtually the same, however the power was marginally increased by using only five dependent variables. What are the statistically significant differences between college students that persist beyond the second college year and those that leave after the second year for each of the five selected sub-scales (desire to transfer, attitude toward educators, study skills, verbal confidence, and sense of financial security) as measured by the College Student Inventory Form - B (CSI-B)?

One hundred fifty-nine subjects were randomly selected and fell into one of two groups: those that enrolled in the fifth college semester and those that did not. A multivariate analysis of variance (MANOVA) was conducted with persistence group the independent variable and the CSI-B sub-scale scores the dependent variables. Box's test for equality of covariance matrices revealed no differences in variability between groups, $F(15,7833)=1.00, p>.05$.

The MANOVA was not statistically significant, Hotelling's trace $=.048, F$ $(5,150)=1.443, p>.05$. Tests on individual dependent variables indicated differences for the study habits sub-scale. On study habits, the mean for persistence $(M=59.254)$ exceeded that of non-persistence $(M=43.423), F(1,154)=6.337, p<.05$. Partial eta 
square statistics were .040 indicating that the effect size or magnitude of the differences in study habits between persistence and non-persistence can be classified as small to moderate.

MANOVA performed to compare means among the student persistence variable and the CSI-B sub-scale scores. For these variables, the national norm is a score of 50. Therefore, high mean scores on any of the CSI-B sub-scale scores corresponds to high levels of the characteristic described in the scale's name. Table 19 describes the CSI-B score means and standard deviations for the sample.

\section{Table 19}

Mean and Standard Deviation CIS-B Sub-Scales for Research Question 5

CSI Sub-Scale Scores

\begin{tabular}{|c|c|c|c|c|c|c|c|c|c|c|}
\hline \multirow[t]{2}{*}{$\begin{array}{l}\text { Independent } \\
\text { Variable } \\
\text { Levels } \\
\end{array}$} & \multicolumn{2}{|c|}{$\begin{array}{l}\text { Attitude } \\
\text { toward } \\
\text { educators }\end{array}$} & \multicolumn{2}{|c|}{$\begin{array}{l}\text { Desire to } \\
\text { transfer }\end{array}$} & \multicolumn{2}{|l|}{$\begin{array}{l}\text { Study } \\
\text { habits }\end{array}$} & \multicolumn{2}{|c|}{$\begin{array}{l}\text { Verbal } \\
\text { confidence }\end{array}$} & \multicolumn{2}{|c|}{$\begin{array}{l}\text { Sense of } \\
\text { financial } \\
\text { security }\end{array}$} \\
\hline & $\mathbf{M}$ & SD & $\mathbf{M}$ & SD & $\mathbf{M}$ & SD & $\mathbf{M}$ & SD & $\mathbf{M}$ & SD \\
\hline Non- & 49.89 & 5.65 & 47.46 & 3.79 & 43.42 & 5.74 & 64.46 & 5.43 & 53.27 & 5.76 \\
\hline Persister & 56.65 & 2.53 & 48.03 & 1.69 & 59.25 & 2.57 & 63.38 & 2.43 & 58.55 & 2.58 \\
\hline
\end{tabular}

Mean scores for persisters were higher than non-persisters on every scale except the verbal confidence scale. Students that persisted tended to have better attitude toward educators, better study habits, greater verbal confidence, and a higher sense of financial security. Students that did not persist had a greater desire to transfer.

\section{Research Question 6}

What are the predictive relationships among (a) student background variables (age, gender, zip code, race/ethnicity, decided/undecided major, number of intended work 
hours, parental education level, income); (b) academic ability (high school GPA, ACT composite score, ACT reading and math sub-scores); (c) CSI-B scale scores (17 subscales); (d) financial aid (aid that must be repaid, aid that does not require repayment, no aid) on the dependent variable students that enroll in the fourth college semester?

Binomial logistic regression was conducted to address research question six. Logistic regression was an appropriate procedure due to the dichotomous dependent variable and the continuous and categorical independent variables. The variables were entered in four blocks: (1) cumulative college GPA and academic standing; (2) background variables: age, gender, ethnicity, median family income, decided/undecided about college major, number of intended work hours, admission status, and parental education level; (3) CSI-B sub-scale scores; (4) financial aid awards: no aid/data, aid to be repaid only, aid the required no repayment only, and combination repaid/no repayment required. Statistical significance was based on an alpha level of .05. The descriptive statistics revealed that 145 students did not persist to the fourth college semester and 1409 students did enroll in the fourth college semester.

The test of overall goodness of fit for a logistic regression model is the Hosmer and Lemeshow test, which is more robust than the traditional chi-square test for this statistical procedure. Chi-square $=2.238(8 d f), p>.05$. The finding of non-significance confirmed that the model adequately fit the data.

The Omnibus Tests of Model Coefficients represents the traditional chi-square test which tests if the model with the predictor variables is significantly different from the model with only the intercept. For this research question, the full equation is significant, 
chi-square $=634.162(26 d f), p<.001$. The finding of significance indicated that at least one of the predictor variables is significantly related to dependent variable of persistence.

The proportion of variance in the dependent variable accounted for by the predictors was estimated to be between .345 (Cox \& Snell R squared) and .744 (Nagelkerke R squared)

An examination of the classification table depicted how well the model predicted persistence or non-persistence. Typically, the model is stronger in one area over the other. For this research question, the model did a better job of predicting persistence at a rate of $97.2 \%$ correct (1338 out of 1376) than at predicting non-persistence at a rate of $76.9 \%$ correct (110 out of 143).

Results of the logistic regression are summarized in Table 20. 
Table 20

Logistic Regression Results for Research Question 6

\begin{tabular}{lrrrrr}
\hline \multicolumn{1}{c}{ Variable Name } & \multicolumn{1}{c}{$\boldsymbol{\beta}$} & \multicolumn{1}{c}{ S.E. } & \multicolumn{1}{c}{ Wald } & \multicolumn{1}{c}{ Sig. } & Exp(B) \\
\hline Cumulative College GPA & 1.141 & .237 & 23.244 & .000 & 3.129 \\
Gender & -.225 & .326 & .476 & .490 & .799 \\
Ethnicity & -.039 & .278 & .020 & .888 & .961 \\
Intended Work Hours & -.205 & .141 & 2.120 & .145 & .815 \\
Age & -1.580 & 1.624 & .947 & .331 & .206 \\
Median Family Income & 1.839 & .546 & 11.328 & .001 & 6.287 \\
First Generation College & .154 & .387 & .160 & .690 & 1.167 \\
Student & & & & & \\
Decided About Major & -.291 & .355 & .675 & .411 & .747 \\
High School GPA & -.021 & .418 & .002 & .961 & .980 \\
ACT Composite Score & .083 & .129 & .415 & .520 & 1.086 \\
ACT Math Score & -.049 & .076 & .422 & .516 & .952 \\
ACT Reading Score & -.076 & .063 & 1.447 & .229 & .927 \\
Attitude Toward Educators & -.013 & .006 & 4.662 & .031 & .987 \\
Desire to Finish College & .003 & .006 & .190 & .663 & 1.003 \\
Desire to Transfer & .018 & .007 & 6.112 & .013 & 1.018 \\
Intellectual Interests & .006 & .006 & .914 & .339 & 1.006 \\
Math \& Science Confidence & .012 & .006 & 3.531 & .060 & 1.012 \\
Study Habits & -.007 & .007 & .975 & .323 & .993 \\
Verbal Confidence & -.017 & .007 & 6.401 & .011 & .983 \\
Career Closure & .002 & .007 & .077 & .781 & 1.002 \\
Family Emotional Support & .007 & .006 & 1.601 & .206 & 1.007 \\
Opinion Tolerance & .005 & .006 & .942 & .332 & 1.005 \\
Sense of Financial Security & .006 & .006 & .945 & .331 & 1.006 \\
Sociability & -.001 & .006 & .032 & .859 & .999 \\
Academic Assistance & -.009 & .007 & 1.626 & .202 & .991 \\
Career Counseling & .011 & .007 & 2.788 & .095 & 1.012 \\
Financial Guidance & .001 & .007 & .022 & .881 & 1.001 \\
Personal Counseling & -.001 & .007 & .021 & .885 & .999 \\
Social Enhancement & -.004 & .007 & .316 & .574 & .996 \\
Financial Aid Award & 4.447 & .728 & 37.283 & .000 & 85.360 \\
Constant & -3.300 & 3.469 & .905 & .342 & .037
\end{tabular}

The $\beta$ coefficients specify the amount of change in the logit with a one unit change in the predictor, holding constant the other predictors. The Wald statistic is used 
to test the significance of individual logistic regression coefficients for each predictor variable (which is analogous to t-tests). The $p$ values represent whether or not the predictor was statistically significant, holding the other predictors constant. Exp ( $\beta$ ) values are the odds ratios, which indicate by what amount the odds of persistence increase based on changes in the predictor variables. In other words, the odds ratios indicate by what amount the odds of persistence changed based on changes in the predictor variables. If the $\operatorname{Exp}(\beta)$ value equals one, then the odds are unchanged; if greater than one, the odds increase; if less than one, the odds decrease; the more distinct from one, the greater the effect in changing the odds.

Cumulative University of Louisville GPA $(p<.001)$, median family income $(p<$ $.01)$, attitude toward educators $(p<.05)$, desire to transfer $(p<.05)$, verbal confidence ( $p$ $<.05)$, and financial aid award $(p<.001)$ were found to be statistically significant in predicting persistence beyond the second college year. Both verbal confidence and attitude toward educators had negative values.. This means that low verbal confidence and low attitude toward educators decreases the likelihood of persistence. The rest of the significant predictors had positive values which increase the likelihood of persistence. Of particular interest was the large $\operatorname{Exp}(\beta)$ value for financial aid award which was 85.36. This means that odds of persistence are 85.36 times higher for students that have a financial aid award

\section{Research Question 7}

What are the predictive relationships among (a) student background variables (age, gender, zip code, race/ethnicity, decided/undecided major, number of intended work hours, parental education level, income); (b) academic ability (high school GPA, ACT 
composite score, ACT reading and math sub-scores); (c) CSI-B scale scores (17 subscale); (d) financial aid (aid that must be repaid, aid that does not require repayment, no aid) on the dependent variable students that enroll in the fifth college semester?

Binomial logistic regression was conducted address research question seven. Logistic regression was an appropriate procedure due to the dichotomous dependent variable and the continuous and categorical independent variables. The variables were entered in four blocks: (1) cumulative college GPA and academic standing; (2) background variables: age, gender, ethnicity, median family income, decided/undecided about college major, number of intended work hours, admission status, and parental education level; (3) CSI-B sub-scale scores; (4) financial aid awards: no aid/data, aid to be repaid only, aid the required no repayment only, and combination repaid/no repayment required. Statistical significance was based on an alpha level of .05. The descriptive statistics revealed that 282 students did not persist to the fifth college semester and 1272 students did enroll in the fifth college semester.

The test of overall goodness of fit for a logistic regression model is the Hosmer and Lemeshow test, which is more robust than the traditional chi-square test for this statistical procedure. Chi-square $=47.352(8 d f), p<.001$. The finding of significance suggested that the model did not perfectly fit the data.

The Omnibus Tests of Model Coefficients represents the traditional chi-square test which tests if the model with the predictor variables is significantly different from the model with only the intercept. For this research question, the full equation is significant, chi-square $=971.819(26 d f), p<.001$. The finding of significance indicated that at least one of the predictor variables is significantly related to dependent variable of persistence. 
The proportion of variance in the dependent variable accounted for by the predictors was estimated to be between .472 (Cox \& Snell R squared) and .772 (Nagelkerke R squared)

An examination of the classification table depicted how well the model predicted persistence or non-persistence. Typically, the model is stronger in one area over the other. For this research question, the model did a slightly better job of predicting persistence at a rate of $92.6 \%$ correct (1153 out of 1245$)$ than at predicting non-persistence at a rate of $90.9 \%$ correct ( 250 out of 275$)$.

Results of the logistic regression are summarized in Table 21. 
Table 21

Logistic Regression Results for Research Question 7

\begin{tabular}{|c|c|c|c|c|c|}
\hline Variable Name & $\beta$ & S.E. & Wald & Sig. & $\operatorname{Exp}(\beta)$ \\
\hline Cumulative College GPA & .699 & .176 & 15.726 & .000 & 2.011 \\
\hline Gender & -.389 & .260 & 2.245 & .134 & .678 \\
\hline Ethnicity & -.332 & .244 & 1.844 & .175 & .718 \\
\hline Intended Work Hours & -.065 & .117 & .314 & .575 & .937 \\
\hline Age & .500 & 1.049 & .227 & .634 & 1.648 \\
\hline Median Family Income & .101 & .302 & .112 & .737 & 1.107 \\
\hline $\begin{array}{l}\text { First Generation College } \\
\text { Student }\end{array}$ & .499 & .301 & 2.739 & .098 & 1.646 \\
\hline Decided About Major & .308 & .310 & .989 & .320 & 1.361 \\
\hline High School GPA & .275 & .341 & .651 & .420 & 1.316 \\
\hline ACT Composite Score & .025 & .104 & .059 & .808 & 1.026 \\
\hline ACT Math Score & .065 & .060 & 1.183 & .277 & 1.068 \\
\hline ACT Reading Score & -.081 & .052 & 2.392 & .122 & .922 \\
\hline Attitude Toward Educators & -.010 & .005 & 3.922 & .048 & .990 \\
\hline Desire to Finish College & .001 & .005 & .051 & .821 & 1.001 \\
\hline Desire to Transfer & .003 & .006 & .298 & .585 & 1.003 \\
\hline Intellectual Interests & .000 & .005 & .003 & .956 & 1.000 \\
\hline $\begin{array}{l}\text { Math \& Science } \\
\text { Confidence }\end{array}$ & .009 & .005 & 3.410 & .065 & 1.009 \\
\hline Study Habits & .004 & .005 & .607 & .436 & 1.004 \\
\hline Verbal Confidence & -.002 & .005 & .207 & .649 & .998 \\
\hline Career Closure & -.001 & .006 & .019 & .891 & .999 \\
\hline Family Emotional Support & .001 & .004 & .015 & .904 & 1.001 \\
\hline Opinion Tolerance & .002 & .004 & .165 & .684 & 1.002 \\
\hline Sense of Financial Security & .013 & .005 & 6.787 & .009 & 1.013 \\
\hline Sociability & -.002 & .005 & .117 & .733 & .998 \\
\hline Academic Assistance & .000 & .006 & .001 & .976 & 1.000 \\
\hline Career Counseling & .006 & .005 & 1.243 & .265 & 1.006 \\
\hline Financial Guidance & .004 & .005 & .451 & .502 & 1.004 \\
\hline Personal Counseling & .002 & .006 & .156 & .693 & 1.002 \\
\hline Social Enhancement & -.001 & .006 & .037 & .848 & .999 \\
\hline Financial Aid Award & 3.760 & .441 & 72.847 & .000 & 42.957 \\
\hline Constant & -4.858 & 2.348 & 4.280 & .039 & .008 \\
\hline
\end{tabular}


The $\beta$ coefficients specify the amount of change in the logit with a one unit change in the predictor, holding constant the other predictors. The Wald statistic is used to test the significance of individual logistic regression coefficients for each predictor variable (which is analogous to t-tests). The $p$ values represent whether or not the predictor was statistically significant, holding the other predictors constant. $\operatorname{Exp}(\beta)$ values are the odds ratios, which indicate by what amount the odds of persistence increase based on changes in the predictor variables. In other words, the odds ratios indicate by what amount the odds of persistence changed based on changes in the predictor variables. If the $\operatorname{Exp}(\beta)$ value equals one, then the odds are unchanged; if greater than one, the odds increase; if less than one, the odds decrease; the more distinct from one, the greater the effect in changing the odds.

Cumulative University of Louisville GPA $(p<.001)$, attitude toward educators $(p$ $<.05$, sense of financial security $(\mathrm{p}<.01)$, and financial aid award $(p<.001)$ were found to be statistically significant in predicting persistence beyond the second college year. Attitude toward educators had a negative value. A negative value decreases the logit, which means that low attitude toward educators decreases the likelihood of persistence. The rest of the significant predictors had positive values which increase the likelihood of persistence. Of particular interest was the large $\operatorname{Exp}(\beta)$ value for financial aid award which was 42.96 . This means that odds of persistence are 42.96 times higher for students that have a financial aid award 


\section{Summary}

The purpose of this chapter was to present the results for this study. Inferential and descriptive statistics were used to answer the research questions. The majority of the

students in the sample were female (53.7\%), white (82.03\%), between the ages of 18 and $19(98.8 \%)$, had a median family income between $\$ 36,000$ and $\$ 91,000$, and received some form of financial aid. The mean high school GPA was 3.527 and the mean ACT composite score was 24.06. Most students were admitted to the university in good academic standing $(79.3 \%)$.

Research questions one through five explored whether or not there were differences between students who persist beyond the second college year and those who do not based on several outcome variables. Research questions six and seven sought to determine what variables predicted student persistence beyond the second college year.

Table 22 provides an overview of the research results. Discussion of findings, implications, and limitations are presented in Chapter V. 
Table 22

Overview of Results

\begin{tabular}{lll}
\hline Research Question & Statistical Procedure & Results
\end{tabular}

Questions $1 \& 2 \quad$ MANOVA

MANOVA
MANOVA

Question 3

Question 4

MANOVA

MANOVA significant $p<.05$ univariate follow up procedures indicated a small to moderate effect size for high school GPA. ACT was not significant at the univariate level.

No significance found

MANOVA significant $p<.01$; univariate follow up procedures indicated a large effect size for cumulative college GPA and academic standing

Question 5

MANOVA

MANOVA was not significant; univariate follow up procedures indicated a small to moderate effect size for study habits

Question $6 \quad$ Logistic Regression Predictive relationship found; cumulative GPA ( $p<001)$, median family income $(p<.01)$, attitude toward educators $(p<.05)$, desire to transfer $(p<.05)$, verbal confidence $(p<.05)$, and financial aid award $(p<.001)$ had a statistically significant relationship with persistence beyond the second college year.

Question $7 \quad$ Logistic Regression

Predictive relationship found; cumulative GPA $(p<.001)$, attitude toward educators $(p<.05)$, sense of financial security $(p<.01)$ and financial aid award $(p<.001)$ had a statistically significant relationship with persistence beyond the second college year. 


\title{
CHAPTER V
}

\section{DISCUSSION, IMPLICATIONS, AND RECOMMENDATIONS}

\author{
Overview
}

This dissertation examined factors that predict college student persistence for second-year students at the University of Louisville. Results were collected through the quantitative analysis of the College Student Inventory Form-B and student background data collected by the Office of Institutional Research and Planning and the Office of Retention Management and Research at the University of Louisville. This chapter will discuss the conclusions and implications of the results and recommendations for practice and future research.

Although there is extensive research on first-year and senior-year transitions, fewer scholars have focused research on the second year despite strong evidence that there are serious transitional issues at this critical time (Gardner, Pattengale, Tobolowsky, \& Hunter, 2010). The reasons for student attrition are complex and include both academic and non-academic factors. Student characteristics such as background, prior experiences, motivation, and commitment impact institutional inputs aimed at retention. It is important for institutions to understand not only who their students are but how these individuals will react to a particular institutional culture. The background characteristics 
and past experiences of students influence their levels of commitment to the institution and persistence to graduation (Tinto, 1993).

The sample for this study consisted of second-year students who entered the University of Louisville as first-time, full-time, degree-seeking college freshmen in the fall 2004 semester and who completed the College Student Inventory Form-B during summer orientation. The original sample of 1554 experienced a $9.3 \%$ drop in enrollment between the third and fourth semesters and an $8.8 \%$ drop in enrollment from the fourth to the fifth semester. The total $18.1 \%$ percent drop of enrollment during the second year is an alarming number. Second year attrition rates may outdistance first year rates if left unchecked.

The first five research questions analyzed the differences between students who persisted past the second college year (to the fifth semester of enrollment) and those who did not persist with respect to several dependent variables. Research questions one and two were significant for the MANOVA, but the follow up univariate procedures revealed that question one was significant and question two was not. Research question three did not reveal significant results. The MANOVA was not significant for research question five, however study skills surfaced as the only significant univariate follow up. Research questions six and seven utilized logistic regression analyses to determine whether a statistically significant relationship between four blocks of predictor variables and the dependent variables of persistence to the fourth and fifth college semesters. 


\section{Discussion of Results and Implications}

\section{Demographic and Background Data}

This study provides a snapshot of one cohort of first-time, full-time degree seeking students who enrolled at the University of Louisville in the fall of 2004 . The sample consisted primarily of students of traditional college age $(98.8 \%)$, who were white $(82.3 \%)$, female $(53.7 \%)$, and were considered to be of middle income levels $(83.9 \%)$. Most of the students were not first generation college students, $82.3 \%$ had a parent that had at least some college. A surprising number of students did not plan to work while attending classes (26.1\%), while many planned to work at least part-time $(69.6 \%)$. These numbers were self-reported and taken prior to entry. There was no way to determine whether the estimates were accurate into the second year of enrollment. Finally, the majority the students in the study had chosen a college major prior to entry $(72.5 \%)$.

None of the background variables presented significant results save one, median family income. Research question six revealed a positive relationship between income and persistence in the logistic regression analysis. This suggests that economics has an impact on persistence. As the level of income increased so did the likelihood of persistence. It is interesting that this variable did not yield significant results for the seventh research question. Perhaps the issue of family income was resolved by increased work hours, attainment of financial aid, or due to the result of non-persistence to the next semester. This issue will be discussed in the recommendations and limitations sections of this chapter. 


\section{Academic Ability}

Tinto (1987) and Pascarella et al., (1986) agree with the use of pre-enrollment academic indicators to predict student persistence. Pre-enrollment predictors provide a foundation or first step to creating a retention plan. Information about the characteristics of incoming students, prepare institutions to plan inputs that are designed to take into account unique student populations.

The MANOVA analysis for research questions one and two revealed significant differences between persisters and non-persisters with respect to high school GPA but not ACT composite scores. Persisters had a mean high school GPA of 3.587 while nonpersisters had a mean high school GPA of 3.260. However, both GPAs are well above the current minimum requirement for admission. The ACT composite scores of both persisters (24.83) and non-persisters (23.62) exceeded the minimum requirement for admission at the time.

This finding suggests that high school GPAs may be more useful in the examination of academic ability and persistence than ACT scores. Many colleges and universities steadily increase admission standards to attract a more academically prepared incoming cohort of students. Issues of high school grade inflation (Cushman, 2003; Stanley \& Baines, 2004) and inequities in standardized test scores for underrepresented minorities (Sherman, 2008; Zwik, 2007) have called this practice into question in recent years. Despite these misgivings, the assumption that attracting higher achieving high school students with high ACT scores continues to be prevalent in higher education. Even though the University of Louisville has become more selective in its admissions standards, the mean ACT score for incoming freshmen in fall 2009 (24.04) was 
consistent with those of the 2004 freshmen cohort (24.06). This calls to question whether there is a ceiling to selection criteria (but that is an issue for future research studies to explore).

Students entering higher education are typically familiar with the letter grading system and the corresponding grade point average. They understand that there are certain expectations to achieve better grades and higher grade point averages. Standardized test scores do not translate into practical terms as well as the grade point average. Students know that a higher ACT score is better and some are quite skilled at taking standardized tests. But not everyone does well on these types of tests. Racial/ethnic biases, and test anxiety can reflect lower scores even if the individual is more than capable of achieving academic success. The standardized tests rely in large part on memorization and the ability to quickly computate mathematical formulas. Although these skills are important in college, the ability to analyze, synthesize, and adapt information becomes increasingly critical as the student progresses. The ability and motivation to achieve higher grade point averages may serve students better in the long run than a minimum average ACT score.

The fact that admission status (good standing, conditional, exception) was not significant further supports the idea that there is more to student success than high ACT scores. High achieving students with tests scores well above average may enter the university and still fail. Some students lack the ability to cope with stress and/or change even if their academic aptitude is high. The student that experiences his/her first grade of "C" while in college may experience issues with self-confidence. High school GPAs may provide a good base-line and ACT scores are an effective tool for enrollment management, but universities should seriously reconsider over reliance on ACT scores to 
predict persistence. Additional measures that gauge coping skills, motivation, and commitment levels may provide a clearer prediction of persistence.

The MANOVA analysis and univariate tests of the ACT reading and math subscores for research question three revealed no significant differences in persistence. In 2004 , sub-scores of 18 or below in math or reading resulted in remedial course placement. $7.2 \%$ of the sample was required to enroll in a course to compensate for a low reading score and $9.6 \%$ placed into a remedial math course. However, enrollment in these courses did not result in significant differences in persistence.

The MANOVA for research question four revealed a significant difference between persisters (mean GPA of 3.048) and non-persisters (mean GPA of 1.555) with regard to cumulative college GPA. Any student that consistently earns a GPA below a 2.0 will eventually be forced to leave the institution, yet it is difficult to determine how many of the students in this sample left on an involuntary basis. However, the mean GPA of the non-persisters confirms the need for tutoring services, intrusive advising, and early intervention strategies.

There was also a significant difference between persisters (mean score of 1.35 ) and non-persisters (mean score of 3.00) with regard to academic standing (see table four for key to categorical coding). Persisters were more likely to be in good standing which is not surprise. However the non-persisters may have been on academic warning or probation rather than suspended or dismissed. Students on probation or suspension in one academic unit may qualify to be in good standing in another academic unit. Differences between GPA requirements, policies, and petition procedures among the academic units 
clouded this finding. This suggests that at least some of the non-persisters departed on an involuntary basis but many departed voluntarily.

Admission status was included as a variable in both logistic regression equations yet neither test had statistically significant results for this variable. This suggests that even if a student was admitted in good standing, it did not mean that the student would retain that status. Students that are admitted in good standing may need additional help in the transition through the first and second years of college just like students who are admitted conditionally.

Motivation and Commitment

Motivation shapes attitudes and behaviors that ultimately impact academic competence. Lack of motivation influences important academic behaviors such as studyskills, class attendance and class participation (DiPerna and Elliott, 2002).

The MANOVA analysis of the CSI-B sub-scales revealed one significant difference with regard to persistence, study skills. This scale was designed to measure the amount of effort a student expends on academics (Noel-Levitz, 2001). Students were more likely to persist if they knew how to prepare for class and if they were willing and motivated enough to spend adequate time studying.

Logistic regression revealed that lower verbal confidence had a negative impact on persistence from the third to the fourth semester (research question six). Students with low verbal confidence were less likely to persist than those with higher scores on this scale. The verbal confidence scale was designed to measure how comfortable a student is with courses that require reading, oral presentations, or at least a moderate amount of writing (Noel-Levitz, 2001). This scale was not a measure of aptitude in these areas. 
During the first year, students typically enroll in general education courses that have very large class sizes. Many of these courses rely on multiple choice or short answer tests.

By the second year, students may be expected to exhibit their skills at public speaking, write papers, tests may be in essay format, and the amount of reading in preparation for tests may increase. Second-year students may have had a difficult transition when course expectations went beyond rote memory or the ability to compute a mathematic formula. Gardner (2000) conducted a study of student learning preferences and found that $60 \%$ of second year students preferred memorization as the primary method for learning academic material. Second year students were less likely to prefer teaching styles that required application or analysis. In the second year, many students may adopt a low-maintenance style of learning.

Unfortunately, second-year students are not typically required to be advised, so they may not have been aware of resources that could have helped them to adjust to different learning styles. It may have helped if faculty had included a list of resources in their syllabi for courses that students traditionally take in the first two years. Support services need to be more integrated into the fabric of the curriculum.

The expectations and motivations that students enter with will impact their experiences and perceptions following enrollment. Motivation to attend college is different from motivation to persist. Students who fail to define academic and future goals may not be prepared to make the types of decisions necessary for persistence (Schaller, 2010). Decided about college major was not a significant predictor for this study. This may indicate that even if a student is decided on major coming into the 
university, he/she may not have chosen a major that fits his/her goals and interests or the student may not have had an aptitude for the requirements of the major.

The reasons for departure are complex and varied. Some students never intended to stay until degree completion, while others enter with the intention to transfer to another institution (Tinto, 1993). This is especially true for the University of Louisville. Many of the students self-reported a desire to transfer in the responses on the CSI-B. The desire to transfer sub-scale proved to be a significant predictor for both research questions six and seven. This suggests that the university needs to do a better job of increasing student commitment level to the institution, especially among students who indicate that the University of Louisville was not their first choice. The desire to transfer may have stemmed from the fact that the university did not offer the student's desired major or the student could not afford to attend another institution farther from home. The university needs to delve deeper into the reasons that students enroll with the desire to transfer.

Gardner, Pattengale, Tobolowsky, and Hunter (2010) made a crucial observation, "One of the major criticisms frequently made about the support strategies for first-year students is that they lack sufficient academic content and rigor and, in fact are often (or even primarily) not delivered by educators with faculty status" (p. 5). Faculty involvement is directly connected to student intellectual engagement, which is especially pertinent to the transitional period during the second year. But the responsibility for first and second-year persistence programs has fallen to professional academic advisors and student affairs professionals. The demands of research and teaching loads on faculty time have resulted in the need for professionals to fill the gap in co-curricular engagement activities. The contributions of these professionals are a key component to student 
success, even though they may have enabled faculty to delay involvement until after the second year (Gardner, Pattengale, Tobolowsky, \& Hunter, 2010).

Habley (2004) echoed this concern in that there is a trend in higher education to consign the advisement of students to the ever growing legions of professional advisors. This is just another area in which faculty have become disengaged from second-year students. If faculty are not intimately involved in retention efforts, then such activities are viewed as add-ons to the curriculum and never become part of the strategic mission of the university. The need for professional advisors, student affairs professionals, and faculty to work in concert is apparent. Creative collaboration is one way that faculty can remain engaged with second year students while still meeting teaching and research demands.

The results of this study support the need for faculty involvement. Logistic regression for both question six and seven revealed a negative relationship between persistence and low scores on the attitude toward educators sub-scale of the CSI-B. This scale was designed to measure pre-college experiences and subsequent attitudes toward faculty, staff, and administrators (Noel-Levitz, 2001). Students who entered the institution with a low desire to engage with faculty did not seem to have received adequate motivation to improve upon this behavior during their enrollment. One of the biggest transitions that students need to make between high school and college is an understanding of the differences between secondary teachers and postsecondary faculty. If the institution does not spark engagement between faculty and students early in the college experience, then not only will the students that desired such interaction be disenfranchised, the institution will have missed an opportunity to improve upon pre- 
entry motivation and commitment levels of students that did not initially understand the benefits of such interactions.

\section{Finances}

Tinto (1993) argued that adequate financial aid eliminates the financial reasons for attrition for low-income students and that grants and Federal Work Study are preferable to loans. However, he cautions that finances are but one factor in a broader number of events that shape persistence. Financial aid decreases the cost for eligible students but has little effect on the benefits side of the equation (Tinto, 1993). Since that time, Tinto (2005) has updated his stance on finances. Income impacts the issue of equity. If policies and funding formulas are not designed to take into account the current economic climate, then the income gap in education will widen. Enrollment by middle and lower income students may steadily decline.

The economic climate has drastically changed in recent years, Pattengale (2000) notes that students' financial needs may change during the course of their college careers. Loss of scholarship, increases in tuition, and loss of income are just a few of the issues that might arise. The U.S. Department of Education found that the gap in graduation rates between high income students and students from lower and middle income has increased over the past ten years (Advisory Committee on Student Financial Assistance, 2006).

Logistic regression revealed that the sense of financial security sub-scale of the CSI-B was a statistically significant predictor of persistence from the fourth to the fifth semester (research question seven). This scale was designed to measure how secure a student felt about his or her financial situation in relation to expected costs of a college education (Noel-Levitz, 2001). Additionally, financial aid award was a statistically 
significant predictor for persistence to both the fourth and fifth semesters (research questions six and seven). Most of the students that started their fourth semester had some form of financial aid, most of which, 55.7\%, had aid packages that did not require repayment (grants, scholarships, and work study). Only $17.5 \%$ of the sample did not receive aid that was reported through the university Office of Financial Aid for the fourth semester. The number of students without a financial aid award for the fifth semester rose to $25.4 \%$ and the number of students that received funds that did not have to be repaid dropped to $49.7 \%$. This suggested that some studerits may have lost eligibility for their aid packages during the second year, which in turn amplified their sense of financial insecurity. A rise in tuition or loss of income may have weighed more heavily on the cost side of the benefit equation.

Increasing persistence to graduation rates is a national concern. The nation's ability to compete in a global economy is severely threatened by the shortage of American adults with a college degree. Financial factors are a major barrier to increasing the numbers of college graduates, especially from low- and moderate-income families (Advisory Committee on Student Financial Assistance, 2006). This loss in intellectual resources indicates that the United States needs to make a greater investment in education and student financial aid.

\section{Recommendations for Practice}

\section{Second-Year Student Persistence}

Research suggests that students experience intensely negative emotions during the second year which is reflected in the second highest attrition rate occurring during this tumultuous time (Almanac Issue, Chronicle of Higher Education, 2007-2008). Second 
year students may face changes in financial aid, course difficulty, and housing. Policies and programs should focus on the transitions and unique issues that second-year students experience.

Gathering as much information about students before and during enrollment is imperative. The expenditure of resources for keeping complete, accurate records is well worth the cost. Policies and procedures that inhibit this process must be closely examined and resolved if at all possible. The more that is known about the characteristics of students, the better institutions will be able to flesh out persistence patterns and to determine what institutional inputs help or hinder persistence. On-going formative and summative assessment of programs, policies, and procedures is a necessity. Many institutions are content to follow the lead of benchmark or aspirational institutions, but what is effective at one institution may not have the same results in a different environment. Looking to other institutions for inspiration is perfectly acceptable but should not replace institution specific initiatives. The use of an assessment tool that gauges the experiences and attitudes of second-year students would be especially useful.

If institutions of higher education are serious about student persistence and success, then more attention will need to be given to student learning. The findings from this study highlight the importance of student engagement. Students start out with particular expectations and predispositions toward education. Institutional inputs further enhance or exacerbate these characteristics. For instance, attitude toward educators was a significant predictor in this study. Whether or not the relationship is positive or negative, the institutional environment will interact with this pre-existing factor. Students expect that faculty will be an integral part of their academic life, yet few second year students 
make these connections (Gardner, 2000). Hopefully, institutional inputs will foster positive relationships and improve poor ones. Unfortunately, the potential for disaster is also present. Positive attitudes that are not nurtured will wither and negative attitudes could further deteriorate.

Tinto (2005) warned that colleges and universities must be willing to make deep, structural changes and commit resources to the goal of student success if attrition rates are to be stemmed. The phenomenon of "prestige creep" could threaten persistence efforts. Many universities aspire to be preeminent research institutions (the University of Louisville included). This is understandable in light of the potential monetary return. Tenure decisions are often based on publication or the ability to secure grants. Teaching and student learning should also be priorities in the tenure process. Student learning and retention efforts must an integral part of the institutional mission.

State Level

State legislators have expressed the need to increase the numbers of adults with at least a bachelor's degree, but the vehicle for achieving this goal will look different at each institution. Cookie cutter mandates from the state level with regard to policy reform will only hinder each institution's effort to achieve the goal of increased graduation rates. A study of the populations and institutional culture of each state institution will provide a clearer picture of how to achieve higher persistence rates while preserving academic integrity. A clear idea of the needs of the students in various regions of the state will provide legislators the information needed to enact meaningful reform particular to each institution. 
But in order to move forward, the state will have to invest in higher education rather than passing down annual cuts in funding. The results of this dissertation support the reality that financial concerns have an impact on student persistence. The necessity to raise tuition to compensate for budget shortfalls only exacerbates the problem and proves to be counterproductive to increasing graduation rates. The Council for Postsecondary Education should encourage research into the impact of budget cuts and rising tuition on the goal of degree attainment. Not only does the state need to collect data, the data must be utilized to guide reform practices.

The state should also invest in its students. Both merit and need based scholarship programs need to be increased. Fully funding or least greatly defraying the cost of a college education would increase students' sense of financial security and increase persistence.

\section{Institutional Level}

Faculty collaboration with professional academic advisors, academic support professionals, and student affairs staff is needed in order to create a comprehensive persistence plan that is seamless from the student perspective. There are several individual efforts to improve persistence operating simultaneously yet in isolation from one another. Duplication of efforts or initiatives that may actually prove to be counterproductive to one another may result in a waste of resources. The findings of this study suggest that second year students still need to make connections with faculty. The demands of research and teaching loads on faculty and the current structure of first and second year programs should be examined. The various stakeholders need to work in 
concert with one another to study, plan, and implement strategies to address the issues that face second year students.

The significant differences in cumulative college GPA despite increased admissions criteria is of concern. Admission status was not a significant predictor of persistence. This indicates that even though incoming students appear to be prepared for the rigors of college work, obviously there are barriers to sustained academic success. The significance of the study skills variable has implications in two areas. First, the study skills sub-scale is an underlying factor of motivation. Students that lack the motivation and discipline to study are less likely to persist. Second, second-year coursework may require different or more intense study strategies. Typically, students begin to transition from general education requirements to courses in the major. Faculty and advisors should be explicit about the expectations going into the second year. Students need to discuss academic progress along with factors that may impede success with academic advisors and faculty.

There is a need for advisor training to specifically address the unique needs of second year students. Second-year students may be ready for more detailed planning than they were as first year students. Through intrusive advising, advisors can help students to become active, empowered participants in learning. Advisors can connect present and future identities and help students to navigate the institutional system. Positive interactions with advisors could help to solidify commitment and increase motivation. 
High levels of commitment to complete a degree at a specific institution and the commitment to obtain a bachelor's degree result in higher persistence rates than students that were merely committed to a particular major (Grauke, Woosley, \& Helms, 2006). Students with strong commitment levels are better able to identify life goals, develop a plan, and take responsibility for their own futures (Schaller, 2005). Second-year students may be ready for more intensive planning than they were as first-year students. Advisors must be able to adjust their advising style to meet the needs of various student populations.

There is the question of when should persistence initiatives be mandatory. Overall, second-year students are not required to be advised at the University of Louisville. Leaving students without required advising when they may need the most help and are the least likely to ask for it is counter productive. Second-year students are left to their own devices to deal with financial concerns, academic difficulty, and lack of engagement. Rather than seek help, these students may simply drop out. Intrusive advising and mentoring that focuses on problem-based learning and critical thinking are key to active engagement. Support efforts need to have some sort of connection to the classroom and academic life. Whether in forefront or behind the scenes, collaboration between faculty, staff, and administration is imperative. Proactive persistence strategies and student learning must be core to the institutional mission.

Policies and procedures that provide intensive support for first year students should not suddenly be dissolved in the second year. These initiatives should instead be refocused to address the specific needs unique to second-year students. Additionally, policies and procedures need to be redesigned to support second year students. Transfer 
policies (both external and internal) and the registration rotation may present obstacles to second year students.

The significance of the verbal confidence scale further supports the notion of an intellectual transition in the second year. A second-year seminar course designed to augment the first year seminar course could address the transition from acculturation strategies to techniques that focus on intellectual and academic development. Sophomore programs and second year seminar courses are cropping up at institutions across the country. The beginning of the second year seems like the logical time to present this type of course. However, this researcher believes that the need for this transition should transpire just prior to the second year. Inclusion during the second semester of the first year would not only support first year initiatives, but would also set the stage for the transition to the second year early enough to avoid pitfalls. Far too few programs approach the issue of transition early enough.

An examination of how general education requirements and major courses place in the academic plan is warranted. Many second year students do not experience a course in the major until the third year. A string of seemingly pointless general education courses that do not clearly support future goals may prove frustrating for some students. A curriculum plan that ties foundational courses to the major and the electives may help second-year students make a smoother transition to the third year.

Anderson and Schreiner (2000) recommended a proactive approach to second year student advisement. Advisors should focus on prevention, planning, and participation to counteract reduced motivation, performance, and persistence. Among the 
strategies suggested were a second year orientation, encouraging course selections that prepare students for the second year, and conducting a second year success survey.

\section{Recommendations for Research}

\section{Second-Year Students}

Although there are few theories that focus specifically on second-year students, Baxter Magolda's (1992) has frequently been applied to the second-year experience. Baxter Magolda's (1992) model of epistemological reflection includes four perspectives: absolute knower, transitional knower, independent knower, and contextual knower. In Baxter Magolda's (1992) longitudinal study, $46 \%$ of second-year students were absolute knowers, 53\% were transitional knowers, and only $1 \%$ was independent knowers. Absolute knowers believe knowledge is concrete, certain, and is something to be gained or mastered; transitional knowers desire a deeper understanding, critical thinking becomes more pertinent; independent knowers believe that knowledge is uncertain and value their own opinions and perspectives (Baxter Magolda, 1992). It would be useful for institutions to know where their first and second year students fall in this continuum. In order for students to develop the critical thinking and decision-making skills necessary to function as engaged students, it is important that greater percentages fall into at least the transitional knower category.

Further research into how far first year policies and programs go toward retention beyond the first year is warranted. First year programs may only be postponing attrition to the second year. Policies and procedures set up to improve first year retention rates may have negative consequences for the second year. It would be wise for first year programs to set up the initiatives for the transition into the second year. First year 
experience courses that are at least co-taught by faculty could set up second year students to continue those relationships. Programs and initiatives need to be spread throughout the first year rather than concentrated in the first semester. The second semester of the first year can be used to prepare students to make the transition to the second year.

\section{Institutional Level}

Hunter, Tobolowshy, \& Gardner (2010) remind us that, "As higher educators, even though we may have differing education philosophies and find ourselves in different types of institutions in terms of mission and student characteristics, our collective overreaching goal is student success" (p. 1). Continued research about how pre-entry variables and institutional inputs impact second year student persistence is needed. Qualitative and quantitative studies that explore the experiences of second-year students will provide valuable insight into the woes and wonderment of the second college year. In order to adequately address the problem of second year attrition, institutions must study and understand their own unique environments.

A study by Martin and Hanrahan (2004) reported difficulty with the issue of delineating between expectations and actual behaviors. Future research should include follow up studies that collect data on actual behaviors over time compared with initial expectations. Advisors could be key personnel in the collection of qualitative data from their advisees. The University of Louisville requires all first-year students to be advised. Academic advisors are in the position to track the experiences of their advisees during the course of the first year. Analysis of those findings could provide administrators with a guide for improving first-year programs and policies, and facilitate the implementation of second-year programs and policies that address specific areas of concern. 
Only the 2004 freshman cohort who participated in summer orientation was represented in this study. Repetitive testing of multiple cohorts may have revealed differences between cohorts. Additionally, current events that will undoubtedly impact future cohorts were not reflected in this study.

Additionally, the sample for this study was fairly heterogeneous. Further exploration how gender, race and ethnicity, age, and income status may reveal strikingly different results. Insight into differences and concerns of students from different backgrounds may assist recruiters and administrators in designing incentives and programs to increase institutional commitment. Future research should focus on how to measure the factors of motivation and commitment in the context of the second year experience.

The significance of factors such as attitude toward educators, study skills, sense of verbal confidence, and desire to transfer signal the need for strategies to improve motivation and commitment. Kuh \& Associates (2005) found that students that take more of an intellectual interest in higher education and interact more frequently with faculty are more likely to persist. However, second-year students may have adopted attitudes and behaviors that decrease the likelihood of persistence. Wilder (1993) studied students that experienced a drop in GPA in the second year. Absenteeism was found to be a significant factor in the drop in GPA. Students in the second year may experience boredom and disillusionment and fall into negative behavior patterns such as skipping class. Yet second year students are not universally required to be advised and many faculty do not take attendance. Many of these students may feel as if no one cares. Future research into 
student behaviors in the first and second years could provide some insight into how students make decisions and fall into bad behavior patterns.

A study of economic factors is imperative. The significance of financial aid, sense of financial security, and income supports the assumption that the economic climate continues to impact retention efforts. An exploration of the relationship between income and the different types of aid available (scholarships, grants, loans) could prove invaluable to retention efforts. Some students may not qualify for need based aid, but in fact will not be able to continue enrollment without it. It would also be helpful to examine how the different criteria required to retain financial aid impacts retention.

Finally, a study of the issues that rural students face in contrast to urban or suburban students may assist institutions in developing programs that meet the needs of particular geographic regions of the state. This study did not explore geographic region of permanent residence as a variable in persistence. The majority of students at the University of Louisville today are Kentucky residents $(17,259,79.31 \%)$ and most of those students are from the Louisville Metropolitan area $(10,278,47.23 \%)$, which was roughly $10 \%$ less than the number of Kentucky residents in 2004 cohort (1390, 89.4\%). It would be useful to understand if students from other regions of the state have different acculturation issues than students from the Louisville Metropolitan area. Even though this study did not explore the impact of permanent geographic residence, the sheer number of locale residents may be correlated with the significant finding for the desire to transfer sub-scale of the CSI-B. Further research should explore the differences between students from different geographic areas. 


\section{Conclusion}

This study focused on the exploration of factors that predict college persistence beyond the second college year. Persistence research is a critical element for improvement strategies aimed at increasing graduation rates. Initiatives aimed at increasing first year persistence are now ingrained in the basic structure of higher education and have proven to be successful. However, these initiatives may have only delayed student departure behaviors.

This dissertation revealed that there are issues which remain constant through the second year of enrollment and others that manifest at different points during the second year. Cumulative GPA proved to a major factor in persistence across the board despite a more academically prepared incoming freshman class. The findings of this study contribute to the literature concerning second year persistence. Issues that plague second year students differ from the acculturation concerns that face first year students. The findings of this study support the need for a focus on academic content and rigor in the second year. It is imperative that research continues for this critical stage in student development. 


\section{REFERENCES}

Advisory Committee on Student Financial Assistance (2006). Mortgaging Our Future: How Financial Barriers to College Undercut America's Global Competitiveness (A Report of Advisory Committee on Student Financial Assistance). Washington, DC: Author.

Aldeman, C. (1999). Answers in the tool box: Academic intensity attendance patterns, and bachelor's degree attainment. Jessup, M. D.: U.S. Department of Education Office of Educational Research and Improvement.

Allen, D. (1999). Desire to finish college: An empirical link between motivation and persistence. Research in Higher Education, 40, 461-485.

Allen, J., Robbins, S. B., Casillas, A., \& Oh, I. (2008). Third-year college retention and transfer: Effects of academic performance, motivation, and social connectedness. Research in Higher Education, 49, 647- 664.

American College Testing Program, Inc. (ACT, Inc.). (2008). Retention/completion summary tables. Iowa City: IA: Author. Retrieved from www.act.org/research/policymakers/reports/retain.html.

Anderson, E., \& Schreiner, L. A. (2000). Advising for sophomore success. In L. A. Schreiner \& Pattengale (Eds.). Visible solutions for invisible students: Helping Sophomores succeed (Monograph No. 31, pp. 79-87). Columbia, SC: University of South Carolina, National Resource Center for the First-Year Experience and Students in Transition.

Arredondo, M., \& Knight, S. (2005-2006). Estimating degree attainment rates of freshmen: A campus perspective. Journal of College Student Retention, 7 (1-2), 91-115.

Astin, A.W., \& Panos, R. J. (1969). The educational and vocational development of college students. Washington D. C.: American Council on Education.

Astin, A. W., (1972). College dropouts: A national profile. American Council on Education Reports, 7, 1.

Astin, A. W., (1977). What matters in college: Four critical years revisited. San Francisco: Jossey-Bass.

Astin, A. W., (1993). What matters in college: Four critical years revisited. San Francisco: Jossey-Bass. 
Astin, A. W. (2005-2006). Making sense out of degree completion rates. Journal of College Student Retention, 7 (1-2), 5-17.

Attewell, P., Lavin, D., Domina, T., \& Levey, T. (2006). New evidence on college remediation. Journal of Higher Education, 77, 886-924.

Babbie, E. (1998). Survey research methods $\left(2^{\text {nd }}\right.$ ed.). Belmont, CA: Wadsworth.

Baker, R. W., Mc Neil, O. V., \& Siryk, B. (1985). Expectation and reality in freshman adjustment to college. Journal of Counseling Psychology, 32 (1), 94-103.

Barefoot, B. ( 2004). Higher education's revolving door: Confronting the problem of student drop out in U.S. colleges and universities. Open Learning, 10 (1), 9-18.

Baxter Magolda, M. B. (1992). Knowing and reasoning in college. San Francisco: Jossey-Bass.

Bean, J. P., (1980). Dropouts and turnover: The synthesis and test of a causal model of student attrition. Research in Higher Education, 12, 155 - 187.

Bean, J. P. (1985). Interaction effects based on class level in and explanatory model of college student dropout syndrome. American Educational Research Journal, 22, $35-64$.

Bean, J. P. \& Eaton, S. B. (2001-2002). The psychology underlying successful retention practices. Journal of College Student Retention, 3 (1), 73-89.

Beil, C., Reisen, C. A., Zea, M. C., \& Caplan R. C. (1999). A longitudinal study of the effects of academic and social integration and commitment on retention. NASPA Journal, 37 (1), 376-385.

Berkener, L., He, S., \& Cataldi, E. F. (2002). Decriptive summary of 1995 - 1996 beginning postsecondary students: Six years later (NCES 2003 151). U.S.

Department of Education, National Center for Education Statistics. Washington, DC: U.S. Government Printing Office

Bettinger, E. P., \& Long, T. L. (2006). Institutional responses to reduce inequalities in college outcomes: Remedial and developmental courses in higher education. In Dickert-Conlin, S., \& Rubenstein, R. (Eds.), Economic inequality and higher education: Access, persistence, and success. New York: Russell Sage Foundation Press.

Boivin, M., Fountain, G.A., \& Bayard, B. (2000). Meeting the challenges of the sophomore year. In L.A. Schreiner \& J. Pattengale (Eds.), Visible solutions for invisible students: Helping sophomores succeed (Monograph No. 31). Columbia, 
SC: University of South Carolina, National Resource Center for The First-Year Experience and Students in Transition.

Braustein, A., McGrath, M., \& Pescatrice, D. (2000-2001). Measuring the impact of financial factors on college persistence. Journal of College Student Retention, 2 (3), $191-203$.

Braxton, J. M., \& McClendon, S. A. (2001-2002). The fostering of social integration and retention through institutional practice. Journal of College Student Retention, 3 (1), 57-71.

Braxton, J. M., Hirschy, A. S., \& McClendon, S. A. (2004). Understanding and reducing college departure. ASHE-ERIC Higher Education Report: Volume 30, Number 3.

Bresciani, M. J., \& Carson, L. (2002). A study of undergraduate persistence by unmet need and percentage of gift aid. NASPA Journal, 40 (1), 104-123.

Cabrera, A. F., Stampen, J. O., \& Hansen, W. L. (1990). Exploring the effects of ability to pay on persistence in college. Review of Higher Education, 13, $303-356$.

Cabrera, A. F., Castaneda, M. B., Nora, A., \& Hossler, D. (1992). The convergence between two theories of college persistence. Journal of Higher Education, 63, 143 -164 .

Cabrera, A, F., Nora, A., \& Casteneda, M. B. (1993). College persistence: Structural equations modeling test of an integrated model of student retention. Journal of Higher Education, 64, 123 - 139.

Cashell, B. W. (2007). Who are the middle class? (CRS report for Congress). Congressional Research Service: Library of Congress. (Order Code RS22626).

Chickering, A. W. (1969). Education and identity. San Francisco: Jossey-Bass.

Chickering, A. W., \& Reisser, L. (1993). Education and identity (2nd ed.). San Francisco: Jossey-Bass.

College Board. (2006). 2006 College-bound seniors: Total group profile report. New York: Author. In Long, B. T., and Riley, E. (2007). Financial aid: A broken bridge to college success. Harvard Educational Review, 77, (1), 39-63.

Conley, D. T. (2003). Understanding university success: A report from standards for success. Eugene, OR: University of Oregon Center for Educational Policy Research. 
Crawford, F. (2007). The impact of income and minority status in the prediction of college student persistence and graduation in a reform context. Unpublished Dissertation, University of Louisville.

Cushman, T. (2003). Who best to tame grade inflation? Academic Questions, fall, 48-56.

Daddona, M. F. \& Cooper, D. L. (2002). Comparison of freshmen perceived needs prior to and after participation in an orientation program. NASPA Journal, 39 (4), 300318.

Daugherty, T. K., \& Lane, E. J. (1999). A longitudinal study of academic and social predictors of college attrition. Social Behavior and Personality, 27 (4), 355-362.

Davis, M., Greenberg, K., Kluken, G. Pollio, H. R., Thomas, S., \& Thompson, C. L. (2004). A fly in the buttermilk: Descriptions of university life by successful black undergraduate students at a predominantly white southeastern university. Journal of Higher Education, 71, 420-445.

DiPerna, J. C., \& Elliot, S. N. (2002). Promoting academic enablers to improve student achievement: An introduction to the mini-series. School Psychology Review, 31 (3), $293-297$.

Dowd, A. C., \& Coury, T. (2006). The effect of loans on the persistence and attainment of community college students. Research in Higher Education, 47 (1), 33-62.

DuBrock, C. (2000, May). Financial aid and college persistence: A five-year longitudinal study of 1993 and 1994 beginning freshmen students. Contributed paper presented at the Association for Institutional Research 40th forum. Cincinnati, Ohio.

Durkheim, E. (1951). Le Suicide: etude de sociologie (Suicide: A study in sociology. Spalding, J. A. \& Simpsom, G., Trans). New York: Free Press. (Original work published 1897).

Educational Policy Institute. (2004). The art of student retention: A handbook for practitioners and administrators. Austin, TX: Texas Higher Eduation Coordinating Board. Retrieved on December, 2006, from http://educationalpolicy.org.

Education Resources Institute \& Institute for Higher Education Policy. (1995). College debt and the American family. Washington, DC: Author. In Kim, Dongbin (2007). The effects of loans on students' degree attainment: Differences by student and institutional characteristics. Harvard Educational Review, 77 (1), 64100 .

Eggen, P., \& Kauchak, D. (2004). Educational psychology: Windows on classrooms $\left(6^{\text {th }}\right.$ ed.). Upper Saddle River, NJ: Pearson Education, Inc. 
Erikson, E. (1968). Identity: Youth and crisis. New York: Norton.

Feldman, K., \& Newcomb, T. (1969). The impact of college on students. San Francisco: Jossey-Bass.

Flanagan, W. (1991). Sophomore retention: The missing strategy in small college retention efforts (Doctoral dissertation, University of Wisconsin-Madison, 1991). UMI No. 911372.

Freedman, M. B. (1956). The passage through college. Journal of Social Issues, 12, 1328.

Furr, S. R., \& Gannaway, L. (1982). Easing the sophomore slump: A student development approach. Journal of College Student Personnel, 23, 340-341.

Gahagan, J., \& Hunter, M. S. (2006). The second-year experience: Turning attention to the academy's middle children. About Campus, July-August, 17-22.

Gardner, P. D. (2000). From drift to engagement: Finding purpose and making career connections in the sophomore year. In Schreiner, L.A. \& Pattengale, J. (Eds.). (2000). Visible solutions for invisible students: Helping sophomores succeed (Monograph No. 31). Columbia, SC: University of South Carolina, National Resource Center for the First-Year Experience and Students in Transition.

Gardner, J. N., Pattengale, J. A., Tobolowsky, B. F., \& Hunter, M. S. (2010). Introduction. In Hunter, M. S., Tobolowsky, B. F., \& Gardner, J. N., Evenbeck, S. E., Pattengale, J. A., Schaller, M. A., Schreiner, L. A., \& Associates (2010). Helping sophomores succeed: Understanding and improving the second-year experience. Columbia, SC: University of South Carolina, National Resource Center for the First-Year Experience and Students in Transition.

Gerdes, H., \& Mallinckrodt, B. (1994). Emotional, social, and academic adjustment of college students: A longitudinal study of retention. Journal of Counseling \& Development, 72, 281-288.

Gohn, L., Swartz, J., \& Donnelly, S. (2000-2001). A case study of second year student persistence. Journal of College Student Retention, 2 (4), 271 - 294.

Graunke, S. S., Woosley, S. A., \& Helms, L. L. (2005). An exploration of the factors that affect the academic success of college sophomores. College Student Journal, 39 (2), 367-376.

Greene, J. P., \& Forster, G. (2003, September). Public high school graduation and college readiness rates in the United States. (Education working paper No. 3). New York: Manhattan Institute. 
Habley, W. R. (2004). The status of academic advising: Findings from the ACT Sixth National Survey. (Monograph No. 10). National Academic Advising Association.

Helkowski, C., \& Sheahan, M. (2004). Too sure too soon: When choosing should wait. About Campus, May-June, 19-24.

Herzog, S. (2005). Measuring determinants of student return vs. dropout/stopout vs. transfer: A first-to-second year analysis of new freshmen. Research in Higher Education, 46, 883-928.

Hoyt, J. E., \& Winn, B. A. (2004). Understanding retention and college student bodies: Differences between drop-outs, stop-outs, opt-outs, and transfer-outs. NASPA Journal, 41 (3), 395-417.

Hunter, M. S., Tobolowsky, B. F., \& Gardner, J. N., Evenbeck, S. E., Pattengale, J. A., Schaller, M. A., Schreiner, L. A., \& Associates (2010). Helping sophomores succeed: Understanding and improving the second-year experience. Columbia, SC: University of South Carolina, National Resource Center for the First-Year Experience and Students in Transition.

Institute for Research on Poverty. (2009). What are poverty thresholds and guidelines? Retrieved from http://www.irp.wisc.edu/faqs/faql.htm

Irvine, D. W., (1966). Multiple prediction of college graduation from preadmission data. The Journal of Experimental Education, 35, 84 - 89.

Ishitani, T. T. (2006). Studying attrition and degree behavior among first-generation, lowincome college students. Journal of Higher Education, 77 (5), 861 - 885.

Jassal-Head, P. (2007). The prediction of college student persistence for non-traditional students after first year of college and five year graduation rate at institution of matriculation. Unpublished Dissertation, University of Louisville.

Johnson, I. Y. (2006). Analysis of stopout behavior at a public research university: The multi-spell discrete-time approach. Research in Higher Education, 47, 905-934.

Juillerat, S. (2000). Assessing the expectations and satisfaction levels of sophomores: How are they unique? In L. A. Schreiner \& J. Pattengale (Eds.). Visible solutions for invisible students: Helping Sophomores succeed (Monograph No. 31, pp. $79-$ 87). Columbia, SC: University of South Carolina, National Resource Center for the First-Year Experience and Students in Transition.

Kahn, J. H., \& Nauta, M. M. (2001). Social-cognitive predictors of first-year persistence: The importance of proximal assessment. Research in Higher Education, 42, 633652. 
Kennedy, K. \& Upcraft, M. L. (2010). Keys to student success: A look at the literature. Hunter, M. S., Tobolowsky, B. F., \& Gardner, J. N., Evenbeck, S. E., Pattengale, J. A., Schaller, M. A., Schreiner, L. A., \& Associates (2010). Helping sophomores succeed: Understanding and improving the second-year experience. Columbia, SC: University of South Carolina, National Resource Center for the First-Year Experience and Students in Transition.

Kentucky Council for Postsecondary Education (CPE). (2008). Comprehensive database. Retrieved from http://cpe.ky.gov/info/retention/index.html.

Kim, D. (2007). The effects of loans on students' degree attainment: Differences by student and institutional characteristics. Harvard Educational Review, 77 (1), 64100.

Kuh, G. D. (2001-2002). Organizational culture and student persistence: Prospects and puzzles. Journal of College Student Retention, 3 (1), 23-39.

Kuh, G. D., Kinzie, J., Schuh, J. H., Whitt, E. J., \& Associates. (2005). Student success in college: Creating conditions that matter. San Francisco: Jossey-Bass.

Kulm, T. L. \& Cramer, S. (2006). The relationship of student employment to student role, family, relationships, social interactions and persistence. College Student Journal, 40 (4), 927-938.

Lemons, J. L., \& Richmond, D. R. (1987). A developmental perspective of sophomore slump. NASPA Journal, 24 (3), 15-19.

Leppel, K. (2001). The impact of major on college persistence among freshmen. Higher Education, 41, 327-342.

Leppel, K. (2005). College persistence and student attitudes toward financial success. College Student Journal, 39 (2), 1-19.

Lipka, S. (2006). After the freshman bubble pops. Chronicle of Higher Education, 53 (3), 42.

Long, B. T., \& Riley, E. (2007). Financial aid: A broken bridge to college success. Harvard Educational Review, 77, (1), 39-63.

Low, L. (2003). The retention management system: Assessing for early intervention. Brevard, NC: Policy Center on First Year of College. Retrieved from www.brevard.edu/fyc/listserv/remarks.low.htm.

Macey, T. J. (1993). Meeting the needs of today's students: the evolution of a residential academic program. [Monograph Series No. 5, 35 \& 36]. Gateways: Residential 
colleges and the freshman year experience. National Resource Center for the Freshman Year Experience.

Mansfield, P. M., Pinto, M. B., Parente, D. H., \& Wortman, T. I. (2004). College students and academic performance: A case of taking control. NASPA Journal, 41 (3), $551-567$.

Manski, C., \& Wise, D. (1983). College choice in America. Cambridge: MA: Harvard University Press.

Martin, J. S., \& Hanrahan, K. (2004). Criminology freshmen: Preparation, expectations, and college performance. Journal of Criminal Justice Education, 15, 287-309.

McGrath, M. M., \& Braunstein, A. (1997). The prediction of freshmen attrition: An examination of the importance of certain demographic, academic, financial, and social factors. College Student Journal, 31(3), 396-408.

Metz, G. (2004-2005). Challenge and changes to Tinto's persistence theory: A historic review. Journal of College Student Retention, 6 (2), 191-207.

Miller, R. A. (2005). College student inventory - Form-B of the retention management system: Validity study. Iowa City, IA: Noel-Levitz.

Moradi, B., Mohr, J. J., Worthington, R. L., \& Fassinger, R. E. (2009). Counseling psychology research on sexual (orientation) minority issues: Conceptual and methodological challenges and opportunities. Journal of Counseling Psychology, $56,5-22$.

Morrison, G. B., \& Brown, M. P. (2006). Persistence to graduation among at-risk criminal justice and criminology students: Experiences in intervening with a sophomore cohort. Journal of Criminal Justice Education, 17, 358-376.

Mortenson, T. (1997). Actual versus predicted institutional graduation rates for 1100 colleges and universities, postsecondary education. Opportunity No. 58 (April).

National Center for Higher Education Management Systems (NCHEMS). (2007). Graduation rates. Retrieved from www.higheredinfo.org.

National Center for Public Policy and Higher Education. (2002). Measuring up 2002: The state-by-state report card for higher education. San Jose: Author.

Noel, L., Levitz, R., \& Saluri, D. (Eds.). (1985). Increasing student retention. San Francisco: Jossey-Bass.

Noel, L., \& Levitz, R. (1991). Beating the sophomore slump. Recruitment and Retention in Higher Education, 5 (11), 1 - 3. 
Noel-Levitz (2001). The retention management system advisor's guide. Noel-Levitz Inc.

Noel-Levitz (2006). National student satisfaction and priorities report. Retrieved from www.noellevitz.com.

Noel-Levitz (2007). The College Student Inventory. Retrieved from www.noellevitz.com.

Nunnally, A. M. (1978). Psychometric theory (2nd ed.). New York: McGraw-Hill.

Office of Institutional Research. (2007a). Retention/persistence rates. Louisville, KY: University of Louisville, Office of Institutional Research. Retrieved from http://institutionalresearch.louisville.edu/ir/.

Office of Institutional Research. (2007b). Graduation rates. Louisville, KY: University of Louisville, Office of Institutional Research. Retrieved from http://institutionalresearch.louisville.edu/ir/.

Pascarella, E. T. (1980). Student-faculty informal contact and college outcomes. Review of Educational Research, 50, 545 - 595.

Pascarella, E. T., \& Terenzini, P. T. (1991). How college affects students. San Francisco: Jossey-Bass.

Pascarella, E. T., \& Terenzini, P. T. (2005). How college affects students. San Francisco: Jossey-Bass.

Pattengale, J. (2000). Policies and practices to enhance sophomore success. In Schreiner, L.A. \& Pattengale, J. (Eds.). (2000). Visible solutions for invisible students: Helping sophomores succeed (Monograph No. 31). Columbia, SC: University of South Carolina, National Resource Center for the First-Year Experience and Students in Transition.

Pattengale, J., \& Schreiner, L. (2000). What is the sophomore slump ad why should we care? In Schreiner, L.A. \& Pattengale, J. (Eds.). (2000). Visible solutions for invisible students: Helping sophomores succeed (Monograph No. 31). Columbia, SC: University of South Carolina, National Resource Center for the First-Year Experience and Students in Transition.

Pattengale, J., \& Schreiner, L. (2007). Forward: The advancement of sophomore initiatives. In Tobolowsky, B. F. and Cox, B. E. (Eds.). (2007). Shedding light on sophomores: An exploration of the second college year. (Monograph No. -). Columbia, SC: University of South Carolina, National Resource Center for the First Year Experience and Students in Transition. 
Paulsen, M. \& St. John, E. P. (2002). Social class and college costs: Examing the financial nexus between college choice and persistence. Journal of Higher Education, 189-236.

Perry, W. G. (1968). Forms of intellectual and ethical development in the college years: A scheme. New York: Holt, Rinchart \& Winston.

Perry, S. R., Cabrera, A. F., \& Vogt, W. P. (1999). Career maturity and college student persistence. Journal of College Student Retention, 1 (1), 41-58.

Reason, R. D. (2003). Student variables that predict retention: Recent research and new developments. NASPA Journal, 40 (4), 172-191.

Reason, R. D., Terenzini, P. T., \& Domingo, R. J. (2006). First things first: Developing academic competence in the first year of college. Research in Higher Education, $47,149-175$.

Rogers, R. F. (1990). Recent theories and research underlying student development. In D. G. Creamer (Ed.). College student development: Theory and practice for the 1990s (pp. 27 - 279). Alexandria, VA: American College Personnel Association.

Schaller, M. A. (2005). Wandering and wondering: Traversing the uneven terrain of the second college year. About Campus, July-August, 17-24.

Schaller, M. A. (2007). The developmental of college sophomores. In Tobolowsky, B. F. and Cox, B. E. (Eds.). (2007). Shedding light on sophomores: An exploration of the second college year. (Monograph No. 47). Columbia, SC: University of South Carolina, National Resource Center for the First Year Experience and Students in Transition.

Schaller, M. A., \& Wagner, R. L. (2007). Indecision and an avalance of expectations: Challenges facing sophomore resident assistants. NASPA Journal, 44 (1), 32-56.

Schaller, M. A. (2010). Understanding the impact of the second year of college. Hunter, M. S., Tobolowsky, B. F., \& Gardner, J. N., Evenbeck, S. E., Pattengale, J. A., Schaller, M. A., Schreiner, L. A., \& Associates (2010). Helping sophomores succeed: Understanding and improving the second-year experience. Columbia, SC: University of South Carolina, National Resource Center for the First-Year Experience and Students in Transition.

Schreiner, L. A. ,\& Pattengale, J. (Eds.). (2000). Visible solutions for invisible students: Helping sophomores succeed (Monograph No. 31). Columbia, SC: University of South Carolina, National Resource Center for the First-Year Experience and Students in Transition. 
Schreiner, L. A. (2010). Factors that contribute to sophomore success and satisfaction. Hunter, M. S., Tobolowsky, B. F., \& Gardner, J. N., Evenbeck, S. E., Pattengale, J. A., Schaller, M. A., Schreiner, L. A., \& Associates (2010). Helping sophomores succeed: Understanding and improving the second-year experience. Columbia, SC: University of South Carolina, National Resource Center for the First-Year Experience and Students in Transition.

Sherman, W. H. (2008). No child left behind: A legislative catalyst for superintendent action to eliminate test-score gaps? Educational Policy, 22 (5), $675-704$.

Smith, J. S. (2004-2005). The effects of student receptivity on college achievement and retention. Journal of College Student Retention, 6 (3), 273-288.

Smith, Joshua S., \& Wertlieb, Ellen C. (2005). Do first-year college students' expectations align with their first-year experiences? NASPA Journal, 42 (2), 153174.

Smith, T. \& Renk, K. (2007). Predictors of academic-related stress in college students: An examination of coping, social support, parenting, and anxiety. NASPA Journal, 44 (3), 405-431.

Spady, W. (1970). Dropouts from higher education: An interdisciplinary review and synthesis. Interchange, $1,64-85$.

Spady, W. (1971). Dropouts from higher education: Toward an empirical model. Interchange, 2, 38-62.

Spies, R. A., \& Plake, B.S. (Eds.), (2005). The Sixteenth mental measurement yearbook. Lincoln, NE: Buros Institute of Mental Measurements.

St. John, E. P., Paulsen, M. B., \& Carter, D. F. (2005). Diveristy, college costs, and postsecondary opportunity: An examination of the financial nexus between college choice and persistence for African Americans and whites. The Journal of Higher Education, 76 (5), 545-569.

Stanley, G. \& Baines, L. (2004). No more shopping for grades at B-Mart: Re-establishing grades indicators of academic performance. The Clearing House, January/February.

Stevens, J. (2002). Applied multivariate statistics for social sciences (4th ed). Mahwah, NJ: Lawrence Erlbaum Associates.

Stratil, M. (1988). The RMS interpretive guide for advisors and counselors. Coraville, IA: Noel Levitz Center for Institutional Effectiveness and Innovation. 
Stratil, M., Schreiner, L.A., \& Noel, P. (Eds). (2001). Retention management system: Advisor's guide - Form B. National Center for Student Retention. Iowa City, IA: USA Group Noel-Levitz.

Stratil, M., Schreiner, L.A., \& Noel, P. (Eds). (2006). Retention management system: Coordinator's guide - Form B. Iowa City, IA: USA Group Noel-Levitz.

Terenzini, P.T., Lorang, W.G., \& Pascarella, E.T. (1977). Voluntary freshman attrition and patterns of social and academic integration in a university: A test of a conceptual model. In Tinto, V. (1993). Leaving college: Rethinking the causes and cures of student attrition (2nd ed.). Chicago: University of Chicago Press.

Tinto, V. (1975). Dropout from higher education: A theoretical synthesis of recent research. Review of Educational Research, 45, 89-125.

Tinto, V. (1987). Leaving college. Chicago: University of Chicago Press.

Tinto, V. (1991). Dropping out and other forms of withdrawl from college. In Noel, L., Levitz, R., Saluri, D., and Associates (Eds.). Increasing student retention. (pp. 28 -43). San Francisco: Jossey-Bass.

Tinto, V. (1993). Leaving college: Rethinking the causes and cures of student attrition (2nd ed.). Chicago, University of Chicago Press.

Tinto, V. (2000). Looking at the university through different lenses. About Campus, January-February, 2-3.

Tinto, V. (2005, July). Student retention: What next? Presented at the National Conference on Student Recruitment, Marketing, and Retention, Washington, D.C.

Tinto, V. (2008, March). Taking student retention seriously: Rethinking the first year of college. Presented at Creating Conditions for Student Success, University of Maine Systems.

Titus, M. A. (2006). Understanding the influence of the financial context of institutions on student persistence at four-year colleges and universities. The Journal of Higher Education, 77, 353-375.

Tobolowsky, B. F., \& Cox, B. E. (Eds.). (2007). Shedding light on sophomores: An exploration of the second college year. (Monograph No. 47). Columbia, SC: University of South Carolina, National Resource Center for the First Year Experience and Students in Transition.

Tobolowsky, B. F., \& Cox, B. E. (2007). Findings from the 2005 National Survey on Sophomore Year Initiatives. In Tobolowsky, B. F. and Cox, B. E. (Eds.). 
Shedding light on sophomores: An exploration of the second college year. (Monograph No. 47). Columbia, SC: University of South Carolina, National Resource Center for the First Year Experience and Students in Transition.

Tobolowsky, B. F., \& Serven, S. K. (2007). Introduction. In Tobolowsky, B. F. and Cox, B. E. (Eds.). (2007). Shedding light on sophomores: An exploration of the second college year. (Monograph No. 47). Columbia, SC: University of South Carolina, National Resource Center for the First Year Experience and Students in Transition.

United States Census Bureau (2007). American factfinder and glossary. Retrieved from http://www.census.gov.

United States Department of Education. (2006). Digest of educational statistics (NCES Publication No. 2006-030). Washington, DC: U.S. Government Printing Office.

Upcraft, M. L. (1984). Orientation programs: Myths and realities. In Upcraft, M. L. (Ed.). (1984). New directions for student services: Orienting students to college. San Francisco: Jossey-Bass.

Upcraft, M. L. \& Gardner, J. N., \& Associates (1989). The freshman year experience. San Francisco: Jossey-Bass.

Upcraft, M. L., Gardner, J. N., \& Barefoot, B. O. (2005). Challenging and supporting the first-year student: $A$ handbook for improving the first year of college. San Francisco: Jossey-Bass.

van Gennep, A. (1960) Rites of passage (Vizedom, M., and Caffee, G., Trans.). Chicago: University of Chicago Press. (Original work published 1908).

Voorhees, R. A. (1984). Financial aid and new freshman persistence: An exploratory model. Paper presented at the annual meeting of the Association for Institutional Research. Fort Worth: Texas.

Waterman, A. S. ,\& Waterman, C.K. (1972). Relationship between freshman ego identity status and subsequent academic behavior: A test of the predictive validity of Marcia's categorization system of identity status. Developmental Psychology, 6, 179.

Wilder, J. (1999, Spring). The sophomore slump: A complex developmental period that contributes to attrition. College Student Affairs Journal, 12 (2), 18-27.

Winter, G. M., Bowers, C., Gordner, N., \& Lange, L. (2006). Re-evaluating the university attrition statistic: A longitudinal follow-up study. Journal of Adolescent Research, 21 (2), 111-132. 
Wohlgemuth, D., Whalen, D., Sullivan, J., Nading, C., Shelley, M., \& Wang, Y. (20062007). Financial, academic, and environmental influences on the retention and graduation of students. Journal of College Student Retention, 8 (4), 457-475.

Zajacova, A., Lynch, S. M., \& Espenshade, T. J. (2005). Self-efficacy, stress, and academic success in college. Research in Higher Education, 46 (6), 677-706.

Zwick, R. (2007). College admissions in twenty-first-century America: The role of grades, tests, and games of chance. Harvard Educational Review, 77 (4), 419 428. 


\section{CURRICULUM VITAE}

NAME: $\quad$ Nora Allen Scobie

ADDRESS: University of Louisville

Undergraduate Advising Practice

338 Strickler Hall

Louisville, KY 40292

DOB: $\quad$ Louisville, KY - April 3, 1967

EDUCATION

\& TRAINING: $\quad$ Bachelor of Arts, University of Louisville

Communications major

May 1990

Master of Education, University of Louisville

College Student Personnel

May 1993

Ph.D, Education, Counseling and Personnel Services

University of Louisville

May 2010

HONOR

SOCIETIES

\& AWARDS: Omicron Delta Kappa Honor Society (1990)

- $\quad$ Provost's Award for Exemplary Advising (2005)

- $\quad$ NACADA Certificate of Merit for Outstanding Advising (2005)

Golden Key National Honor Society

2010

\section{PROFESSIONAL}

SOCIETIES \&

LEADERSHIP: National Association of Academic Advising (NACADA)

- Research Coordinator, Mid-South Region 3, 2007 - present

- Member, Professional Development Committee, 2008 - present

- Member, Consultant's Advisory Board, 2008 - present

- Chair, Advisor Training and Development Commission, 2009- 2011

- National Association of Campus Activities (NACA) 


\section{NASPA Student Affairs Administrators in Higher Education}

PUBLICATIONS: Allen, Nora (2004) Confessions of a Ph.D. Student: The Internship. The Mentor: An Academic Advising Journal.

CONFERENCE

PRESENTATIONS:

- N.A.C.A. National Conference, Washington, D.C., 1989.

- N.A.C.A. National Conference, Nashville, Tennessee, 1991.

- NACADA Mid-South Regional Conference, Memphis, Tennessee, 2001 (Presenter).

- NACADA National Conference, Salt Lake City, Utah, 2002.

- Spring 2003 Research Conference, University of Louisville, College of Education, 2003.

- Spring 2004 Research Conference, University of Kentucky, College of Education, 2004 (Presenter).

- $\quad$ CPE Faculty Development Conference, Lexington, Kentucky, 2004.

- NACADA National Conference, Cincinnati, Ohio, 2004 (Presenter).

- NACADA Mid-South Regional Conference, Louisville, KY 2005 (Presenter).

- CPE Faculty Development Conference, Lexington, Kentucky, 2005.

- First Year Experience Conference, Ashville, N.C., 2005.

- Celebration of Teaching and Learning, Louisville, KY, 2005 (presenter).

- NACADA National Conference, Las Vegas, NV, 2005.

- NACADA Mid-South Regional Conference, Ashville, N.C., 2007 (Presenter).

- NACADA National Conference, Baltimore, Maryland, 2007 (Presenter).

- NACADA Mid-South Regional Conference, Columbia, S.C., 2008 (Presenter).

- NACADA National Conference, Chicago, Il, 2008 (Presenter).

- NACADA National Conference, San Antonio, TX, 2009 (Presenter) 